TIAGO LIMA D'ALBUQUERQUE E CASTRO

\title{
Previsão da Vida em Fadiga de Eixos Virabrequim e Componentes Mecânicos Estruturais sob Carregamento \\ Multiaxial
}

\section{Dissertação de Mestrado}

\begin{abstract}
Dissertação apresentada ao Programa de Pós-Graduação em Engenharia de Materiais e de Processos Químicos e Metalúrgicos da PUC-Rio como requisito parcial para obtenção do grau de Mestre em Engenharia de Materiais e de Processos Químicos e Metalúrgicos
\end{abstract}

Orientador: Prof. Marcos Venicius Soares Pereira 
Pontifícia U Uiversidade Católica $_{\text {a }}$

DO RIO DE JANEIRO

\title{
TIAGO LIMA D'ALBUQUERQUE E CASTRO
}

\section{Previsão da Vida em Fadiga de Eixos Virabrequim e Componentes Mecânicos Estruturais sob Carregamento Multiaxial}

\begin{abstract}
Dissertação apresentada como requisito parcial para obtenção do grau de Mestre pelo Programa de Pósgraduação em Engenharia de Materiais e de Processos Químicos e Metalúrgicos da PUC-Rio. Aprovada pela Comissão Examinadora abaixo assinada.
\end{abstract}

Prof. Marcos Venicius Soares Pereira

Orientador

Departamento de Engenharia Química e de Materiais - PUC-Rio

Prof. Fathi Aref Ibrahim Darwish Universidade Federal Fluminense - UFF

Prof. Rodrigo Fernandes Magalhães de Souza Departamento de Engenharia Química e de Materiais - PUC-Rio

Prof. Gilvania Terto Alves

CEFET-RJ

Rio de Janeiro, 29 de março de 2019. 
Todos os direitos reservados. É proibida a reprodução total ou parcial do trabalho sem autorização da universidade, do autor e do orientador.

\section{Tiago Lima d'Albuquerque e Castro}

Graduou-se em Engenharia Elétrica com ênfase em Eletrônica pela Pontifícia Universidade Católica do Rio de Janeiro em 2011.

Ficha Catalográfica

Castro, Tiago Lima d'Albuquerque e

Previsão da vida em fadiga de eixos virabrequim e componentes mecânicos estruturais sob carregamento multiaxial / Tiago Lima d'Albuquerque e Castro ; orientador: Marcos Venicius Soares Pereira. 2019.

100 f. : il. color. ; $30 \mathrm{~cm}$

Dissertação (mestrado)-Pontifícia Universidade Católica do Rio de Janeiro, Departamento de Engenharia Química e de Materiais, 2019.

Inclui bibliografia

1. Engenharia Química e de Materiais - Teses. 2. Previsão de vida em fadiga finita. 3. Fadiga multiaxial. 4. Superfície de vida em fadiga. 5. Generalização da curva de Wöhler. 6. Eixo virabrequim. I. Pereira, Marcos Venicius Soares. II. Pontifícia Universidade Católica do Rio de Janeiro. Departamento de Engenharia Química e de Materiais. III. Título. 


\section{Agradecimentos}

A meus orientadores, Prof. Marcos e Prof. Fathi, pela amizade e orientação.

Aos membros da banca, Prof. Gilvania e Prof. Rodrigo, pela disponibilidade e disposição de participar dessa etapa de titulação.

A meus pais José e Tânia, pelo apoio e incentivo, acreditando em meu potencial e valorizando sempre, e de maneira incondicional, a construção de conhecimento e desenvolvimento intelectual. Tudo aquilo que sou, a eles devo.

À minha irmã Tatiana e meus demais familiares, por estarem sempre presentes.

À minha namorada Rayane, pela companhia, carinho e encorajamento.

A meus amigos e parceiros acadêmicos, que participaram comigo dessa empreitada.

A meus demais amigos e pares de trabalho, pelo suporte e incentivo.

À PUC-Rio, por toda a minha formação.

A todos os colaboradores do DEQM.

A todos os professores que tive.

A todos os colaboradores do PIUES, por todo o carinho ao ceder espaço de estudo e por nossa convivência diária.

A todos os colaboradores do ITUC e LEM, pela atenção e assistência nos experimentos.

A todos ligados ao projeto ENEVA, por fazerem parte dessa iniciativa.

À empresa ENEVA pelo apoio financeiro e suporte à pesquisa.

À toda comunidade científica e agências de fomento

A todos que se empenham em lutar por uma sociedade melhor e mais justa.

A todos que não se calam diante do injusto.

A todos que me ajudam.

A todos a quem ajudo ou já ajudei.

A todos que possam, de alguma forma, ter feito parte dessa trajetória.

Por tudo e por todos que amo. 
Trabalho desenvolvido no âmbito do Programa de Pesquisa e Desenvolvimento Tecnológico do Setor de Energia Elétrica regulado pela ANEEL, com o apoio das empresas da Eneva - Pecém II Geração de Energia S.A., Itaqui Geração de Energia S.A. Paranaíba I, II e III Geração de Energia S.A.

O presente trabalho foi realizado com apoio da Coordenação de Aperfeiçoamento de Pessoal de Nível Superior - Brasil (CAPES) - Código de Financiamento 001. 


\section{Resumo}

Castro, Tiago Lima d'Albuquerque e; Pereira, Marcos Venicius Soares (Orientador). Previsão da Vida em Fadiga de Eixos Virabrequim e Componentes Mecânicos Estruturais sob Carregamento Multiaxial. Rio de Janeiro, 2019. 100p. Dissertação de Mestrado - Departamento de Engenharia Química e de Materiais, Pontifícia Universidade Católica do Rio de Janeiro.

Critérios de fadiga multiaxial para vida infinita tinham por objetivo apenas avaliar a ocorrência de fratura em um componente mecânico quando submetido a carregamentos multiaxiais totalmente reversíveis. Carpinteri \& Spagnoli propuseram uma modificação em seu próprio modelo, substituindo por outros parâmetros os limites de resistência à fadiga em flexão $f_{-1}$ e torção $t_{-1}$ para ensaios totalmente reversíveis, introduzindo na equação uma variável $N_{f}$ que permitiu realizar uma previsão de vida em fadiga finita. O objetivo do presente estudo é verificar experimentalmente a consistência dessa modificação. A metodologia consistiu em obter experimentalmente curvas de Wöhler para tração e torção referentes ao aço DIN 42CrMo4 a fim de obter os parâmetros $m$ e $m *$, que são os coeficientes angulares das mesmas em escala log-log, produzindo meios para a aplicação do critério. Como o equacionamento do modelo não apresenta solução analítica, foi desenvolvido uma solução numérica para obter junto ao critério uma previsão teórica de vida em fadiga. Adicionalmente, o estudo busca discutir acerca de uma possível relação direta entre amplitude de tensão normal $\sigma_{a}$, amplitude de tensão cisalhante $\tau_{a}$ e número de ciclos para falha $N_{f}$. O modelo em si apresentou consistência parcial com os experimentos, tendo sido assertivo nos ensaios de torção pura, mas discrepante em ensaios de tração pura. Para carregamentos combinados, houve razoável precisão em dois casos e grande dispersão em outra, mas a avaliação final depende de mais pontos experimentais.

\section{Palavras-chave}

Previsão de vida em fadiga finita; fadiga multiaxial; superfície de vida em fadiga; generalização da curva de Wöhler; eixo virabrequim. 


\section{Abstract}

Castro, Tiago Lima d'Albuquerque e, Marcos Venicius Soares (Advisor). Fatigue-Life Prediction of Crankshafts and Mechanical Structural Components under Multiaxial Fatigue Loadings. Rio de Janeiro, 2019. 100p. Dissertação de Mestrado - Departamento de Engenharia Química e de Materiais, Pontifícia Universidade Católica do Rio de Janeiro.

Infinite-life multiaxial fatigue criteria had only the ability to evaluate whether or not fatigue failure is to occur to a mechanical componente once subjected to multiaxial fatigue loadings. Carpinteri \& Spagnoli proposed a modification to their own model, substituting both fully reversed bending and torsion fatigue endurance limits, $f_{1}$ and $t_{-1}$ respectively, introducing into the equation a new variable $N_{f}$, allowing the model to predict the fatigue-life of the mechanical component. The main goal of the presente study is to assess the accuracy of the modified model via experiments. The research methodology consisted in determining $m$ and $m *$, which are the slopes of the S-N curves for fully reversed bending and torsion experiments on regards to DIN 42CrMo4 steel when plotted into a log-log scale, providing means to apply the model. Since there is no analytic solution to the model, the criterion's equation has to be solved numerically. Furthermore, the present study discusses the possibility of a direct relation between amplitude of normal stress $\sigma_{a}$, amplitude of shear stress $\tau_{a}$ and number of cycles to failure $N_{f}$. The modified Carpinteri \& Spagnoli's criterion proved itself to be partially consistent, presenting both accurate predictions of torsional fatigue-life and discrepant results for axial loadings. For combined loadings, the model provided two consistent results while another experimental point was proved far off. The final assessment on regards to the model's accuracy depends on more experimental points.

\section{Keywords}

Finite fatigue-life prediction; multiaxial fatigue; fatigue-life surface; generalization of the S-N Curve; crankshaft. 


\section{Sumário}

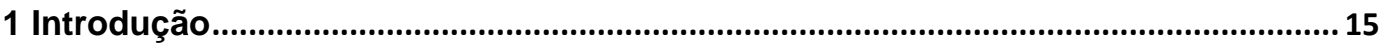

2 Revisão Bibliográfica..................................................................................................... 16

2.1 Fadiga

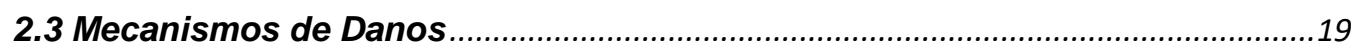

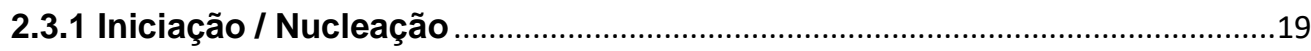

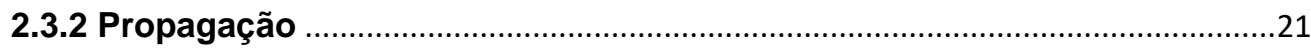

2.4 Superfície de Fratura de uma Trinca de Fadiga ....................................................24

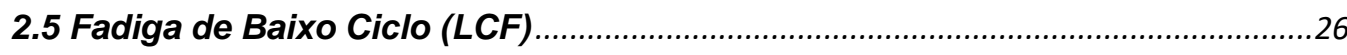

2.6 Fadiga de Alto Ciclo (HCF), Fadiga de Altíssimo Ciclo (UHCF) e Limite de

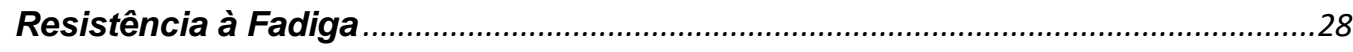

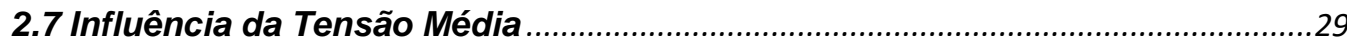

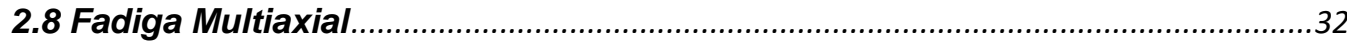

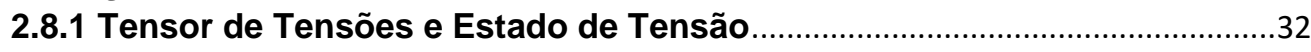

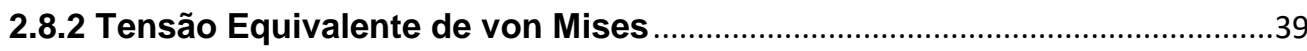

2.8.3 Modelos Matemáticos .....................................................................................

3 Materiais e Metodologia de Pesquisa e de Ensaios ....................................................56

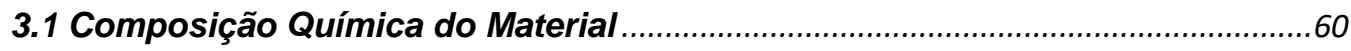

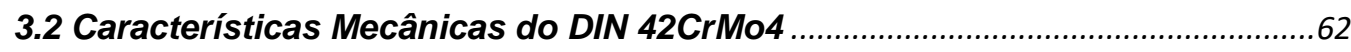

3.3 Características da Máquina Utilizada para Ensaio .............................................63

3.4 Determinação da Geometria do Corpo de Provas ..................................................65

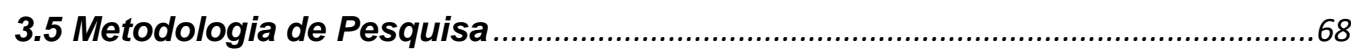

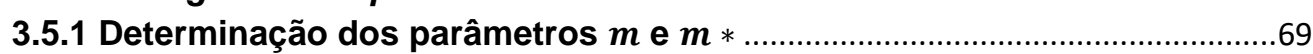

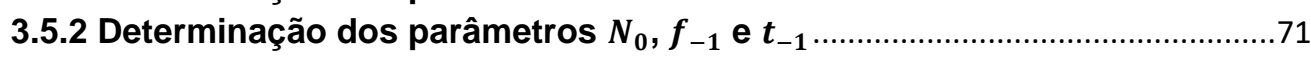

3.5.3 Previsão de Vida em Fadiga.......................................................................

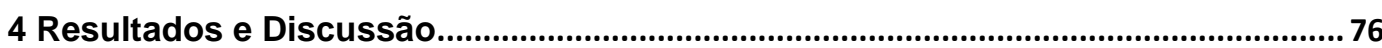

4.1 Curvas de Wöhler Experimentais para Tração e Torção.....................................76

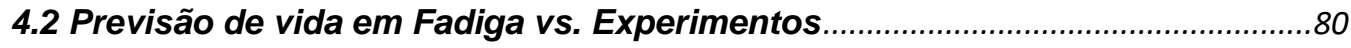

4.2.1 Previsão de Vida em Fadiga para ensaios Biaxiais .....................................8

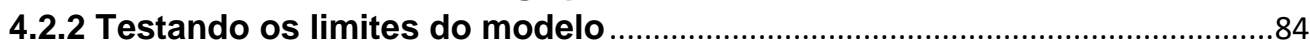

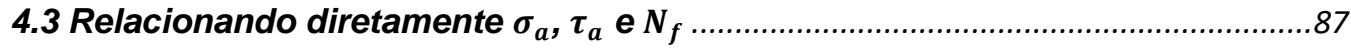

4.4 Generalização da Curva de Wöhler - Estudo das Características de uma

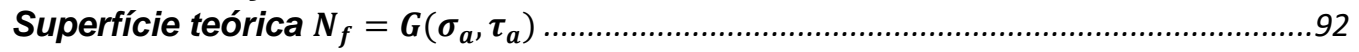

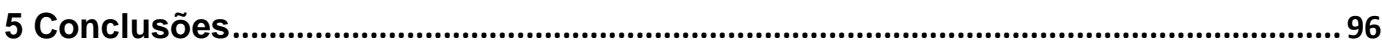

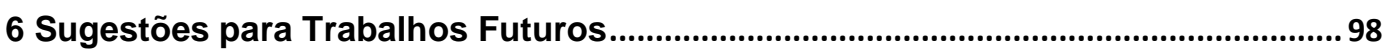

7 Referências Bibliográficas....................................................................................................99 


\section{Lista de figuras}

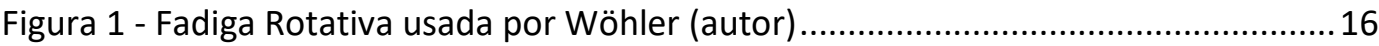

Figura 2 - Exemplo de Curva de Wöhler (Teixeira, 2018)............................................. 17

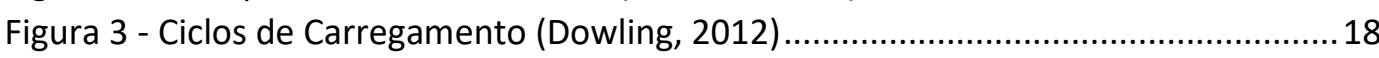

Figura 4 - Intrusões e extrusões de Persistent Slip Bands (Takahashi, 2014) .................... 20

Figura 5 - Esquema típico de nucleação por PSB (Feiferis, 2018) .....................................2 20

Figura 6 - Superposição sítios vizinhos de PSB (Kumar, 2010) ...........................................2 20

Figura 7 - Intrusões e extrusões na superfície de um cristal de Cu (Suresh, 2001) ...........21

Figura 8 - Balanço de Energia de Griffith - Adaptado (Peixoto, 2018) ...............................2 22

Figura 9 - Curva $d a / d N$ versus $\Delta K$, indicando o crescimento da trinca

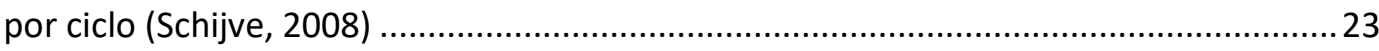

Figura 10 - Típica superfície de fratura de uma trinca de fadiga (Meyers, 2009) ..............24

Figura 11 - Superfície típica de Fratura por fadiga, indicando iniciação (A),

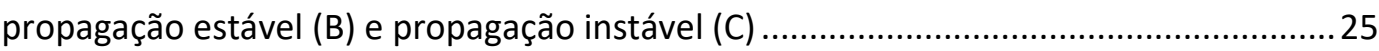

Figura 12 - Marcas de praia e marcas de rio (Castro\&Meggiolaro, 2009) ......................... 25

Figura 13 - Estrias de fadiga em liga de $\mathrm{Ni}$ (Castro\&Meggiolaro, 2009) ............................. 26

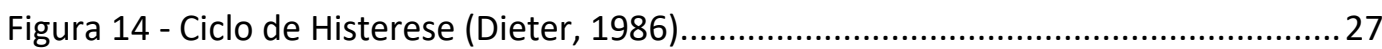

Figura 15 - Redução do limite de resistência à fadiga em 107 ciclos (Dowling, 2012)..... 29

Figura 16 - Influência da tensão média sobre a curva de Wöhler (Teixeira, 2018) ...........30

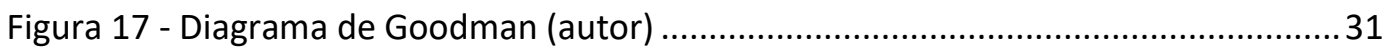

Figura 18 - Modificações no trabalho de Goodman propostas por Gerber

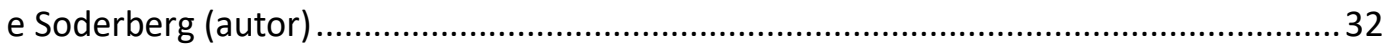

Figura 19 - Tensor de tensões de Cauchy (Medeiros) ....................................................... 33

Figura 20 - Tensões associadas a plano genérico de orientação $\psi$ em

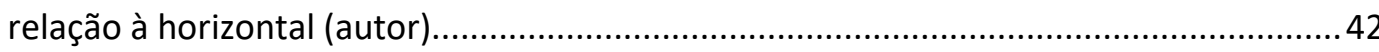

Figura 21 - Elemento de Área para critérios de Carpinteri \& Spagnoli e

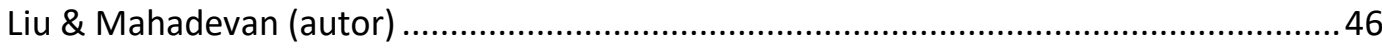

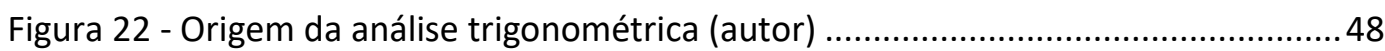

Figura 23 - Trigonometria ilustrando relação entre todos os ângulos (autor).................. 48

Figura 24 - Ilustração de eixo virabrequim (Fonte: Schwaben Engineering) ......................56

Figura 25 - Geometria complexa com defasagem angular entre os mancais

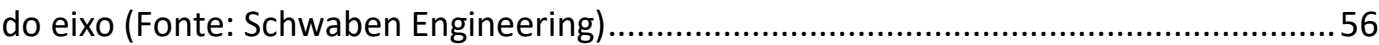

Figura 26 - Representação do mancal 01 e de suas bielas A e B

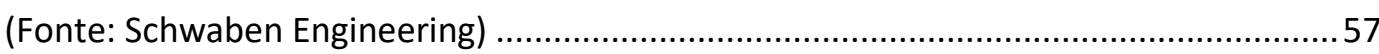

Figura 27 - Sequencia de disparo dos pistões do eixo virabrequim

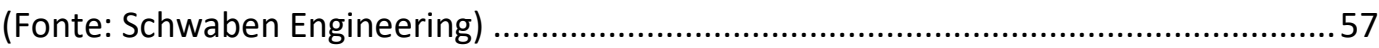

Figura 28 - Segmento da análise por elementos finitos

(Fonte: Schwaben Engineering)

Figura 29 - Variação das tensões principais e tensão de von Mises

para todo o ciclo de carregamento (Fonte: Schwaben Engineering) ..............................58

Figura 30 - Fotografia de fratura 01 (Fonte: Linhares Engenharia)..................................59

Figura 31 - Fotografia de fratura 02 (Fonte: Linhares Engenharia)................................59

Figura 32 - Fotografia de fratura 0 (Fonte: Linhares Engenharia) .....................................59

Figura 33 - Fotografia de fratura 04 (Fonte: Linhares Engenharia)...................................59 
Figura 34 - Mosaico de Imagens do aço DIN 42CrMo4 (Peixoto, 2018) .............................61

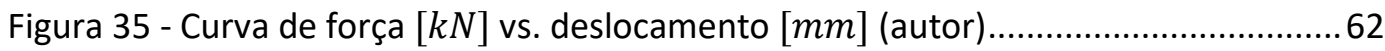

Figura 36 - Fotografia da Máquina Instron servo-hidráulica modelo 8874 (autor) ............63

Figura 37 - Fotografia da Máquina Instron servo-hidráulica modelo 8874 (autor) ...........64

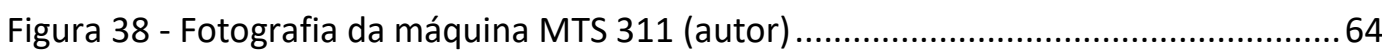

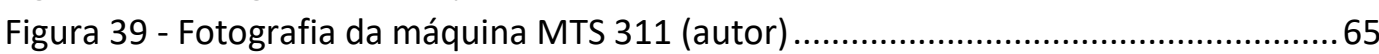

Figura 40 - Geometria proposta pela norma ASTM E466-15 ...........................................65

Figura 41 - Dimensões finais do corpo de provas (modificado de

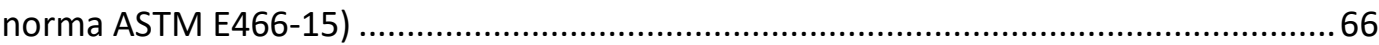

Figura 42 - Solução para equação do modelo de Carpinteri \& Spagnoli para um

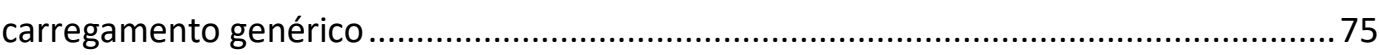

Figura 43 - Dispersão de pontos para curva de Wöhler de tração-compressão................ 77

Figura 44 - Dispersão de pontos para curva de Wöhler de torção .................................... 77

Figura 45 - Curva de Wöhler para tração com número de ciclos

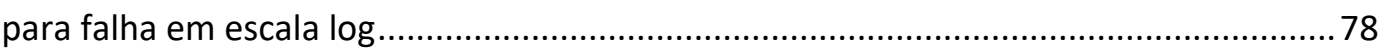

Figura 46 - Curva de Wöhler para tração com número de ciclos

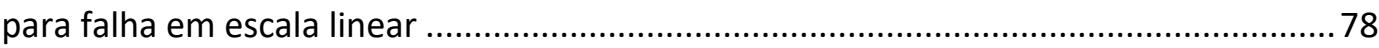

Figura 47 - Curva de Wöhler para torção com número de ciclos

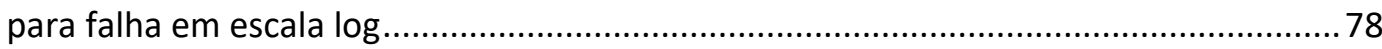

Figura 48 - Curva de Wöhler para torção com número de ciclos

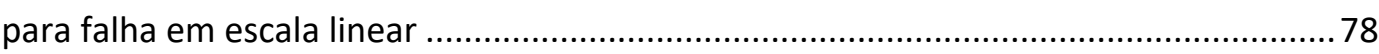

Figura 49 - Previsão de vida em fadiga sob carregamento de

$\sigma_{a}=429,33 \mathrm{MPa}$ e $\tau_{a}=247,88 \mathrm{MPa}$

Figura 50 - Previsão de vida em fadiga sob carregamento de

$\sigma_{a}=350,17 M P a$ e $\tau_{a}=278,74 M P a$

Figura 51 - Previsão de vida em fadiga sob carregamento de

$\sigma_{a}=450 \mathrm{MPa}$ e $\tau_{a}=174,71 \mathrm{MPa}$

Figura 52 - Curvas para solução dos modelos teóricos para ensaios de tração pura ........ 85

Figura 53 - Curvas para solução dos modelos teóricos para ensaios de torção pura ........8 86

Figura 54 - Distribuição dos pontos teóricos sobre curva de nível

no domínio da função

Figura 55 - Correlação entre distribuição de pontos e equação de elipse proposta ......... 89

Figura 56 - Afastamento dos pontos centrais dos arcos de elipse

para os pontos teóricos das curvas de nível 90

Figura 57 - Afastamento do ponto da curva de nível à elipse proposta

$\left(N_{f}=10^{6}\right.$ ciclos $)$

Figura 58 - Afastamento do ponto da curva de nível à elipse proposta

$\left(N_{f}=10^{6}\right.$ ciclos $)$ 91

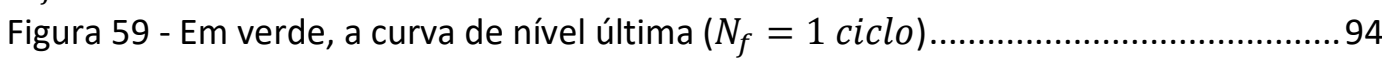

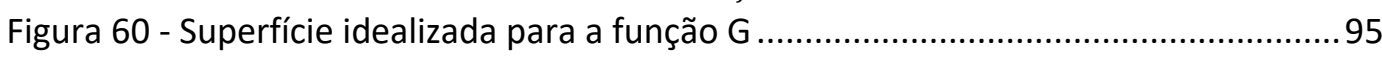




\section{Lista de Tabelas}

Tabela 1 - Propriedades do material em função dos limites de resistência à fadiga em flexão e torção (Liu\&Mahadevan, 2005) ......................................51

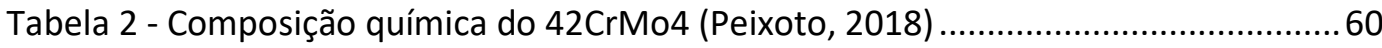

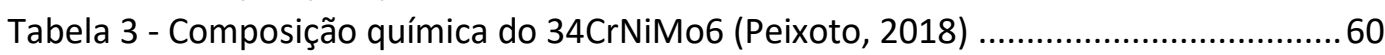

Tabela 4 - Tabela com propriedades mecânicas do DIN 42CrMo4 (Giovani) .....................63

Tabela 5 - Substituição de parâmetros para o critério de vida finita

de Carpinteri \& Spagnoli ................................................................................................ 73

Tabela 6 - Valor de tensão normal totalmente reversível e número

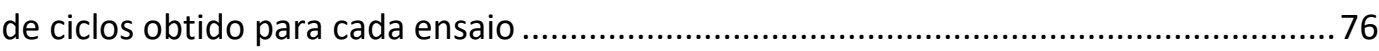

Tabela 7 - Valor de tensão cisalhante totalmente reversível e número

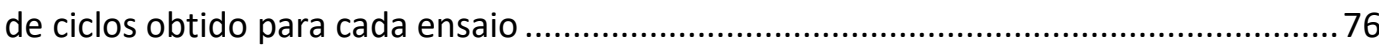

Tabela 8 - Propriedades de materiais referentes aos ensaios de Nishihara e Kawamoto (Nishihara\&Kawamoto, 1945) ................................................... 79

Tabela 9 - Cálculos parciais para carregamento de

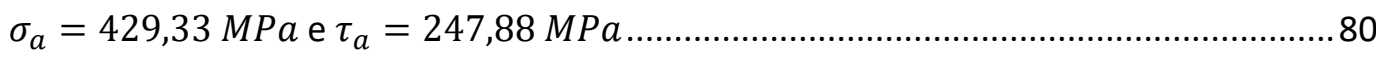

Tabela 10 - Cálculos parciais para carregamento de

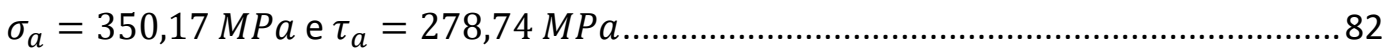

Tabela 11 - Cálculos parciais para carregamento de

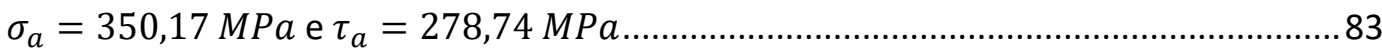

Tabela 12 - Resultados teóricos e experimentais para ensaios de tração pura.................. 85

Tabela 13 - Resultados teóricos e experimentais para ensaios de torção pura ................. 86

Tabela 14 - Pares ordenados teóricos de tensão normal e

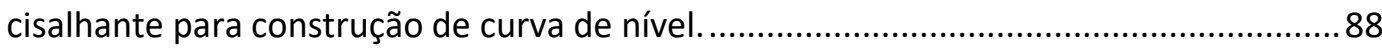

Tabela 15 - Pontos da utilizados para a idealização da Superfície G................................99 


\section{Lista de símbolos}

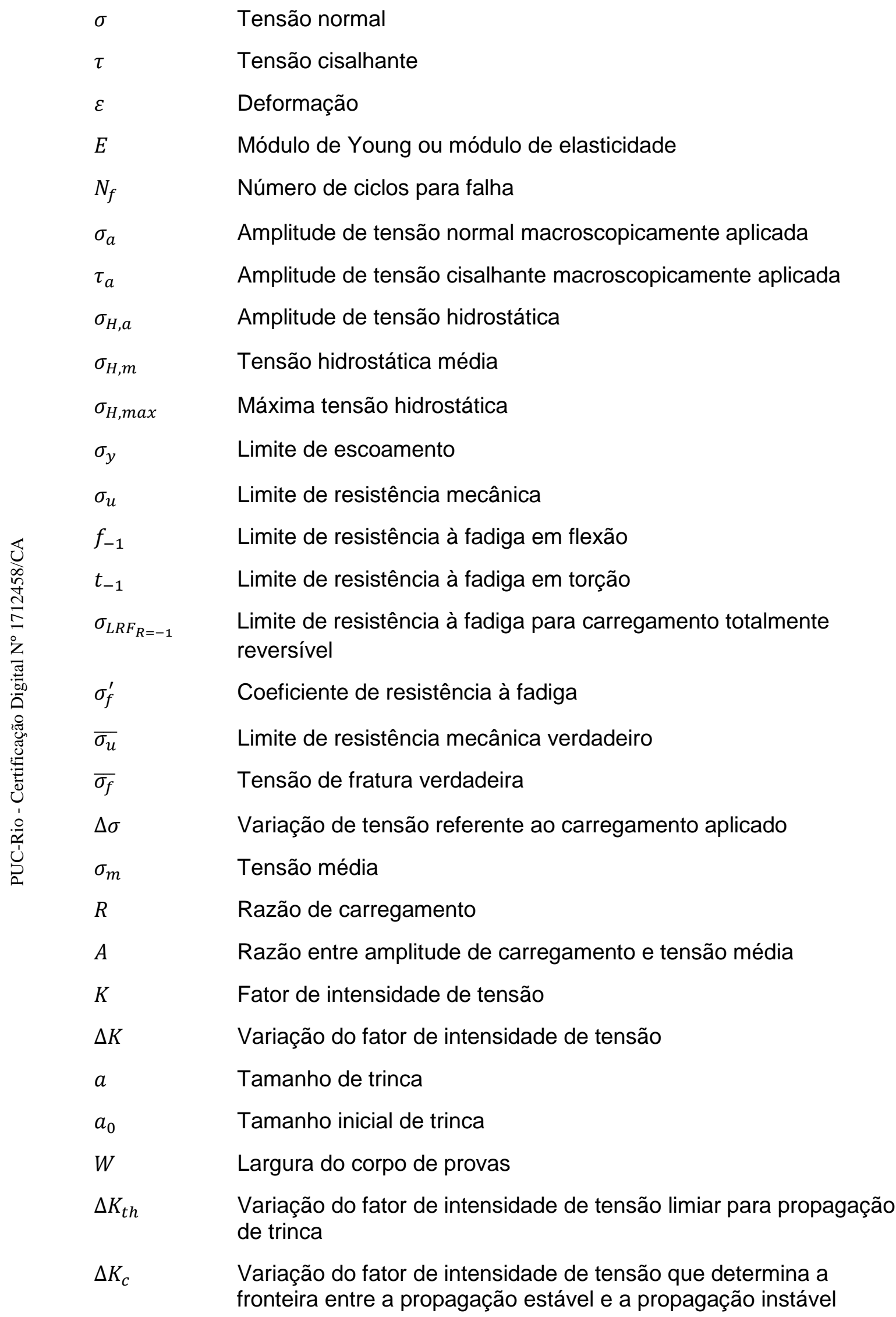




\begin{tabular}{|c|c|}
\hline$N_{\max }$ & Máxima tensão normal dos modelos \\
\hline$N_{m}$ & Tensão normal média dos modelos \\
\hline$N_{a}$ & Amplitude de tensão normal dos modelos \\
\hline$C_{a}$ & Amplitude da tensão cisalhante dos modelos \\
\hline$\psi$ & $\begin{array}{l}\text { Ângulo de orientação de um determinado plano em relação ao } \\
\text { eixo horizontal }\end{array}$ \\
\hline$\varphi$ & $\begin{array}{l}\text { Ângulo de orientação de um determinado plano em relação ao } \\
\text { eixo vertical }\end{array}$ \\
\hline$\psi_{f}$ & $\begin{array}{l}\text { Ângulo de orientação do plano de fratura em relação ao eixo } \\
\text { horizontal }\end{array}$ \\
\hline$\varphi_{f}$ & $\begin{array}{l}\text { Ângulo de orientação do plano de fratura em relação ao eixo } \\
\text { vertical }\end{array}$ \\
\hline$\psi_{c}$ & $\begin{array}{l}\text { Ângulo de orientação do plano crítico em relação ao eixo } \\
\text { horizontal }\end{array}$ \\
\hline$\varphi_{c}$ & Ângulo de orientação do plano crítico em relação ao eixo vertical \\
\hline$\delta$ & Ângulo definido entre plano de fratura e plano crítico \\
\hline$\beta$ & Ângulo de defasagem entre carregamento normal e de torção \\
\hline$\theta$ & Ângulo de Euller definido entre o eixo $\hat{z}$ e o eixo vertical \\
\hline$k$ & Propriedade de material para o modelo de Findley \\
\hline$f$ & $\begin{array}{l}\text { Constante referente a propriedade do material para o modelo de } \\
\text { Findley }\end{array}$ \\
\hline$\eta$ & Parâmetro de material no modelo de Liu \& Mahadevan \\
\hline$\mu$ & Propriedade de material para o modelo de Matake \\
\hline$\alpha$ & Constante referente a propriedade de material para Papadopoulos \\
\hline$f_{-1}^{\prime}$ & Limite de resistência à fadiga em flexão para vida finita \\
\hline$t_{-1}^{\prime}$ & Limite de resistência à fadiga em torção para vida finita \\
\hline$N_{0}$ & $\begin{array}{l}\text { Número de ciclos de referência para modelo de Carpinteri \& } \\
\text { Spagnoli modificado }\end{array}$ \\
\hline$m$ & $\begin{array}{l}\text { Coeficiente angular da curva de Wöhler para tração em escala } \\
\text { log-log }\end{array}$ \\
\hline$m *$ & $\begin{array}{l}\text { Coeficiente angular da curva de Wöhler para torção em escala } \\
\text { log-log }\end{array}$ \\
\hline$\sigma_{\text {mises }}$ & Tensão equivalente de von Mises \\
\hline$F\left(N_{f}\right)$ & $\begin{array}{l}\text { Função auxiliar para solução numérica do critério de Carpinteri \& } \\
\text { Spagnoli modificada }\end{array}$ \\
\hline$G\left(\sigma_{a}, \tau_{a}\right)$ & $\begin{array}{l}\text { Função que relaciona diretamente as amplitudes de tensão normal } \\
\text { e cisalhante a um determinado número de ciclos para falha }\end{array}$ \\
\hline
\end{tabular}


"Não faça da tua vida um rascunho.

Poderás não ter tempo de passa-la a limpo." Mario Quintana 


\section{Introdução}

Fadiga é um processo de dano cumulativo que ocorre quando um componente mecânico é submetido a uma variação cíclica das cargas aplicadas. Inicialmente, uma trinca é nucleada, depois essa trinca se propaga de maneira estável até atingir um tamanho crítico de trinca, quando seu regime de propagação se torna instável levando o material a falhar sob carregamentos mecânicos tipicamente bastante inferiores àqueles que o material resistiria em condições monotônicas de carregamento.

Eixos virabrequim são estruturas tipicamente submetidas a carregamento cíclico, portanto bastante sujeitos ao fenômeno de Fadiga. Há diversos critérios de fadiga para vida infinita, mas estudos recentes indicam que o conceito de vida infinita associado a carregamentos inferiores ao limite de resistência à fadiga não se mostra válido para um altíssimo número de ciclos. Sendo assim, é extremamente importante que o fenômeno de fadiga seja compreendido, de modo que seja possível projetar considerando não mais uma vida infinita do componente estrutural, mas uma vida finita que seja razoável para as condições operacionais, de modo que as paradas para manutenção e/ou substituição possam ser programadas, garantindo a segurança da operação.

Eixos virabrequins são estruturas tipicamente sujeitas a condições de carregamentos multiaxiais. Até recentemente, os critérios de fadiga multiaxiais existentes consideravam apenas a análise de vida infinita. Em 2012, Carpinteri \& Spagnoli propuseram uma modificação no seu critério, capaz de prever o número de ciclos para falha sob carregamento biaxial.

Falhas mecânicas vêm sendo reportadas nos eixos virabrequins de motores de usinas termoelétricas, forjados em aços 34CrNiMo6 e 42CrMo4 devido a suas propriedades mecânicas. Essas falhas recentemenre reportadas motivam o presente estudo, que tem por objetivo avaliar o critério de Carpinteri \& Spagnoli modificado e contribuir para a concepção de uma abordagem de fadiga biaxial menos complexa, independente dos procedimentos de determinação de plano crítico. 


\section{Revisão Bibliográfica}

\subsection{Fadiga}

Fadiga é um processo de acúmulo de danos associado à flutuação de carregamento atuando sobre um componente mecânico, que poderá levar o material em questão à falha.

Projetos de engenharia são tipicamente concebidos para submeter seus componentes a esforços elásticos. Com a revolução industrial do século XIX, espalharam-se ferrovias por toda Europa, facilitando o transporte de bens a diferentes mercados consumidores cada vez mais distantes. E com as distâncias maiores, os eixos ferroviários foram gradativamente submetidos a um maior número de ciclos, culminando em cada vez mais falhas por fadiga.

Nesse contexto, o engenheiro e pesquisador alemão August Wöhler iniciou pesquisas, e observou que eixos submetidos a condições de carregamentos cíclicos tinham a sua resistência comprometida. A análise era feita submetendo um corpo de provas a um carregamento cíclico rotativo, conforme indicado na Fig. 1, onde o eixo girava submetendo a parte superior à linha neutra ao estado trativo, para após meio ciclo, $180^{\circ}$ depois submeter a mesma porção de matéria a um estado compressivo.

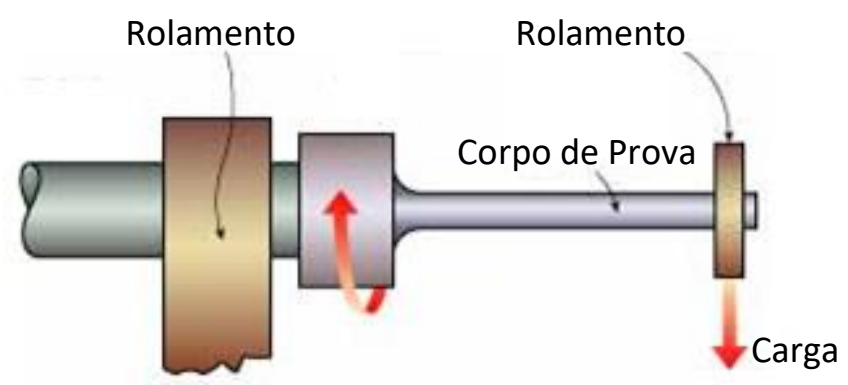

Figura 1 - Fadiga Rotativa usada por Wöhler (autor)

Desse modo, em 1860 Wöhler caracterizou o comportamento em fadiga de um determinado material relacionando a amplitude de tensão do carregamento versus o número de ciclos para falha. Essa curva ficou popularmente conhecida 
como curva S-N (Stress-Number of Cycles), ou simplesmente curva de Wöhler. A Fig. 2 apresenta um exemplo de esse tipo de curva para um material genérico.

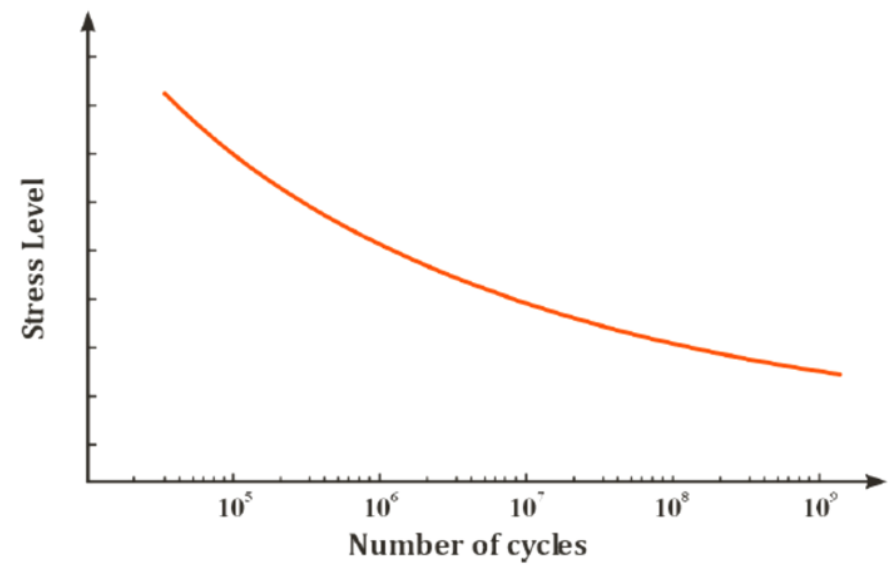

Figura 2 - Exemplo de Curva de Wöhler (Teixeira, 2018)

Apesar de embrionários, os estudos de Wöhler permitiram uma melhor seleção de materiais para as aplicações desejadas, pois era possível avaliar previamente se um material submetido a uma determinada amplitude de tensão seria capaz de suportar um determinado número de ciclos, ou seja, um determinado tempo de serviço seguro para a atividade em questão. Normalmente, a curva de Wöhler é modelada através da equação de Basquin apresentada na equação (1), ou de sua equação equivalente, apresentada na equação (2), onde $A, B, \sigma_{f}^{\prime}$ e $b$ são constantes para cada material e $N_{f}$ é o número de ciclos para falha.

$$
\begin{gathered}
\sigma_{a}=A N_{f}^{B} \\
\sigma_{a}=\sigma_{f}^{\prime}\left(2 N_{f}\right)^{b}
\end{gathered}
$$

É importante mencionar que $\sigma_{f}^{\prime}$ é o coeficiente de resistência à fadiga e é aproximadamente igual à tensão real de fratura $\overline{\sigma_{f}}$ obtido a partir do ensaio de tração, que para materiais metálicos dúcteis esse valor é superior ao limite de resistência mecânica $\sigma_{u}$ (Dowling, 2012). O parâmetro $b$ é conhecido como expoente de Basquin e, para a maioria dos metais, está entre $-0,05$ a $-0,12$. 


\subsection{Conceitos em Fadiga}

A fadiga é um processo de dano progressivo que é incrementado a cada ciclo de carregamento que o componente mecânico experiencia. Apesar de ser projetado para receber carregamentos macroscopicamente elásticos, concentradores de tensão atuam no sentido de amplificar localmente a tensão, eventualmente excedendo o limite de escoamento do material, levando a uma deformação plástica local. Sendo assim, a cada ciclo de carregamento o componente estrutural experiencia um incremento de deformação plástica local, culminando na nucleação de uma trinca de fadiga (Teixeira, 2018).

Há três fatores que favorecem à formação de uma trinca de fadiga: tensões trativas, número de ciclos e variação das cargas aplicadas. Os conceitos relevantes para o estudo de fadiga são variação de tensão, amplitude de tensão, tensão média, razão de carregamento, razão entre amplitude e tensão média obtidos a partir das equações (3), (4), (5), (6) e (7). A Fig. 3 exemplifica um ciclo de carregamento e a tensão média.
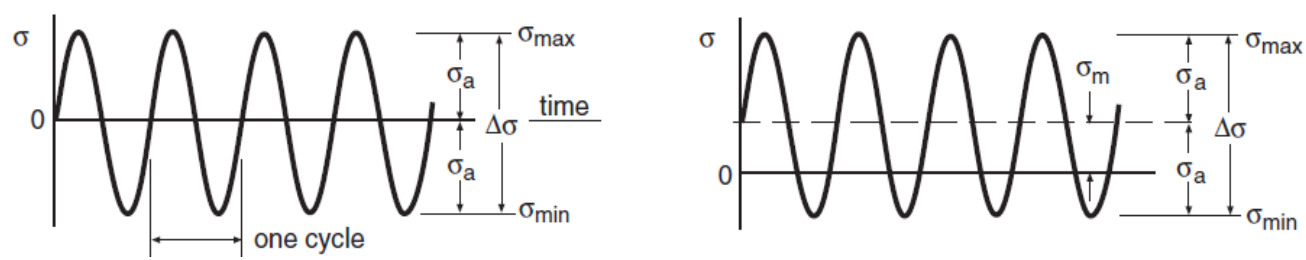

Figura 3 - Ciclos de Carregamento (Dowling, 2012)

$$
\begin{gathered}
\Delta \sigma=\sigma_{\max }-\sigma_{\min } \\
\sigma_{a}=\frac{\sigma_{\max }-\sigma_{\min }}{2} \\
\sigma_{m}=\frac{\sigma_{\max }+\sigma_{\min }}{2} \\
R=\frac{\sigma_{\min }}{\sigma_{\max }} \\
A=\frac{\sigma_{a}}{\sigma_{m}}
\end{gathered}
$$




\subsection{Mecanismos de Danos}

O processo de falha por fadiga ocorre em três etapas: iniciação ou nucleação, propagação estável e propagação instável, que serão discutidos a seguir.

\subsubsection{Iniciação / Nucleação}

Apesar de as estruturas de engenharia estarem tipicamente dimensionadas para serem submetidas a carregamentos macroscopicamente elásticos, o processo de falha por fadiga está associado a deformações plásticas. E para que carregamentos macroscopicamente elásticos produzam deformações locais plásticas, é necessário que algum elemento atue como um concentrador de tensões local. A cada ciclo de carregamento, essas pequenas deformações plásticas se acumulam culminando na nucleação de trincas, sendo esta a primeira etapa do processo de fadiga.

Tipicamente, qualquer elemento que provoque descontinuidade nas linhas de campo de tensão é tratado como um concentrador de tensões, podendo este ser uma descontinuidade geométrica, possivelmente visível na superfície do componente mecânico, ou até mesmo imperfeições metalúrgicas como inclusões não metálicas no interior do material, entre outros. Existem outros aspectos que podem influenciar no processo de nucleação como carregamentos prévios ou qualquer outro processo que gere algum tipo de encruamento local, como difusão de hidrogênio para dentro da estrutura cristalina do aço, gerando tensões residuais na rede ou outros processos de perda de massa como corrosão, que pode gerar perfurações pontiagudas (pites) que se comportam como concentradores de tensões. Entretanto, embora contribuam para a iniciação, esses fenômenos em si não são tratados como parte do processo de fadiga.

Além das descontinuidades geométricas e das imperfeições metalúrgicas, há um outro mecanismo de iniciação de trincas que ocorre devido ao ciclo de cargas de muita relevância para o estudo de fadiga. Este mecanismo é conhecido como Bandas de Deslizamento Persistentes (Persistant Slip Bands, PSB) e ocorre na superfície do objeto em questão. Uma vez de acordo que as regiões mais próximas à superfície do componente mecânico estão sob a predominância de um estado 
plano de tensões enquanto a que as partes mais centrais estão sob predominância de um estado triaxial de tensões, é natural que as regiões mais próximas à superfície estejam mais susceptíveis a deformações plásticas. Com isso, sempre haverá uma ação cisalhante na superfície, que levará a uma deformação plástica local do tipo intrusão ou extrusão (Peixoto, 2018). Com o encruamento decorrente deformação plástica, no próximo ciclo de carregamento a banda de deslizamento vizinha à primeira também sofrerá a ação cisalhante, o que também resultará em uma intrusão ou extrusão local. A repetição desse processo culmina em uma asperização da superfície, podendo até dois sítios de PSB próximos virem a se sobrepor (Mughrabi, 2006), resultando em um processo de nucleação de trinca. As Figs. 4, 5, 6 e 7 apresentam o processo de formação de intrusões e extrusões referentes às PSB.
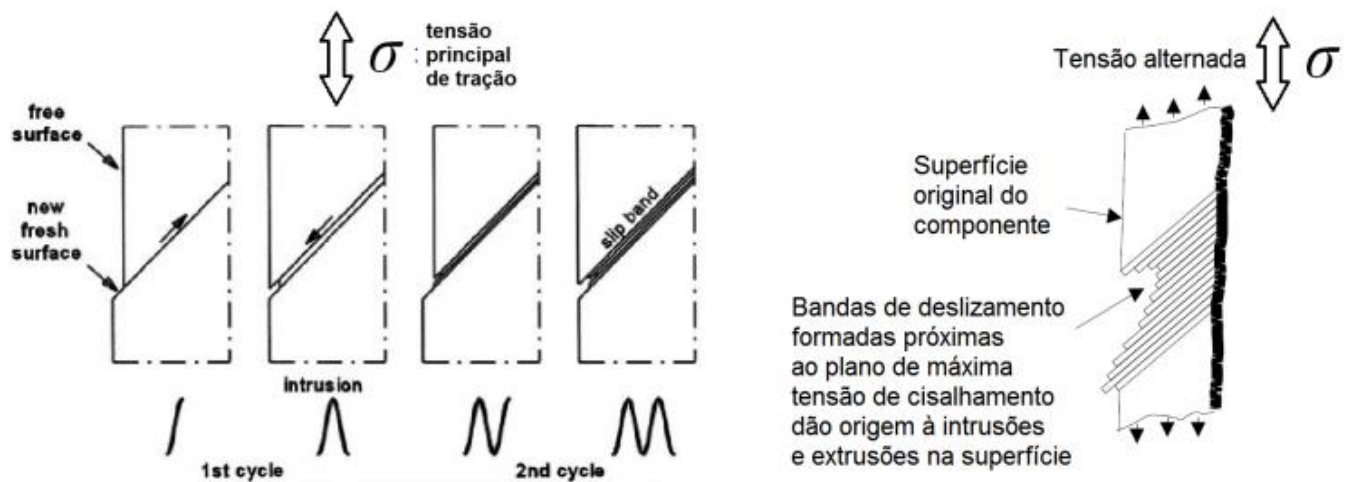

Figura 4 - Intrusões e extrusões de Persistent Slip Bands (Takahashi, 2014)

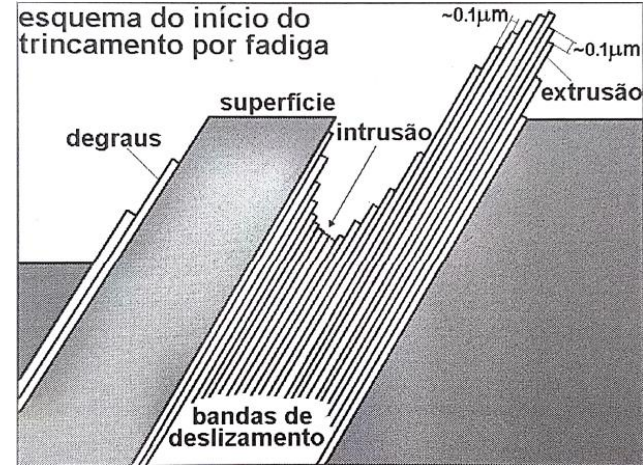

Figura 5 - Esquema típico de nucleação por PSB (Feiferis, 2018)

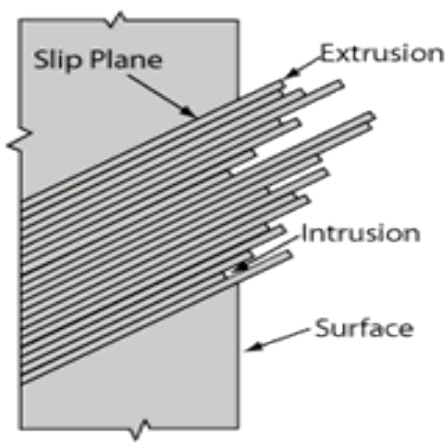

Figura 6 - Superposição sítios vizinhos de PSB (Kumar, 2010) 


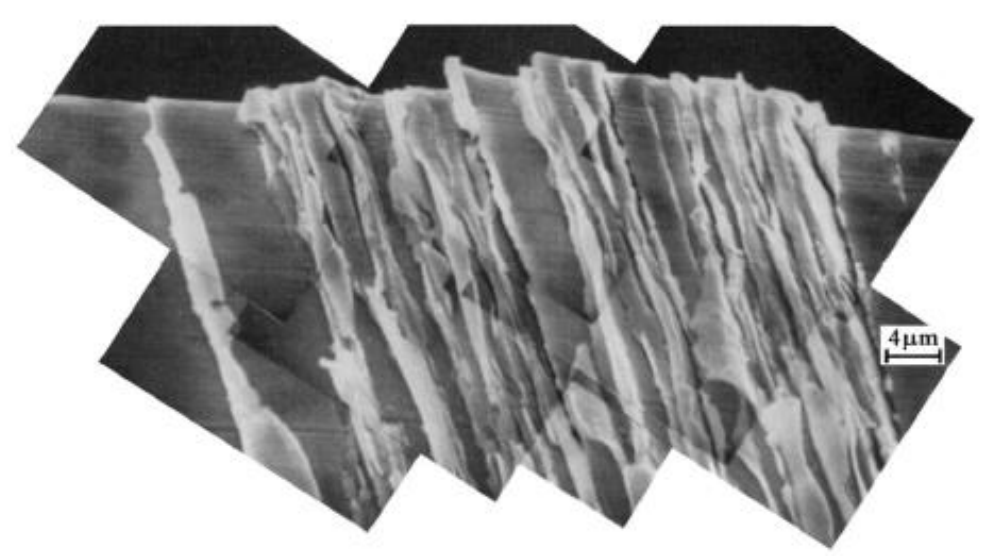

Figura 7 - Intrusões e extrusões na superfície de um cristal de Cu (Suresh, 2001)

\subsubsection{Propagação}

Uma vez nucleada a trinca, o processo de fadiga entra em seu segundo momento que é a etapa de crescimento de trinca. A etapa de crescimento de trinca se divide em crescimento estável e crescimento instável.

Sempre que é aplicada uma tensão sobre uma trinca, entrega-se a esta trinca uma quantidade de energia que pode ser direcionada para a geração de novas superfícies. Quando isso ocorre, diz-se que a trinca cresceu ou se propagou.

Segundo Griffith, a trinca cresce de maneira estável enquanto a taxa de energia de deformação liberada (como força motriz para a geração de novas superfícies) for inferior à taxa de energia superficial para romper ligações e gerar novas superfícies. Quando estas duas grandezas se igualam, temos a situação de criticalidade. Quando a taxa de energia de deformação liberada excede a taxa de energia superficial, a trinca se propaga muito rapidamente e de maneira instável (Griffith, 1920).

Diferentemente da Mecânica da Fratura, em fadiga não tratamos de um fator de intensidade de tensões $K=Y \sigma \sqrt{\pi a}$, mas de um $\Delta K=Y \Delta \sigma \sqrt{\pi a}$, onde $a$ é o tamanho da trinca, $\sigma$ é o carregamento aplicado e $Y$ é um fator de correção geométrica que, para fins de simplificação da análise, vamos considerar a situação proposta por Inglis onde $Y=1$. Essa variação do fator de intensidade de tensões $\Delta K$ se deve ao fato da natureza cíclica do carregamento, onde $a$ é constante dentro de um ciclo de carregamento, mas a tensão oscila entre um valor máximo e um valor mínimo, levando-nos a $\Delta \sigma=\sigma_{\max }-\sigma_{\min }$. Vale observar que, apesar de constante 
dentro de um único ciclo, $a$ terá suas dimensões incrementadas a cada ciclo de carregamento. Sendo assim, é natural que $d a / d N$ passe a ser uma grandeza de interesse.

Naturalmente, se o tamanho da trinca nucleada e/ou o carregamento externo for(em) muito pequeno(s), resultará em um fator de intensidade de tensões muito baixo, que fará com que o crescimento da trinca seja tão lento que, para todos os efeitos práticos, será considerado desprezível. Entretanto, existe um valor de $\Delta K$ limiar (que pode ser obtido com um tamanho de trinca $a$ pequeno e uma tensão elevada $\sigma$ ou vice e versa) a partir do qual será possível se observar um crescimento de trinca $d a / d N$. Para valores gradativamente superiores de $\Delta K$, o crescimento da trinca $d a / d N$ também irá se incrementar de maneira estável. Isso se mantém até que se atinge um determinado valor de $\Delta K$ crítico, a partir do qual a trinca cresce de maneira instável, levando à falha do componente mecânico.

Todo o processo acima descrito está retratado na Fig. 8 (Balanço de Energia de Griffith) e na Fig. 9 (curva $d a / d N$ vs. $\Delta K$ ). A curva $d a / d N$ vs. $\Delta K$ é dividida em três regiões, cujas fronteiras são o $\Delta K_{t h}$ (limiar) e o $\Delta K_{c}$ (crítico).

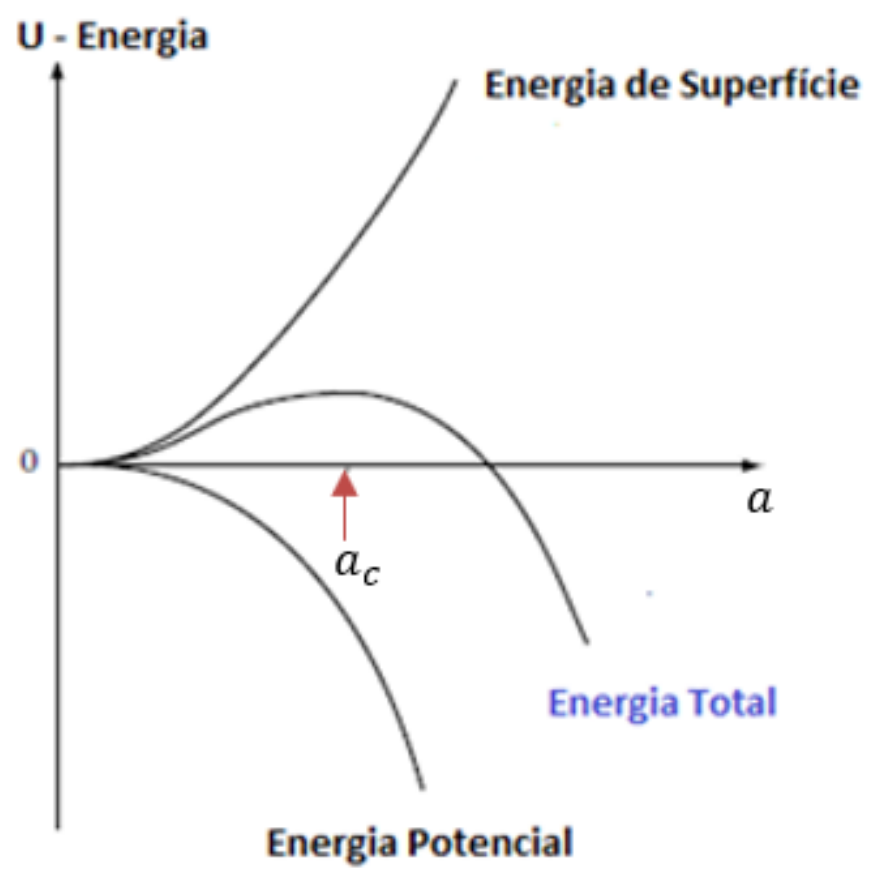

Figura 8 - Balanço de Energia de Griffith - Adaptado (Peixoto, 2018) 


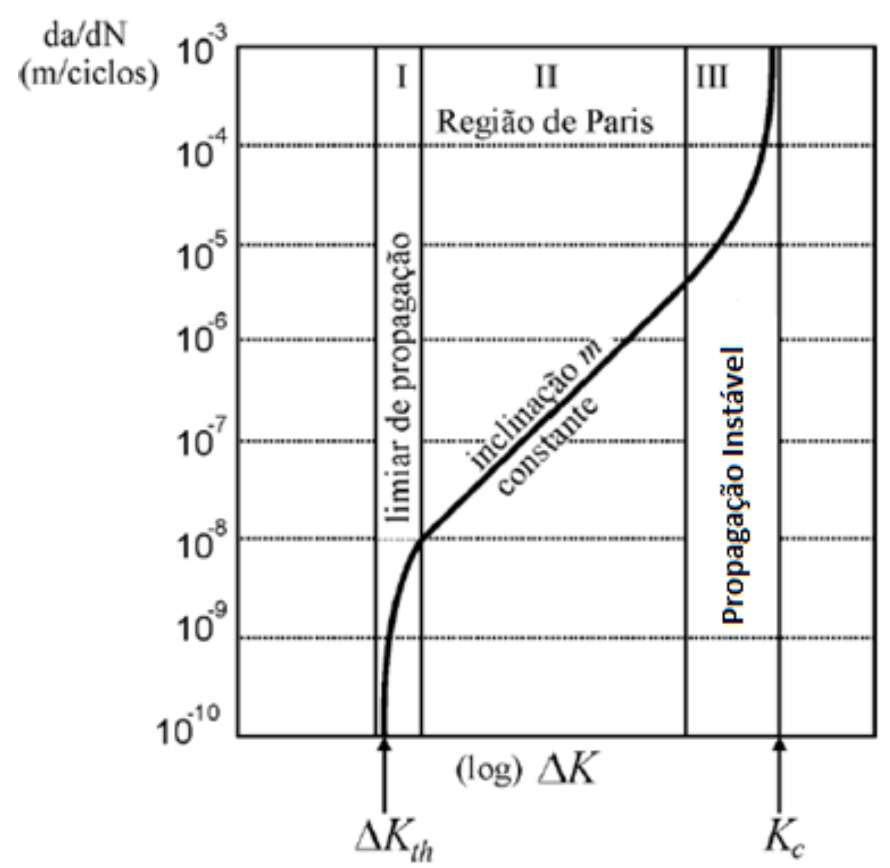

Figura 9 - Curva $d a / d N$ versus $\Delta K$, indicando o crescimento da trinca por ciclo (Schijve, 2008)

Uma vez existindo uma trinca não embrionária, a maior parte da vida em fadiga do componente mecânico se dá na região II, associada ao crescimento estável de trinca. Essa região foi modelada por Paris, e seu equacionamento está apresentado na equação (8).

$$
\frac{d a}{d N}=C(\Delta K)^{m}
$$

O número de ciclos para falha $N_{f}$ pode ser determinado separando as variáveis e integrando conforme indicado na equação (9):

$$
\int_{0}^{N_{f}} d N=\int_{a_{0}}^{a_{c}} \frac{d a}{C(\Delta K)^{m}}
$$

onde $a_{0}$ é o tamanho da trinca quando $\Delta K=\Delta K_{t h}$ e $a_{c}$ é o tamanho da trinca 
quando $\Delta K=\Delta K_{c}$. A equação (9) tem como solução a equação (10), apresentada a seguir, já considerando a substituição $\Delta K=Y \Delta \sigma \sqrt{\pi a}$.

$$
N_{f}=\frac{1}{C \pi^{m / 2}(\Delta \sigma)^{m}} \int_{a_{0}}^{a_{c}} \frac{d a}{Y^{m} a^{m / 2}}
$$

É importante ressaltar que $Y$ é função do comprimento de trinca $a$ e da largura do componente mecânico $W$, por isso não pode ser tratado como constante em $a$ na integração.

\subsection{Superfície de Fratura de uma Trinca de Fadiga}

A Superfície de fratura de uma trinca de fadiga é bastante característica, sendo possível identificar o(s) sítio(s) de nucleação, uma região associada ao crescimento estável de trinca, bem como uma região associada à falha catastrófica do componente mecânico. A Fig. 10 e Fig. 11 ilustram uma típica superfície de fratura por fadiga.

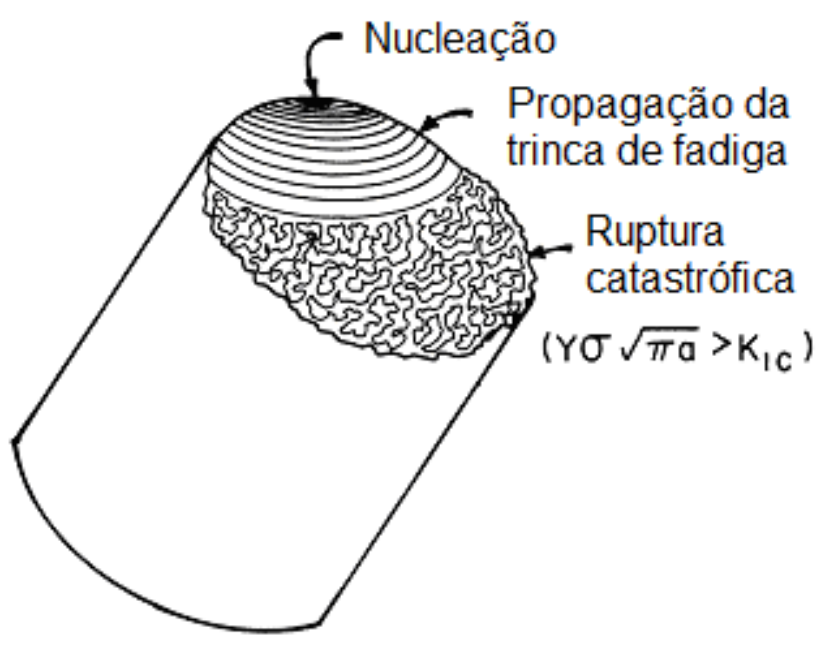

Figura 10 - Típica superfície de fratura de uma trinca de fadiga (Meyers, 2009) 


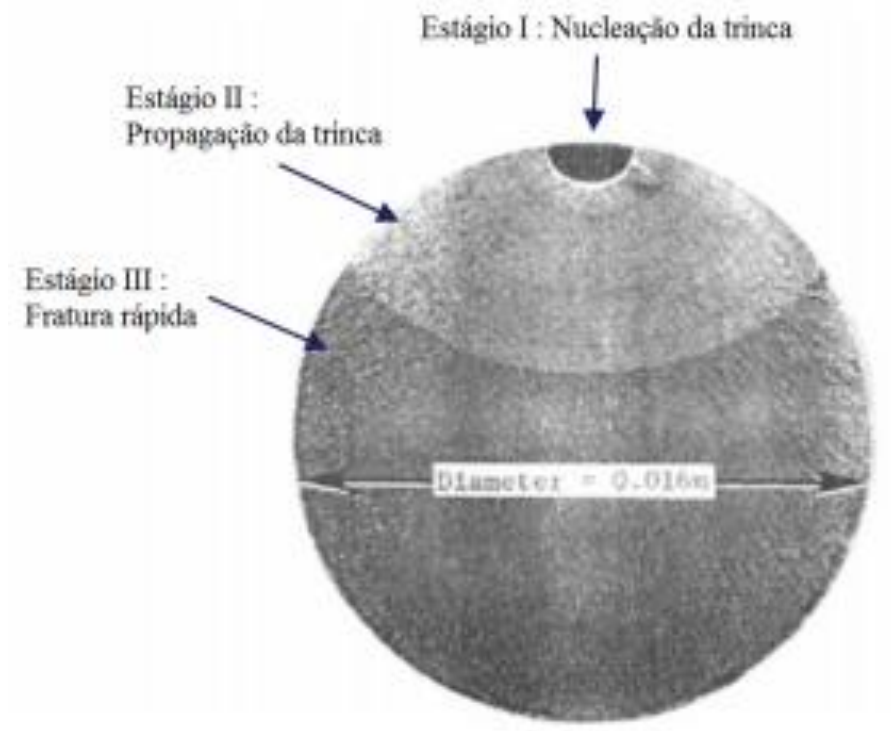

Figura 11 - Superfície típica de Fratura por fadiga, indicando iniciação (A), propagação estável (B) e propagação instável (C)

Na região de propagação estável, é possível identificar um padrão macroscópico conhecido como marcas de praia. Estas estão relacionadas a paradas de equipamentos e variação de cargas, e estão dispostas perpendicularmente à direção de crescimento das trincas. Outra característica relevante são as marcas de rio, dispostas radialmente, sendo possível acompanhar as mesmas para rastrear o local de iniciação da trinca. A Fig. 12 exemplifica os dois padrões. A contrário das ilustrações anteriores que sugeriam uma iniciação na superfície, a Fig. 12 retrata uma iniciação ocorrida em uma área central da superfície de fratura, nucleada a partir de uma inclusão não metálica.

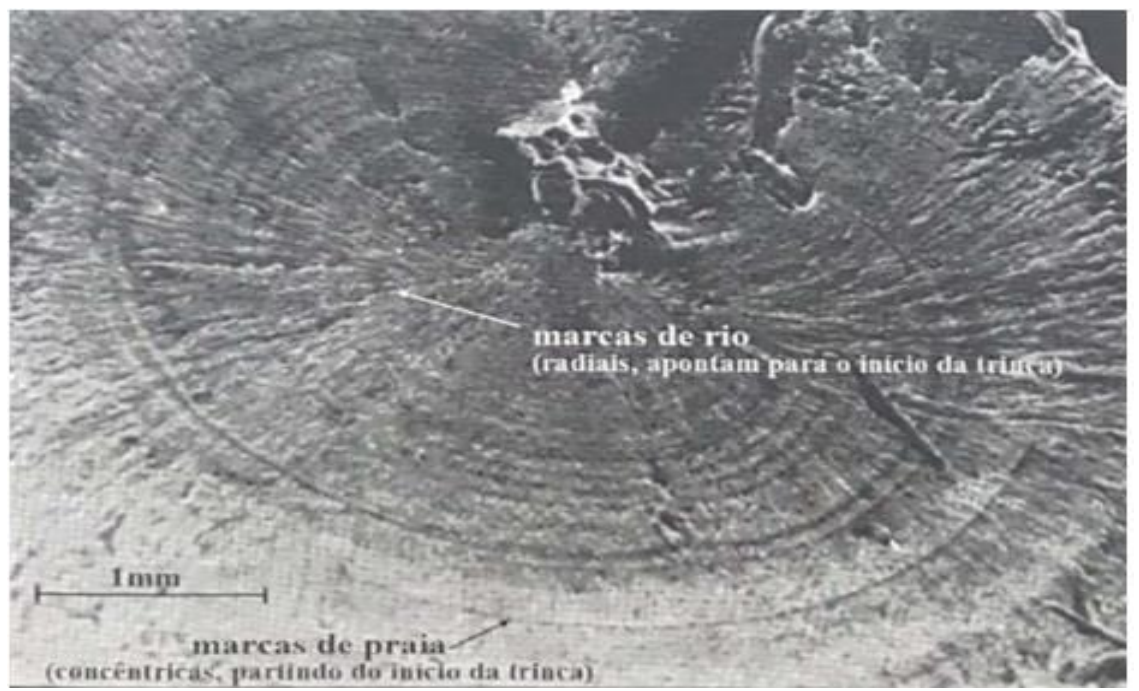

Figura 12 - Marcas de praia e marcas de rio (Castro\&Meggiolaro, 2009) 
Em uma escala microscópica, as estrias de fadiga também são uma característica importante pois, quando é possível detectá-las (nem sempre permanecem bem definidas), são indicativos do histórico de carregamento, onde o espaçamento entre as estrias está relacionado à taxa de propagação de trinca. A Fig. 13 apresenta estrias de fadiga em uma superfície de fratura de uma liga de Ni.

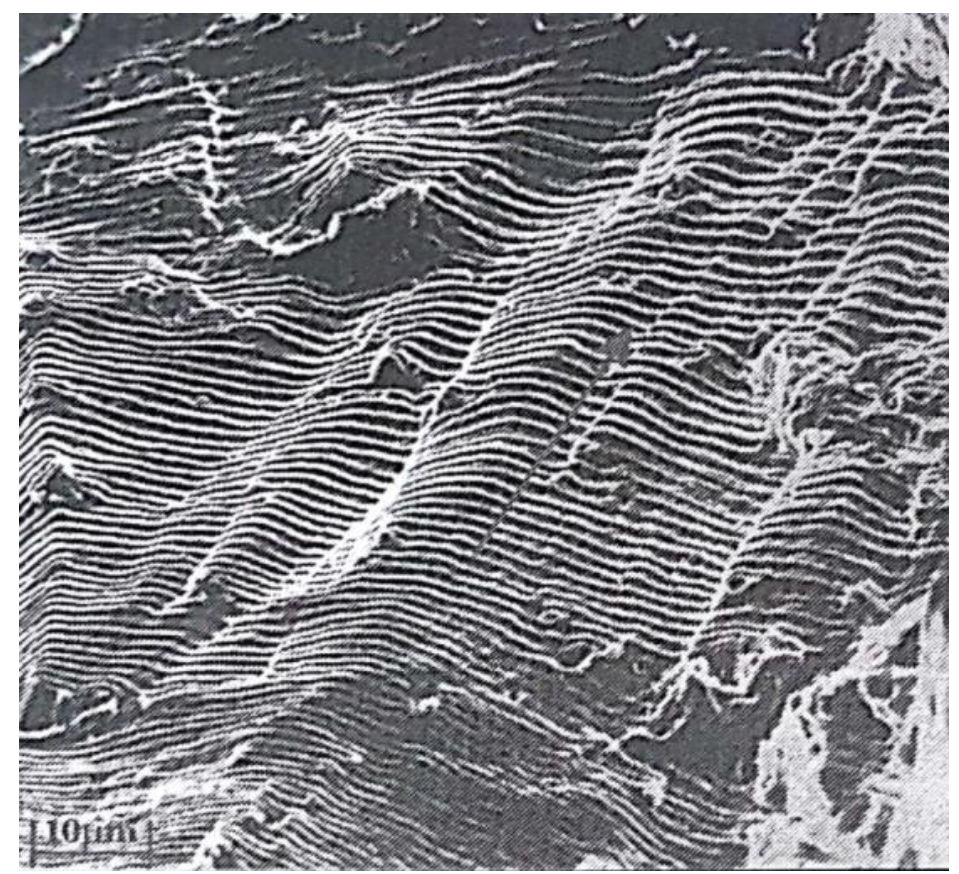

Figura 13 - Estrias de fadiga em liga de Ni (Castro\&Meggiolaro, 2009)

\subsection{Fadiga de Baixo Ciclo (LCF)}

A fadiga de baixo ciclo (Low Cycle Fatigue) está associada a uma amplitude de tensão bastante elevada, o que resulta em um baixo número de ciclos para que o componente estrutural frature. Devido aos elevados carregamentos, se estes ultrapassarem o limite de escoamento do material, é comum que se verifique deformações plásticas cíclicas associadas ao processo, resultando em uma curva de histerese, ilustrada na Fig. 14. A fadiga de baixo ciclo é um processo de falha controlado por deformação. 


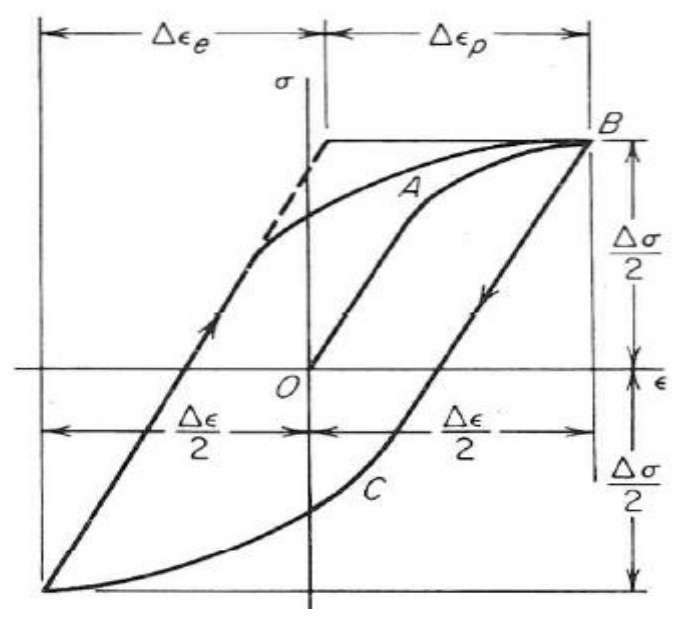

Figura 14 - Ciclo de Histerese (Dieter, 1986)

A relação entre as tensões plásticas e o número de ciclos para falha na fadiga de baixo ciclo foi estabelecida por Coffin-Manson, que trabalhando separadamente propuseram uma relação empírica (Suresh, 2001) apresentada na equação (11):

$$
\frac{\Delta \varepsilon_{p}}{2}=\varepsilon_{f}^{\prime}\left(2 N_{f}\right)^{c}
$$

onde $\frac{\Delta \varepsilon_{p}}{2}$ é a amplitude de deformação plástica, $\varepsilon_{f}^{\prime}$ é o coeficiente de ductilidade em fadiga, $N_{f}$ é o número de ciclos para a falha e $c$ é o expoente da ductilidade em fadiga. Em geral, $\varepsilon_{f}^{\prime}$ é aproximadamente igual a $\varepsilon_{f}$ (deformação de fratura dúctil no ensaio de tração) e $c$ está na faixa de $-0,5$ a $-0,7$ para a maioria dos metais (Suresh, 2001).

Naturalmente, a amplitude de deformação total pode ser descrita como uma soma da amplitude de derfomação elástica com a amplitude de deformação plástica, conforme indicado na equação (12).

$$
\frac{\Delta \varepsilon}{2}=\frac{\Delta \varepsilon_{e}}{2}+\frac{\Delta \varepsilon_{p}}{2}
$$

Entretanto, podemos relacionar a amplitude de deformação elástica com a amplitude de tensão elástica, o que nos leva à equação (13). 


$$
\frac{\Delta \varepsilon_{e}}{2}=\frac{\Delta \sigma}{2 E}=\frac{\sigma_{a}}{E}=\frac{\sigma_{f}^{\prime}}{E}\left(2 N_{f}\right)^{b}
$$

Por fim, podemos substituir os termos da equação (12) com as relações das equações (11) e (13), o que nos leva ao resultado apresentado na equação (14).

$$
\frac{\Delta \varepsilon}{2}=\frac{\sigma_{f}^{\prime}}{E}\left(2 N_{f}\right)^{b}+\varepsilon_{f}^{\prime}\left(2 N_{f}\right)^{c}
$$

\subsection{Fadiga de Alto Ciclo (HCF), Fadiga de Altíssimo Ciclo (UHCF) e Limite de Resistência à Fadiga}

No regime de fadiga de alto ciclo (High Cycle Fatigue), o processo de fadiga é caracterizado por amplitudes de tensões mais baixas, decorrentes de carregamentos elásticos. O desdobramento natural é que os componentes mecânicos atingem uma vida em fadiga maior, precisando de um maior número de ciclos para atingir a fratura.

Segundo Dowling, a fronteira que separa o regime de baixo ciclo do regime de alto ciclo varia de acordo com o material em questão, mas encontra-se tipicamente na faixa entre $10^{2}$ e $10^{4}$ ciclos.

Conforme se reduz a amplitude de tensão aumentando o número de ciclos que o corpo suporta, verifica-se que a curva apresenta uma tendência a um comportamento assintótico, sugerindo a existência de um platô. Isso significa que, para amplitudes de tensões suficientemente baixas, o material atingiria vida infinita, isto é, o componente mecânico estaria seguro para operar com amplitudes de tensões inferiores àquelas associadas ao platô, teoricamente livre do risco de falhas. O valor dessa amplitude de tensão associado à vida infinita em fadiga é conhecido como limite de resistência à fadiga (endurance limit), e esse conceito é largamente utilizado na concepção e implementação de projetos mecânicos. Para alguns materiais, o limite de resistência à fadiga não é tão evidente, nesse caso o limite de resistência à fadiga será o valor de amplitude de tensão associado a uma vida longa, para uma determinado número de ciclos arbitrário (Dowling, 2012). 
Para o caso de flexão, o limite de resistência à fadiga será denotado por $f_{-1}$, enquanto que para torção será denotado por $t_{-1}$. Tipicamente, o limite de resistência à fadiga em flexão $f_{-1}$ está entre $35 \%$ a $50 \%$ do limite de resistência mecânica do material. Já o limite de resistência à fadiga em torção $t_{-1}$ tipicamente encontra-se em uma faixa que varia de $f_{-1} / \sqrt{3}$ a $f_{-1}$, dependendo da capacidade de deformação plástica do aço em questão.

Estudos posteriores de Fadiga de Altíssimo Ciclo (Ultra High Cycle Fatigue) contestam a existência de um platô definitivo (Bathias, 2003), pois alguns autores identificaram uma queda no valor de limite de resistência à fadiga após $10^{7}$ ciclos (Mughrabi, 2006).

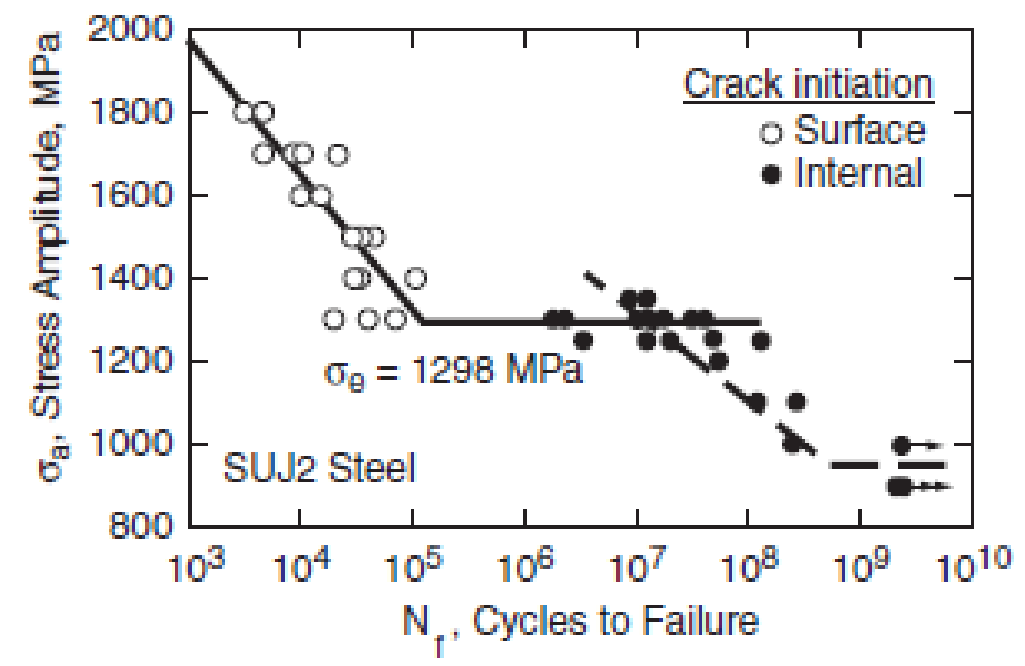

Figura 15 - Redução do limite de resistência à fadiga em $10^{7}$ ciclos (Dowling, 2012)

\subsection{Influência da Tensão Média}

Tanto a amplitude de tensão quanto a tensão média são fatores que influenciam na vida em fadiga de um componente estrutural. Entretanto, se por um lado a amplitude de tensão de carregamento influencia na etapa de nucleação de trincas, a tensão média tem influência direta na etapa de propagação das mesmas. Isso se dá porque a presença de uma tensão média trativa, por exemplo, mantém a ponta da trinca tracionada por uma maior parte do tempo (senão pelo tempo inteiro) de um ciclo de carregamento. E trincas tracionadas têm a sua propagação favorecida. De maneira análoga, se a tensão média de um carregamento for 
negativa, isso significa que durante a maior parte do ciclo a trinca está sob compressão, o que atua no sentido de inibir sua propagação.

A Fig. 16 apresenta esquematicamente como a tensões médias maiores deslocam a curva S-N para baixo, reduzindo os valores de amplitudes de tensões associadas a cada número de ciclos específico e o limite de resistência à fadiga.

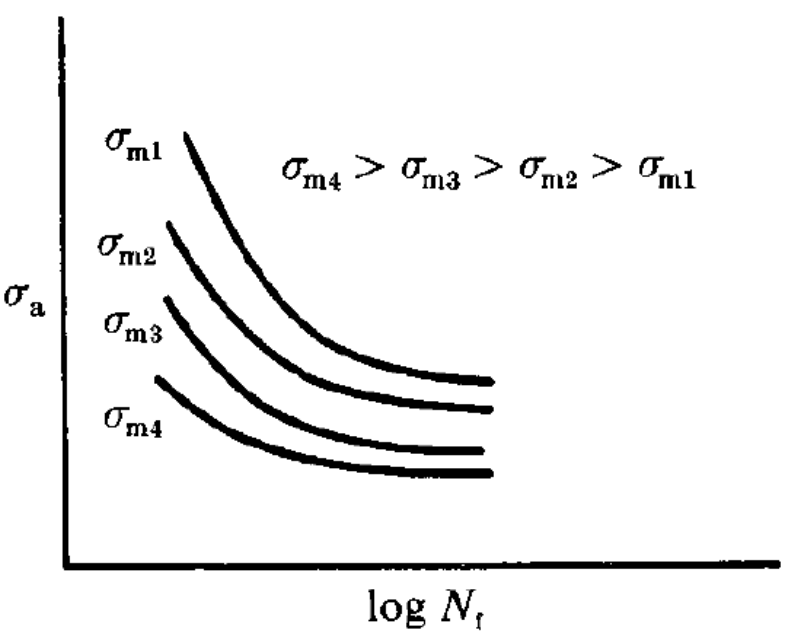

Figura 16 - Influência da tensão média sobre a curva de Wöhler (Teixeira, 2018)

A maior parte dos dados de fadiga obtidos em pesquisa são para condições de carregamento com reversão total $(R=-1)$, isto é, tensão trativa e compressiva têm mesmo módulo, mas com sinal trocado. Entretanto, Goodman propôs um modelo que permite prever a influência da tensão média a partir de uma relação simples apresentada na equação (15).

$$
\sigma_{a}=\left(\sigma_{L R F_{R=-1}}\right)\left[1-\frac{\sigma_{m}}{\sigma_{L R M}}\right]
$$

onde $\sigma_{a}$ é a amplitude de tensão do carregamento, $\sigma_{L R F_{R=-1}}$ é o limite de resistência à fadiga para um carregamento genérico totalmente reversível, $\sigma_{m}$ é o a tensão média imposta pelo carregamento e $\sigma_{L R M}$ é o limite de resistência mecânica do material.

Tal relação é possível de ser representada por uma reta, conforme o esquema abaixo ilustrado na Fig. 17. 


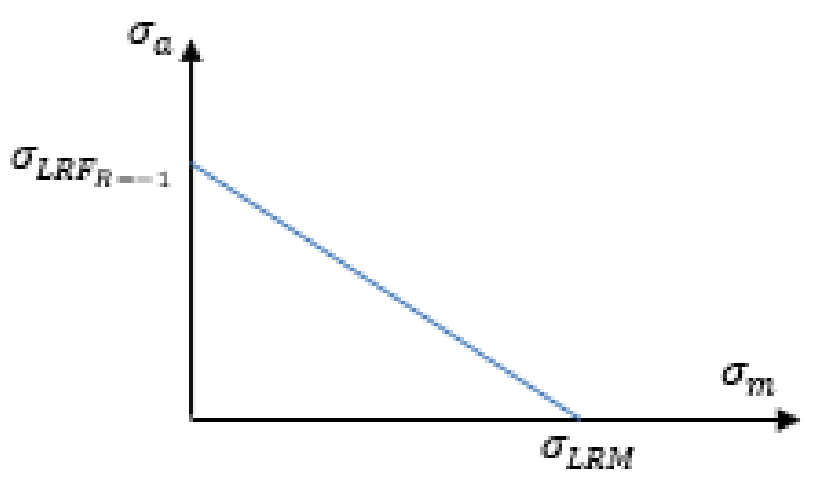

Figura 17 - Diagrama de Goodman (autor)

Na prática, essa curva estabelece uma fronteira de segurança de operação de um componente mecânico submetido a uma amplitude de tensão de carregamento com presença de tensão média. Quaisquer combinações de $\sigma_{a}$ e $\sigma_{m}$ que possam ser representadas por um ponto que esteja abaixo da curva (no interior da área obtida), então essa operação é segura e o material teoricamente atinge vida em fadiga infinita. Para outras combinações representadas por um ponto acima da curva, então em algum momento essa operação resultará cedo ou tarde em falha da estrutura.

É pertinente destacar o comportamento nas condições limites. Quando a tensão média for nula, naturalmente a amplitude de tensão limiar para falha será o limite de resistência à fadiga, como esperado. Obviamente, amplitudes de tensões inferiores ao limite de resistência à fadiga resultam em uma operação segura, enquanto amplitudes de tensões superiores ao limite de resistência à fadiga resultarão em falha. Analogamente, supondo amplitude de tensão de carregamento nula, o componente mecânico suportará uma tensão média (constante) até o limite de resistência mecânica. Esse resultado é óbvio e está de acordo com o que se esperaria de um ensaio de tração convencional.

A condição de real interesse é uma condição intermediária, na presença de tensão média e amplitude de tensões ambas maiores que zero. Com isso, verificase que para que não ocorra falha, é necessário considerar uma amplitude de tensão de carregamento inferior ao limite de resistência à fadiga, naturalmente o valor de amplitude correspondente à tensão média em questão, sem que o ponto específico extrapole a curva de Goodman.

Posteriormente outros trabalhos foram apresentados no sentido de produzir modificações no trabalho de Goodman. Gerber optou por uma abordagem 
paraboloide mais adequada para materiais muito dúcteis visto que a área adicional obtida está relacionada à capacidade de plastificação do material sob solicitação mecânica, enquanto Soderberg propôs uma modificação para materiais muito frágeis, substituindo o limite de resistência mecânica $\sigma_{L R M}$ pelo limite de escoamento $\sigma_{y}$, situações retratadas pelas equações (16) e (17) e Fig. 18.

$$
\begin{gathered}
\sigma_{a}=\left(\sigma_{L R F_{R=-1}}\right)\left[1-\left(\frac{\sigma_{m}}{\sigma_{L R M}}\right)^{2}\right] \\
\sigma_{a}=\left(\sigma_{L R F_{R=-1}}\right)\left[1-\frac{\sigma_{m}}{\sigma_{y}}\right]
\end{gathered}
$$

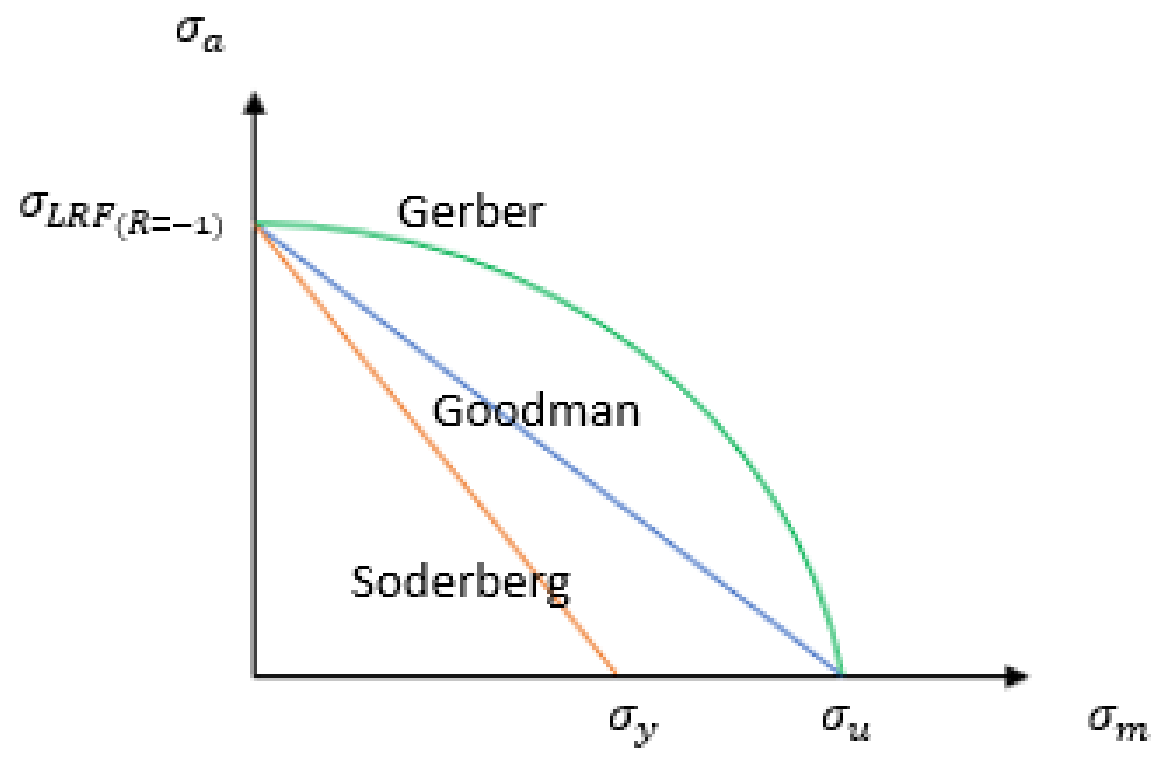

Figura 18 - Modificações no trabalho de Goodman propostas por Gerber e Soderberg (autor)

\subsection{Fadiga Multiaxial}

\subsubsection{Tensor de Tensões e Estado de Tensão}

O estado de tensões é a condição sobre a qual um elemento infinitesimal de área ou volume fica quando submetido a um carregamento externo. Tipicamente representado em coordenadas cartesianas, um carregamento pode ser interpretado como uma combinação de tensões normais e cisalhantes atuando sobre o mesmo 
elemento infinitesimal. Um mesmo estado de tensões pode ser representado por diversos tensores diferentes, e essa possibilidade se deve exclusivamente à liberdade que temos para escolher a orientação de um sistema de eixos cartesianos de acordo com a nossa maior conveniência.

\subsubsection{Tensor}

Um tensor é uma entidade que generaliza o conceito de escalares, vetores e matrizes. Na prática, um tensor $\boldsymbol{T}$ recebe como entrada uma determinada direção $\boldsymbol{v}$ e tem como resposta uma tensão $\boldsymbol{T}^{(\boldsymbol{v})}$ atuando sobre o plano perpendicular à direção $\boldsymbol{v}$. Essa tensão-resposta atuando sobre o plano perpendicular à direção $\boldsymbol{v}$ tem componentes normais e pertencentes ao plano perpendicular a $\boldsymbol{v}$.

A Fig. 19 ilustra o tensor de tensões de Cauchy, amplamente utilizado na área de comportamento mecânico dos materiais, pois a partir do mesmo podemos determinar as componentes normais e cisalhantes atuando sobre qualquer face do elemento infinitesimal.

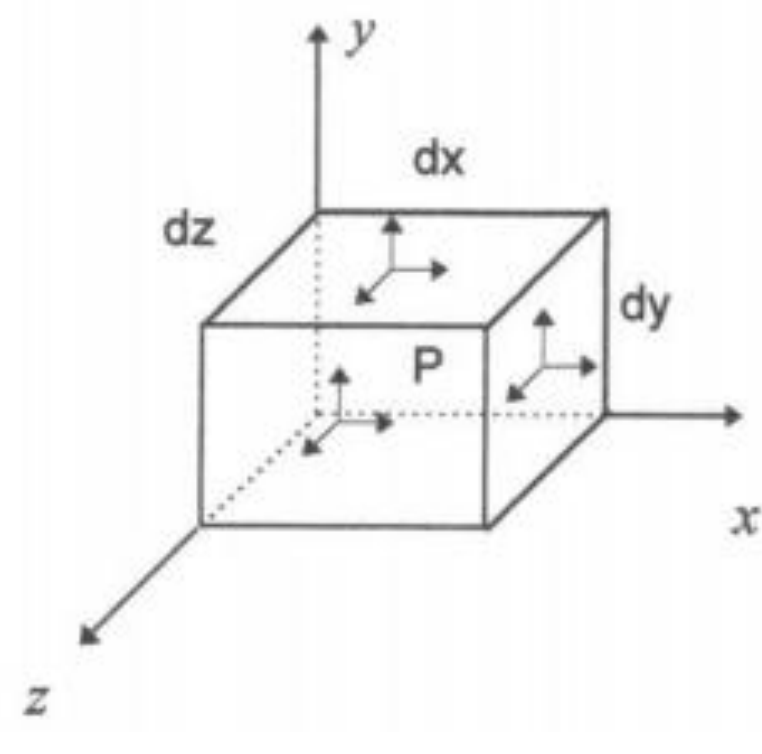

Figura 19 - Tensor de tensões de Cauchy (Medeiros)

Por exemplo, seja $\boldsymbol{\sigma}_{i j}$ um tensor de tensões $3 \times 3$ que representa um estado de tensões genérico, apresentado na equação (18). Para que o elemento de volume esteja em equilíbrio, o tensor de tensões é necessariamente simétrico em relação à diagonal principal. Seja $\boldsymbol{v}_{a}$ a direção paralela ao eixo $\hat{\mathrm{e}}_{x_{a}}$ onde 
$\boldsymbol{v}_{a}=\left(v_{a}, 0,0\right), \boldsymbol{v}_{b}$ a direção paralela ao eixo $\hat{\mathrm{e}}_{x_{b}}$ onde $\boldsymbol{v}_{b}=\left(0, v_{b}, 0\right)$ e $\boldsymbol{v}_{c}$ a direção paralela ao eixo $\hat{e}_{x_{c}}$ onde $\boldsymbol{v}_{c}=\left(0,0, v_{c}\right)$. As equações (19), (20) e (21) representam as respostas do tensor de tensões $\boldsymbol{\sigma}_{i j}$ a cada uma das direções em questão.

$$
\begin{aligned}
& \boldsymbol{\sigma}_{i j}=\left[\begin{array}{lll}
\sigma_{x x} & \tau_{x y} & \tau_{x z} \\
\tau_{x y} & \sigma_{y y} & \tau_{y z} \\
\tau_{x z} & \tau_{y z} & \sigma_{z z}
\end{array}\right] \\
& \boldsymbol{T}^{\left(\boldsymbol{v}_{a}\right)}=\boldsymbol{\sigma}_{i j} \cdot \boldsymbol{v}_{a}=\left[\begin{array}{ccc}
\sigma_{x x} & \tau_{x y} & \tau_{x z} \\
\tau_{x y} & \sigma_{y y} & \tau_{y z} \\
\tau_{x z} & \tau_{y z} & \sigma_{z z}
\end{array}\right]\left[\begin{array}{c}
v_{a} \\
0 \\
0
\end{array}\right]=\left[\begin{array}{l}
\sigma_{x x} v_{a} \\
\tau_{x y} v_{a} \\
\tau_{x z} v_{a}
\end{array}\right] \\
& \boldsymbol{T}^{\left(\boldsymbol{v}_{b}\right)}=\boldsymbol{\sigma}_{i j} \cdot \boldsymbol{v}_{b}=\left[\begin{array}{ccc}
\sigma_{x x} & \tau_{x y} & \tau_{x z} \\
\tau_{x y} & \sigma_{y y} & \tau_{y z} \\
\tau_{x z} & \tau_{y z} & \sigma_{z z}
\end{array}\right]\left[\begin{array}{c}
0 \\
v_{b} \\
0
\end{array}\right]=\left[\begin{array}{l}
\tau_{x y} v_{b} \\
\sigma_{y y} v_{b} \\
\tau_{y z} v_{b}
\end{array}\right] \\
& \boldsymbol{T}^{\left(\boldsymbol{v}_{c}\right)}=\boldsymbol{\sigma}_{i j} \cdot \boldsymbol{v}_{c}=\left[\begin{array}{ccc}
\sigma_{x x} & \tau_{x y} & \tau_{x z} \\
\tau_{x y} & \sigma_{y y} & \tau_{y z} \\
\tau_{x z} & \tau_{y z} & \sigma_{z z}
\end{array}\right]\left[\begin{array}{c}
0 \\
0 \\
v_{c}
\end{array}\right]=\left[\begin{array}{c}
\tau_{x z} v_{c} \\
\tau_{y z} v_{c} \\
\sigma_{z z} v_{c}
\end{array}\right]
\end{aligned}
$$

As equações (18), (19) e (20) produzem respostas esperadas, isto é, uma tensão normal paralela ao eixo em questão e duas tensões cisalhantes perpendiculares ao eixo em questão, onde todas as tensões atuando em cada um dos planos perpendiculares a $\boldsymbol{v}_{a}, \boldsymbol{v}_{b}$ e $\boldsymbol{v}_{c}$ respectivamente, que representam as faces do elemento cúbico de volume infinitesimal.

\subsubsection{Tensões Principais}

Para todo estado de tensões, existem n possibilidades de representação do mesmo que são obtidas a partir da mudança de orientação dos eixos do sistema de coordenadas. Entretanto, existe uma única orientação específica do sistema de eixo de coordenadas que produz um tensor $\boldsymbol{\sigma}_{i j}$ cujas componentes cisalhantes (fora da diagonal principal) são nulas. A orientação desse sistema de eixos será de acordo com as direções $\hat{e}_{x_{1}}, \hat{e}_{x_{2}}$ e $\hat{e}_{x_{3}}$ e as tensões normais atuando em cada uma dessas direções serão respectivamente $\sigma_{1}, \sigma_{2}$ e $\sigma_{3}$, onde $\sigma_{1}>\sigma_{2}>\sigma_{3}$. 
Para determinar as direções das tensões principais $\hat{\mathrm{e}}_{x_{1}}, \hat{\mathrm{e}}_{x_{2}}$ e $\hat{\mathrm{e}}_{x_{3}}$, primeiro é necessário determinar as tensões principais $\sigma_{1}, \sigma_{2}$ e $\sigma_{3}$, que podem ser encontrados a partir dos autovalores de um estado de tensões qualquer imposto por um carregamento externo genérico. Essa condição está expressa na equação (22).

$$
\left|\begin{array}{ccc}
\sigma_{x x}-\sigma & \tau_{x y} & \tau_{x z} \\
\tau_{x y} & \sigma_{y y}-\sigma & \tau_{y z} \\
\tau_{x z} & \tau_{y z} & \sigma_{z z}-\sigma
\end{array}\right|=0
$$

A equação (22) é de terceira ordem, e se desdobra na equação (23)

$$
\begin{aligned}
& -\sigma^{3}+\left(\sigma_{x x}+\sigma_{y y}+\sigma_{z z}\right) \sigma^{2} \\
& -\left(\sigma_{x x} \sigma_{y y}+\sigma_{y y} \sigma_{z z}+\sigma_{x x} \sigma_{z z}-\tau_{x y}^{2}-\tau_{y z}^{2}-\tau_{x z}^{2}\right) \sigma \\
& +\left(\sigma_{x x} \sigma_{y y} \sigma_{z z}+2 \tau_{x y} \tau_{y z} \tau_{x z}-\sigma_{x x} \tau_{y z}^{2}-\sigma_{y y} \tau_{x z}^{2}\right. \\
& \left.-\sigma_{z z} \tau_{x y}^{2}\right)=0
\end{aligned}
$$

Sabendo que a soma da diagonal principal de qualquer um dos $\mathrm{n}$ tensores $\boldsymbol{\sigma}_{i j}, \boldsymbol{\sigma}_{i j}^{\prime}, \boldsymbol{\sigma}_{i j}^{\prime \prime}, \ldots, \boldsymbol{\sigma}_{i j}^{(n)}$ que representem um determinado estado de tensões é sempre a mesma, sendo este o primeiro invariante de tensão $I_{1}$ representado na equação (24), e que o segundo invariante de tensão $I_{2}$ para qualquer um dos n tensores é a soma dos determinantes de segunda ordem representado na equação (25) e o terceiro invariante de tensão $I_{3}$ é a o próprio determinante de qualquer um dos $n$ tensores representado na equação (26), então podemos reduzir a equação (23) à equação (27) (Dieter, 1986).

$$
\begin{gathered}
I_{1}=\sigma_{x x}+\sigma_{y y}+\sigma_{z z} \\
I_{2}=\left|\begin{array}{ll}
\sigma_{x x} & \tau_{x y} \\
\tau_{x y} & \sigma_{y y}
\end{array}\right|+\left|\begin{array}{ll}
\sigma_{x x} & \tau_{x z} \\
\tau_{x z} & \sigma_{z z}
\end{array}\right|+\left|\begin{array}{ll}
\sigma_{y y} & \tau_{y z} \\
\tau_{y z} & \sigma_{z z}
\end{array}\right| \\
I_{3}=\left|\begin{array}{lll}
\sigma_{x x} & \tau_{x y} & \tau_{x z} \\
\tau_{x y} & \sigma_{y y} & \tau_{y z} \\
\tau_{x z} & \tau_{y z} & \sigma_{z z}
\end{array}\right| \\
-\sigma^{3}+I_{1} \sigma^{2}-I_{2} \sigma+I_{3}=0
\end{gathered}
$$


As soluções da equação (27) serão $\sigma_{1}, \sigma_{2}$ e $\sigma_{3}$, onde $\sigma_{1}>\sigma_{2}>\sigma_{3}$. Uma vez determinados os autovalores, podemos encontrar os autovetores $\boldsymbol{v}_{1}, \boldsymbol{v}_{\mathbf{2}}$ e $\boldsymbol{v}_{3}$ que serão justamente as direções das tensões principais. Deverá ser encontrada uma determinada direção que, quando submetida à transformação linear em questão, retorne um múltiplo do vetor original, conservando sua direção original. A constante de proporcionalidade é justamente o autovalor, e a direção em si é o autovetor. Observe que $\boldsymbol{v}_{1}, \boldsymbol{v}_{\mathbf{2}}$ e $\boldsymbol{v}_{3}$ são vetores unitários e podem ser calculados resolvendo as equações (28), (29) e (30), que se desdobram nas equações (31), (32) e (33), respectivamente.

$$
\begin{gathered}
\boldsymbol{\sigma}_{i j} \boldsymbol{v}_{1}=\sigma_{1} \boldsymbol{v}_{1} \\
\boldsymbol{\sigma}_{i j} \boldsymbol{v}_{2}=\sigma_{2} \boldsymbol{v}_{2} \\
\boldsymbol{\sigma}_{i j} \boldsymbol{v}_{3}=\sigma_{3} \boldsymbol{v}_{3} \\
{\left[\begin{array}{lll}
\sigma_{x x} & \tau_{x y} & \tau_{x z} \\
\tau_{x y} & \sigma_{y y} & \tau_{y z} \\
\tau_{x z} & \tau_{y z} & \sigma_{z z}
\end{array}\right]\left[\begin{array}{l}
v_{1 x} \\
v_{1 y} \\
v_{1 z}
\end{array}\right]=\sigma_{1}\left[\begin{array}{l}
v_{1 x} \\
v_{1 y} \\
v_{1 z}
\end{array}\right]} \\
{\left[\begin{array}{lll}
\sigma_{x x} & \tau_{x y} & \tau_{x z} \\
\tau_{x y} & \sigma_{y y} & \tau_{y z} \\
\tau_{x z} & \tau_{y z} & \sigma_{z z}
\end{array}\right]\left[\begin{array}{l}
v_{2 x} \\
v_{2 y} \\
v_{2 z}
\end{array}\right]=\sigma_{2}\left[\begin{array}{l}
v_{2 x} \\
v_{2 y} \\
v_{2 z}
\end{array}\right]} \\
{\left[\begin{array}{lll}
\sigma_{x x} & \tau_{x y} & \tau_{x z} \\
\tau_{x y} & \sigma_{y y} & \tau_{y z} \\
\tau_{x z} & \tau_{y z} & \sigma_{z z}
\end{array}\right]\left[\begin{array}{l}
v_{3 x} \\
v_{3 y} \\
v_{3 z}
\end{array}\right]=\sigma_{3}\left[\begin{array}{l}
v_{3 x} \\
v_{3 y} \\
v_{3 z}
\end{array}\right]}
\end{gathered}
$$

A solução dos sistemas acima fornecerá somente uma relação de proporções entre as componentes de cada vetor. Para solução única, utiliza-se a informação de que os autovetores são unitários, culminando nas equações (34), (35) e (36).

$$
\begin{aligned}
& \left\|\boldsymbol{v}_{1}\right\|=\sqrt{v_{1 x}^{2}+v_{1 y}^{2}+v_{1 z}^{2}}=1 \\
& \left\|\boldsymbol{v}_{2}\right\|=\sqrt{v_{2 x}^{2}+v_{2 y}^{2}+v_{2 z}^{2}}=1 \\
& \left\|\boldsymbol{v}_{3}\right\|=\sqrt{v_{3 x}^{2}+v_{3 y}^{2}+v_{3 z}^{2}}=1
\end{aligned}
$$


Uma vez encontrados $\boldsymbol{v}_{1}$ e $\boldsymbol{v}_{2}$, o autovetor $\boldsymbol{v}_{3}$ pode ser encontrado a partir do produto vetorial dos dois primeiros. Ao final deste processo, podemos reescrever o tensor de tensões $\boldsymbol{\sigma}_{i j}$ para um novo sistema de coordenadas, cujas direções foram determinadas $\hat{\mathrm{e}}_{x_{1}}, \hat{\mathrm{e}}_{x_{2}}$ e $\hat{\mathrm{e}}_{x_{3}}$ (paralelos a $\boldsymbol{v}_{1}, \boldsymbol{v}_{2}$ e $\boldsymbol{v}_{3}$ ). O estado de tensões descrito a partir das tensões principais tem como característica os termos apenas na diagonal principal, isto é, as tensões cisalhantes do tensor de tensões quando este estiver representado nas direções principais serão nulas. Sendo assim, podemos representar o estado de tensões $\boldsymbol{\sigma}_{i j}$ conforme apresentado na equação (37) (Dieter, 1986).

$$
\boldsymbol{\sigma}_{i j}=\left[\begin{array}{ccc}
\sigma_{1} & 0 & 0 \\
0 & \sigma_{2} & 0 \\
0 & 0 & \sigma_{3}
\end{array}\right]
$$

\subsubsection{Componentes Hidrostática e Desviadora de Tensão}

Qualquer estado de tensão pode ser decomposto em dois outros tensores. O primeiro tensor, $\sigma_{m} \boldsymbol{\delta}_{i j}$, chamado de componente média ou hidrostática, está associado à variação de volume, isto é, não causa distorção no material. Já o segundo tensor, $\boldsymbol{\sigma}_{i j}^{\prime}$, chamado de componente desviadora de tensão, está associado a distorções no material.

Define-se, portanto, a tensão média ou tensão hidrostática conforme o apresentado na equação (38). Isto é válido para qualquer representação $\boldsymbol{\sigma}_{i j}$ de um estado de tensões genérico, independentemente de ter o seu sistema de eixos alinhado às direções principais ou não.

$$
\sigma_{m}=\frac{I_{1}}{3}=\frac{\sigma_{x x}+\sigma_{y y}+\sigma_{z z}}{3}=\frac{\sigma_{1}+\sigma_{2}+\sigma_{3}}{3}
$$

Define-se também o tensor $\boldsymbol{\delta}_{i j}$, conhecido como delta de Kronecker, apresentado na equação (39). 


$$
\boldsymbol{\delta}_{i j}=\left[\begin{array}{lll}
1 & 0 & 0 \\
0 & 1 & 0 \\
0 & 0 & 1
\end{array}\right]
$$

Tem-se então que a componente hidrostática apresentada na equação (40).

$$
\boldsymbol{\sigma}_{i j}=\boldsymbol{\sigma}_{i j}^{\prime}+\sigma_{m} \boldsymbol{\delta}_{i j}
$$

Conforme o início da discussão, o tensor de tensões pode ser decomposto em duas componentes, hidrostática e desviadora de tensões. Sendo assim, segue apresentado o conceito nas equações (41) e (42).

$$
\boldsymbol{\sigma}_{i j}^{\prime}=\boldsymbol{\sigma}_{i j}-\sigma_{m} \boldsymbol{\delta}_{i j}
$$

$$
\boldsymbol{\sigma}_{i j}^{\prime}=\left[\begin{array}{ccc}
\frac{2 \sigma_{x x}-\sigma_{y y}-\sigma_{z z}}{3} & \tau_{x y} & \tau_{x z} \\
\tau_{x y} & \frac{2 \sigma_{y y}-\sigma_{x x}-\sigma_{z z}}{3} & \tau_{y z} \\
\tau_{x z} & \tau_{y z} & \frac{2 \sigma_{z z}-\sigma_{x x}-\sigma_{y y}}{3}
\end{array}\right]
$$

São válidos para esse tensor $\boldsymbol{\sigma}_{i j}^{\prime}$ todos os desenvolvimentos anteriores referentes à determinação dos autovalores e autovetores, culminando na equação geral da desviadora de tensão é dada pela equação (43).

$$
-\left(\sigma^{\prime}\right)^{3}+J_{1}\left(\sigma^{\prime}\right)^{2}-J_{2} \sigma^{\prime}+J_{3}=0
$$

onde $J_{1}, J_{2}$ e $J_{3}$ são os invariantes da tensão desviadora, e $J_{1}$ é nulo (Dieter, 1986). 


\subsubsection{Tensão Equivalente de von Mises}

Quando se tem um estado de tensões simples atuando sobre um componente mecânico, uniaxial, a fronteira entre o comportamento elástico e o comportamento plástico do material é o limite de escoamento $\sigma_{y}$. Entretanto, essa fronteira se torna menos clara à medida em que o estado de tensões atuando sobre a estrutura se torna mais complexa. O critério de von Mises tem por objetivo encontrar um valor de tensão equivalente, e esta tensão equivalente deverá ser comparado ao limite de escoamento para avaliar se o comportamento do material sob esse estado de tensões será elástico ou plástico.

A rigor, o critério de von Mises afirma que o escoamento do material ocorre quando o segundo invariante de tensão $J_{2}$ exceder um certo limite $k^{2}$. Sendo assim, a condição crítica é quando os dois termos se equivalem, conforme proposto na equação (44)

$$
J_{2}=k^{2}
$$

O segundo invariante de tensão da componente desviadora é conhecido e, agrupando os quadrados, pode ser expresso conforme a equação (45).

$$
\begin{aligned}
J_{2}= & \frac{1}{6}\left[\left(\sigma_{x x}-\sigma_{y y}\right)^{2}+\left(\sigma_{y y}-\sigma_{z z}\right)^{2}+\left(\sigma_{z z}-\sigma_{x x}\right)^{2}\right. \\
& \left.+6\left(\tau_{x y}^{2}+\tau_{x z}^{2}+\tau_{y z}^{2}\right)\right]
\end{aligned}
$$

A priori, o valor de $k$ é desconhecido, mas pode ser encontrado a partir do ensaio de tração uniaxial. Sendo assim, seja um estado de tensão uniaxial (1D) $\boldsymbol{\sigma}_{i j}^{1 D}$, conforme proposto na equação (46). Podemos calcular $J_{2}^{1 D}$ a partir da equação (44), cujo cálculo está disponível nas equaçõs (47) e (48).

$$
\boldsymbol{\sigma}_{i j}^{1 D}=\left[\begin{array}{ccc}
\sigma_{x x} & 0 & 0 \\
0 & 0 & 0 \\
0 & 0 & 0
\end{array}\right]
$$




$$
\begin{gathered}
J_{2}^{1 D}=\frac{1}{6}\left[2\left(\sigma_{x x}\right)^{2}\right] \\
J_{2}^{1 D}=\frac{1}{3} \sigma_{x x}^{2}
\end{gathered}
$$

Naturalmente, o escoamento ocorre quando $\sigma_{x x}$ atinge o limite de escoamento $\sigma_{y}$. Então, substituindo $\sigma_{x x}$ por $\sigma_{y}$, podemos igualar $J_{2}^{1 D}$ (valor conhecido) a $k^{2}$ e determinar o valor de $k$, conforme disponível na equação (49).

$$
k^{2}=\frac{1}{3} \sigma_{y}^{2} \quad \therefore \quad k=\frac{\sigma_{y}}{\sqrt{3}}
$$

Substituindo $k$ na condição crítica do critério de von Mises apresentado na equação (44), após pouca manipulação matemática é possível encontrar uma tensão equivalente de von Mises $\sigma_{\text {mises }}$, que é tudo que está à direita da igualdade na equação (50).

$$
\begin{aligned}
\sigma_{y}= & \frac{1}{\sqrt{2}}\left[\left(\sigma_{x x}-\sigma_{y y}\right)^{2}+\left(\sigma_{y y}-\sigma_{z z}\right)^{2}+\left(\sigma_{z z}-\sigma_{x x}\right)^{2}\right. \\
& \left.+6\left(\tau_{x y}^{2}+\tau_{x z}^{2}+\tau_{y z}^{2}\right)\right]^{\frac{1}{2}}
\end{aligned}
$$

Ressalta-se que a igualdade da equação (50) representa a condição crítica, que é quando a tensão equivalente de von Mises $\sigma_{\text {mises }}$ atinge valor idêntico ao limite de escoamento. Se a tensão equivalente de von Mises ultrapassar o limite de escoamento $\sigma_{y}$, isto é $\sigma_{y}<\sigma_{\text {mises }}$, então o material escoa e experiencia deformação plástica. Do contrário, se a tensão equivalente de von Mises $\sigma_{\text {mises }}$ se mantiver inferior ao limite de escoamento $\sigma_{y}$, isto é $\sigma_{y}>\sigma_{\text {mises }}$, então o componente estrutural não sofrerá plastificação e permanecerá no regime elástico. 


\subsubsection{Modelos Matemáticos}

A abordagem da teoria de fadiga pela curva de Wöhler proporcionou avanços, mas sua aplicação esbarrava na limitação de ser exclusivamente uniaxial. Condições de carregamento gradativamente mais complexas impunham estados de tensões gradativamente mais complexos, fazendo com que uma teoria mais específica fosse desenvolvida. Dentre os vários modelos de fadiga multiaxial que foram desenvolvidos, são apresentados alguns trabalhos em ordem cronológica.

$>$ Critério de Findley (1959)

$>$ Critério de Matake (1977)

$>$ Critério de McDiarmid (1987)

$>$ Critério de Papadopoulos (1997)

$>$ Critério de Carpinteri \& Spagnoli (2001)

Critério de Liu \& Mahadevan (2005)

Diversos critérios de fadiga multiaxial foram divididos essencialmente em três grupos: critérios baseados na tensão, critérios baseados na deformação e critérios baseados na energia. Dentre esses critérios, a abordagem pelo plano crítico se destaca pela sua eficácia e ampla aplicação. Dos modelos citados acima, exceto pelo modelo de Papadopoulos, todos os critérios utilizam as tensões normal e cisalhante atuantes no plano crítico. Desse modo, faz-se necessário definir o conceito de plano crítico e plano de fratura.

- Plano Crítico é aquele onde o processo de fadiga começa, a partir de um viés metalúrgico, com iniciação do processo em planos cristalográficos.

- Plano de fratura é aquele onde a trinca de fadiga se propaga macroscopicamente.

Por fim, é importante destacar que, uma vez iniciado o processo de fadiga, a propagação de uma trinca de fadiga é guiada pelas tensões macroscopicamente aplicadas, tratando-se assim de um trabalho mecânico e não metalúrgico. 


\subsubsection{Tensões Normais e Cisalhantes Atuando em Plano Genérico com Orientação $\psi$ em Relação ao Eixo Horizontal}

Para um elemento de área na superfície de um corpo de provas é possível determinar um plano com certa orientação $\psi$ em relação ao eixo horizontal $x$. Associado a esse plano haverá uma amplitude de tensão normal $N_{a}$ e uma amplitude de tensão cisalhante $C_{a}$, conforme indicado na Fig. 20.

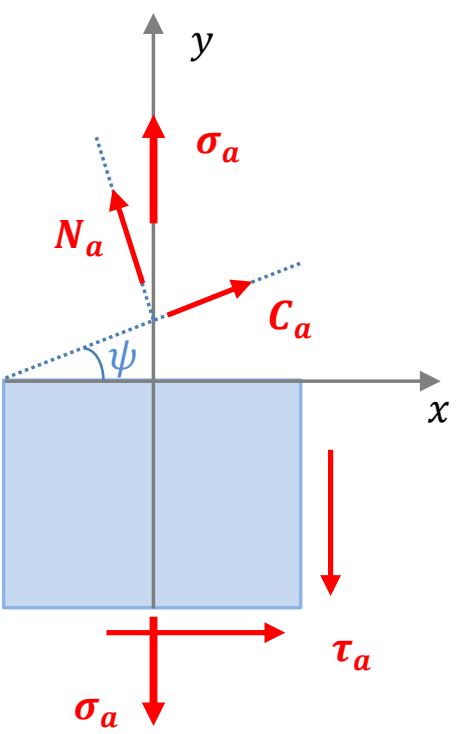

Figura 20 - Tensões associadas a plano genérico de orientação $\psi$ em relação à horizontal (autor)

Verifica-se que $N_{a}$ e $C_{a}$ são funções da amplitude de tensão normal $\sigma_{a}$, da amplitude de tensão cisalhante $\tau_{a}$, do ângulo de defasagem entre o carregamento axial e cisalhante $\beta$ e da própria orientação $\psi$ do plano em si, onde todos esses parâmetros são condições de carregamento. As equações (51) e (52) permitem a determinação de $N_{a}$ e $C_{a}$ (Papadopoulos, 1997).

$$
\begin{gathered}
N_{\max }=N_{a}+N_{m} \\
C_{a}=\sqrt{\frac{f^{2}+g^{2}+p^{2}+q^{2}}{2}+\sqrt{\left(\frac{f^{2}+g^{2}+p^{2}+q^{2}}{2}\right)^{2}-(f q-g p)^{2}}}
\end{gathered}
$$

Faz-se necessário o uso das equações auxiliares (53), (54), (55), (56), (57) e (58), onde $\theta$ é o ângulo de Euller, que no presente estudo pode ser perfeitamente 
definido como o ângulo entre o eixo $z$ e o plano $x y$. Observa-se ainda que $N_{\max }$ é a sobreposição da amplitude de tensão normal $N_{a}$ à tensão média $N_{m}$. No presente estudo, estamos considerando o caso em que a tensão média $N_{m}$ é nula, mas é pertinente destacar que o critério matemático é suficientemente abrangente e pode ser usado em condições de uma tensão média diferente de zero.

$$
\begin{gathered}
f=\operatorname{sen} \theta\left(-\frac{\sigma_{a}}{2} \operatorname{sen} 2 \psi+\tau_{a} \cos 2 \psi \cos \beta\right) \\
g=-\tau_{a} \operatorname{sen} \theta \cos 2 \psi \operatorname{sen} \beta \\
p=-\frac{1}{2} \operatorname{sen} 2 \theta\left(\sigma_{a} \cos ^{2} \psi+\tau_{a} \operatorname{sen} 2 \psi \cos \beta\right) \\
q=\frac{1}{2} \tau_{a} \operatorname{sen} 2 \theta \operatorname{sen} 2 \psi \operatorname{sen} \beta \\
N_{m}=\operatorname{sen}^{2} \theta\left(\sigma_{m} \cos ^{2} \psi+\tau_{m} \operatorname{sen} 2 \psi\right) \\
N_{a}=\operatorname{sen}^{2} \theta|\cos \psi| \sqrt{\sigma_{a}^{2} \cos ^{2} \psi+4 \tau_{a}^{2} \operatorname{sen}^{2} \psi+2 \sigma_{a} \tau_{a} \operatorname{sen}(2 \psi) \cos \beta}
\end{gathered}
$$

\subsubsection{Findley, Matake e McDiarmid}

Devido à similaridade entre os modelos, os três critérios podem ser estudados juntos. A rigor, a tensão normal e a tensão cisalhante presentes nos equacionamentos são aquelas que se referem ao plano crítico de cada modelo. Sendo assim, para poder aplicar os critérios, é necessário primeiro determinar o plano crítico, para em seguida determinar as tensões referentes ao mesmo.

\subsection{Critério de Findley}

Findley propôs um modelo de dano à fadiga baseado em tensão, supondo que a trinca nucleia por fadiga no plano crítico do ponto mais solicitado do componente mecânico. Para Findley, o plano crítico é aquele que maximiza o efeito a ação combinada de amplitude de tensão normal e máxima tensão cisalhante, ou seja, plano crítico é aquele que maximiza o lado esquerdo da inequação (59), que 
descreve um processo de fadiga que culminará na fratura quando o lado esquerdo da equação exceder o lado direto (Findley, 1959).

$$
C_{a}+k N_{\max } \leq f
$$

Onde $k$ e $f$ são propriedades do material dadas pelas equações (60) e (61), sendo ambas funções do limite de resistência à fadiga em flexão e limite de resistência à fadiga em torção.

$$
\begin{gathered}
k=\frac{2-\left(\frac{f_{-1}}{t_{-1}}\right)}{2 \sqrt{\frac{f_{-1}}{t_{-1}}-1}} \\
f=\sqrt{\frac{f_{-1}^{2}}{4\left(\frac{f_{-1}}{t_{-1}}-1\right)}}
\end{gathered}
$$

O plano crítico pode ser encontrado variando o ângulo $\psi$, de modo a encontrar o máximo valor da combinação linear de $C_{a}$ e $k N_{\max }$.

\subsection{Critério de Matake}

Matake tinha uma visão bastante metalúrgica do processo, visto que a iniciação de uma trinca de fadiga ocorre tipicamente na superfície e depende do movimento de discordâncias, sendo esse mais passível de ocorrer nos planos de cisalhamento das estruturas metálicas. Sendo assim, o movimento de discordâncias é mais provável nas direções onde ocorre a maior tensão cisalhante, culminando em sua proposta de que o plano crítico é aquele em que a tensão cisalhante é máxima. De maneira análoga, varia-se o ângulo $\psi$ para que se obtenha o máximo valor de $C_{a}$. Uma vez encontrado o valor de $\psi$, verifica-se se o lado esquerdo da inequação (62) excede o lado direito. Caso isso se confirme, o material falhará (Matake, 1977).

$$
C_{a}+\mu N_{\max } \leq t_{-1}
$$


Onde $\mu$ é propriedade do material, dado pela equação (63).

$$
\mu=2\left(\frac{t_{-1}}{f_{-1}}\right)-1
$$

\subsection{Critério de McDiarmid}

Assim como para Matake, o modelo de McDiarmid tem um viés bastante metalúrgico e também considera que o plano crítico é aquele que maximiza o valor da tensão cisalhante $C_{a}$. Uma vez encontrado o valor de $\psi$, verifica-se se o lado esquerdo da inequação (64) excede o lado direito. Caso isso se confirme, o material falhará (McDiarmid, 1990).

$$
C_{a}+\frac{t_{-1}}{2 \sigma_{u}} N_{\text {max }} \leq t_{-1}
$$

Verifica-se que a constante que multiplica $N_{\max }$ depende do limite de resistência mecânica $\sigma_{u}$ do material. Esse modelo não chega a ser muito diferente do proposto por Matake, uma vez sabido que o limite de resistência à fadiga em flexão $f_{-1}$ é naturalmente uma fração do limite de resistência mecânica $\sigma_{u}$.

\subsubsection{Carpinteri \& Spagnoli e Liu \& Mahadevan}

Assim como os critérios anteriores, tanto o modelo de Carpinteri \& Spagnoli quanto o modelo de Liu \& Mahadevan utilizam em suas equações os valores de $N_{\max }$ e $C_{a}$ associados ao plano crítico. Entretanto, o plano crítico deverá ser calculado a partir do plano de fratura, e sua orientação está associada à determinação de um ângulo $\delta$ definido entre plano de fratura e plano crítico. Conforme indicado na Fig. 21, temos um plano com uma certa orientação $\psi$ em relação à horizontal e uma certa orientação $\varphi$ em relação à vertical. Existe também um outro plano de interesse cuja orientação realiza um ângulo $\delta$ em relação ao 
plano anterior, resultando em um ângulo final $\psi+\delta$ em relação à horizontal. Verifica-se também a aplicação de um carregamento de amplitude $\sigma_{a}$ e $\tau_{a}$. O ângulo de Euller $\theta$ está definido entre o plano $x y$ e o eixo $z$ e, portanto, vale $\pi / 2$.

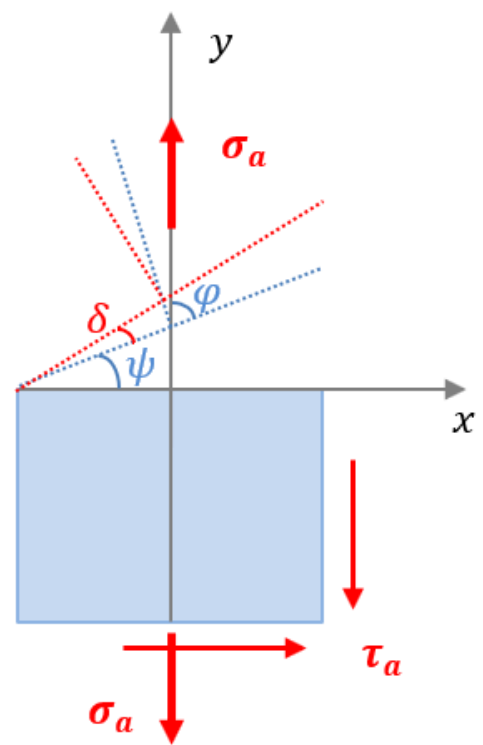

Figura 21 - Elemento de Área para critérios de Carpinteri \& Spagnoli e Liu \& Mahadevan (autor)

Para qualquer plano genérico, é possível encontrar associado ao mesmo uma amplitude de tensão normal $N_{a}$ e uma amplitude de tensão cisalhante $C_{a}$. Naturalmente, $N_{a}$ e $C_{a}$ podem ou não estar sobrepostas a uma tensão normal média $N_{m}$ e a uma tensão cisalhante média $C_{m}$, entretanto no presente trabalho estudamos apenas a condição de tensão média nula.

Naturalmente, o equacionamento de Carpinteri \& Spagnoli e de Liu \& Mahadevan consideram as tensões $N_{\max }$ e $C_{a}$ associadas ao plano crítico, conforme apresentado na equação, cuja determinação deste depende do plano de fratura. Os critérios anteriores dependiam de um ângulo $\psi$ que maximiza o valor de $C_{a}+k N_{\max }$ (Findley) ou tão somente o valor de $C_{a}$ (Matake e McDiarmid), sendo essas grandezas funções do ângulo $\psi$. Nos critérios de Carpinteri \& Spagoli e Liu $\&$ Mahadevan, todas as grandezas de interesse estão expressas em termos de $\varphi$ (que é o complemento de $\psi$ ), conforme mostram as equações do subtópico a seguir. Sendo assim, devemos variar $\varphi$ de modo a maximizar o valor $N_{\max }$ a fim de obter o ângulo $\varphi_{f}$ associado à orientação do plano de fratura. Uma vez determinado $\varphi_{f}$, é possível encontrar a orientação $\varphi_{c}$ associado à orientação do plano crítico, obter analiticamente os valores de $N_{\max }$ e $C_{a}$ e aplicar na equação dos critérios. 


\subsection{Critério de Carpinteri \& Spagnoli}

O equacionamento de Carpinteri \& Spagnoli é dado pela equação (65), onde $N_{\text {max }}$ e $C_{a}$ são o valor máximo de tensão normal e amplitude de tensão cisalhante, ambas associadas ao plano crítico (Carpinteri\&Spagnoli, Multiaxial high-cycle fatigue criterion for hard metals, 2001).

$$
\sqrt{N_{\max }^{2}+\left(\frac{f_{-1}}{t_{-1}}\right)^{2} C_{a}^{2}} \leq f_{-1}
$$

A determinação do plano crítico decorre do plano de fratura. Para se determinar o plano de fratura, primeiro devemos conhecer o equacionamento necessário para se determinar as tensões que atuam sobre um plano genérico que possui uma certa inclinação $\varphi$ em relação ao eixo vertical.

As equações (66) e (67) apresentam valores para $N_{m}$ e $N_{a}$, fazendo-se necessário o uso das equações auxiliares (68) e (69) para o cálculo de $N_{a}$.

$$
\begin{gathered}
N_{m}=\operatorname{sen}^{2} \theta\left(\sigma_{m} \operatorname{sen}^{2} \varphi+\tau_{m} \operatorname{sen} 2 \varphi\right) \\
N_{a}=\sqrt{a^{2}+b^{2}} \\
a=\operatorname{sen}^{2} \theta\left(\sigma_{a} \operatorname{sen}^{2} \varphi+\tau_{a} \cos \beta \operatorname{sen} 2 \varphi\right) \\
b=-\operatorname{sen}^{2} \theta\left(\tau_{a} \operatorname{sen} \beta \operatorname{sen} 2 \varphi\right)
\end{gathered}
$$

A equação (70) apresenta o cálculo de $N_{\max }$.

$$
N_{\text {max }}=N_{m}+N_{a}
$$

Sempre é importante relembrar que o ângulo de Euller $\theta$ vale $\pi / 2$ e que $\beta$ é o ângulo de defasagem entre o carregamento axial e cisalhante.

Com posse dessas informações, varia-se o ângulo $\varphi$ para maximizar $N_{\max }$. O valor de $\varphi$ que entregar o máximo valor de $N_{\max }$ será o ângulo de fratura $\varphi_{f}$. Uma vez conhecido $\varphi_{f}$, a equação (71) apresenta o cálculo para o ângulo $\delta$, 
justamente o ângulo definido entre o plano de fratura (que possui orientação $\psi_{f}$ em relação ao eixo horizontal e $\varphi_{f}$ em relação ao eixo vertical) e o plano crítico (que possui orientação $\psi_{c}$ em relação ao eixo horizontal e $\varphi_{c}$ em relação ao eixo vertical).

$$
\delta=45^{\circ} \times\left\{\frac{3}{2}\left[1-\left(\frac{t_{-1}}{f_{-1}}\right)^{2}\right]\right\}
$$

A partir de uma análise trigonométrica realizada no ponto B da Fig. 22, e ciente de que $\psi_{f}+\varphi_{f}=\pi / 2$, é possível obter a trigonometria apresentada na Fig. 23 , onde $\varphi_{c}+\psi_{f}+\delta=\frac{\pi}{2}$. Com isso, fica fácil de perceber a relação apresentada na equação (72).

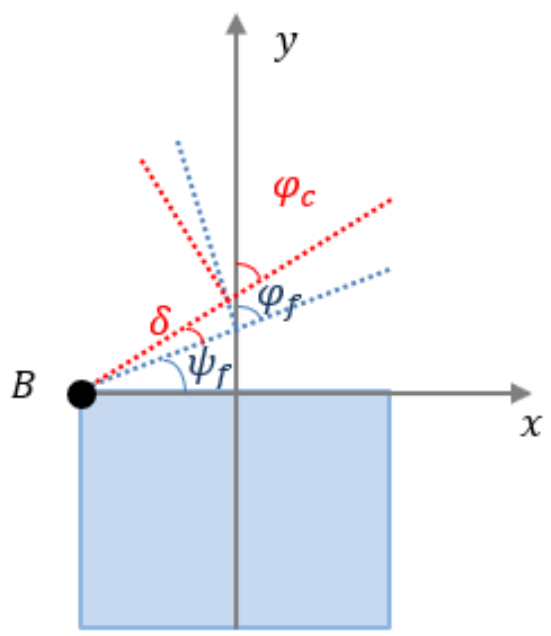

Figura 22 - Origem da análise trigonométrica (autor)

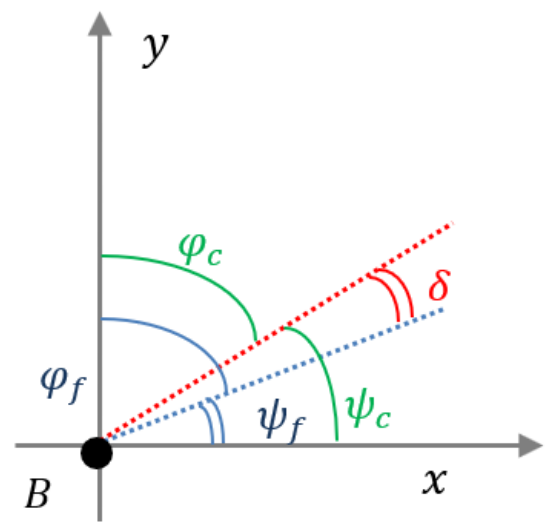

Figura 23 - Trigonometria ilustrando relação entre todos os ângulos (autor)

$$
\varphi_{c}=\varphi_{f}-\delta
$$


A equação (73) apresenta o cálculo para $C_{a}$ fazendo uso das equações auxiliares (74), (75), (76) e (77).

$$
\begin{gathered}
C_{a}=\sqrt{\frac{f^{2}+g^{2}+p^{2}+q^{2}}{2}+\sqrt{\left(\frac{f^{2}+g^{2}+p^{2}+q^{2}}{2}\right)^{2}-(f q-g p)^{2}}} \\
f=\frac{1}{2} \operatorname{sen} 2 \theta\left(\sigma_{a} \operatorname{sen}^{2} \varphi+\tau_{a} \operatorname{sen} 2 \varphi \cos \beta\right) \\
g=-\frac{1}{2} \operatorname{sen} 2 \theta\left(\tau_{a} \operatorname{sen} 2 \varphi \operatorname{sen} \beta\right) \\
p=\operatorname{sen} \theta\left[\left(\frac{\sigma_{a}}{2} \operatorname{sen} 2 \varphi+\tau_{a} \cos 2 \varphi \cos \beta\right)\right] \\
q=-\operatorname{sen} \theta\left(\tau_{a} \cos 2 \varphi \operatorname{sen} \beta\right)
\end{gathered}
$$

Considerando-se o ângulo $\varphi_{c}$, as equações auxiliares podem ser reescritas e $N_{\text {max }}$ pode ser recalculado, não mais para o plano de fratura mas para o plano crítico, por meio das equações (78), (79), (80), (81) considerando o ângulo $\psi_{c}$, culminando em seu cálculo final através da equação (82).

$$
\begin{gathered}
N_{m}=\operatorname{sen}^{2} \theta\left(\sigma_{m} \operatorname{sen}^{2} \varphi_{c}+\tau_{m} \operatorname{sen} 2 \varphi_{c}\right) \\
N_{a}=\sqrt{a^{2}+b^{2}} \\
a=\operatorname{sen}^{2} \theta\left(\sigma_{a} \operatorname{sen}^{2} \varphi_{c}+\tau_{a} \cos \beta \operatorname{sen} 2 \varphi_{c}\right) \\
b=-\operatorname{sen}^{2} \theta\left(\tau_{a} \operatorname{sen} \beta \operatorname{sen} 2 \varphi_{c}\right) \\
N_{\max }=N_{m}+N_{a}
\end{gathered}
$$

Paralelamente, $C_{a}$ pode ser determinado por meio das equações auxiliares (83), (84), (85) e (86), culminando em seu cálculo final através da equação (87), sempre considerando o a orientação do plano crítico por meio de seu ângulo $\varphi_{c}$. 


$$
\begin{gathered}
f=\frac{1}{2} \operatorname{sen} 2 \theta\left(\sigma_{a} \operatorname{sen}^{2} \varphi_{c}+\tau_{a} \operatorname{sen} 2 \varphi_{c} \cos \beta\right) \\
g=-\frac{1}{2} \operatorname{sen} 2 \theta\left(\tau_{a} \operatorname{sen} 2 \varphi_{c} \operatorname{sen} \beta\right) \\
p=\operatorname{sen} \theta\left[\left(\frac{\sigma_{a}}{2} \operatorname{sen} 2 \varphi_{c}+\tau_{a} \cos 2 \varphi_{c} \cos \beta\right)\right] \\
q=-\operatorname{sen} \theta\left(\tau_{a} \cos 2 \varphi_{c} \operatorname{sen} \beta\right) \\
C_{a}=\sqrt{\frac{f^{2}+g^{2}+p^{2}+q^{2}}{2}+\sqrt{\left(\frac{f^{2}+g^{2}+p^{2}+q^{2}}{2}\right)^{2}-(f q-g p)^{2}}}
\end{gathered}
$$

Desse modo, agora $N_{\max }$ e $C_{a}$ associados ao plano crítico são conhecidos, o que permite aplicar a equação (65) e utilizar o critério de Carpinteri \& Spagnoli.

\subsection{Critério de Liu \& Mahadevan}

O critério de Liu \& Mahadevan propõe uma correção no modelo de Carpinteri \& Spagnoli, e por esse motivo os procedimentos e os modelos em si são similares. O modelo de Liu \& Mahadevan é baseado em uma combinação não linear das tensões normal, cisalhante e hidrostática associadas ao plano crítico.

Naturalmente, o processo para encontrar o plano crítico também depende do plano de fratura, cuja orientação é tal que o plano faz um ângulo $\varphi_{f}$ com a vertical. Analogamente, $N_{\max }$ é a soma da tensão normal média $N_{m}$ com a amplitude de tensão normal $N_{a}$, e pode ser obtido a partir das equações (66), (67), (68), (69) e (70). Por meio de análise numérica, varia-se $\varphi$ para encontrar o máximo valor da tensão normal $N_{\max }$, obtendo assim a orientação do plano de fratura $\varphi_{f}$.

Utiliza-se, portanto, as equações (71) e (72) para determinar a orientação do plano crítico $\delta$ em relação ao plano de fratura, determinando consequentemente os ângulos de interesse para o plano crítico $\varphi_{c}$ e seu complemento $\psi_{c}$. A equação (82) fornece um valor para $N_{\max }$ associado ao plano crítico, por meio das equações 
auxiliares (78), (79), (80) e (81). Já a equação (87) fornece o valor da amplitude de tensão cisalhante $C_{a}$ por meio das equações auxiliares (83), (84), (85) e (86). Desse modo, agora conhecidos $N_{a}, N_{m}$ e $C_{a}$ associados ao plano crítico são conhecidos, o que permite aplicar o critério de Liu \& Mahadevan, apresentado sob a equação (82).

$$
\sqrt{\left[\frac{N_{a}\left(1+\eta \frac{N_{m}}{f_{-1}}\right)}{f_{-1}}\right]^{2}+\left(\frac{C_{a}}{t_{-1}}\right)^{2}+k\left(\frac{\sigma_{H, a}}{f_{-1}}\right)} \leq \lambda
$$

Na equação (88), $\left(1+\eta \frac{N_{m}}{f_{-1}}\right)$ é um fator de correção para se considerar o efeito da tensão normal média associada ao plano crítico, $\sigma_{H, a}$ é a amplitude da tensão hidrostática e os parâmetros $\eta, k$ e $\lambda$ são propriedades do material dependentes da relação $t_{-1} / f_{-1}$. A Tabela 1 a seguir apresenta equações para o cálculo de cada uma das propriedades (Liu\&Mahadevan, 2005).

Tabela 1 - Propriedades do material em função dos limites de resistência à fadiga em flexão e torção (Liu\&Mahadevan, 2005)

\begin{tabular}{|c|c|c|}
\hline $\begin{array}{c}\text { Propriedades do } \\
\text { material }\end{array}$ & $s=\frac{t_{-1}}{f_{-1}} \leq 1$ & $s=\frac{t_{-1}}{f_{-1}}>1$ \\
\hline$\eta$ & $\eta=\frac{3}{4}+\frac{1}{4}\left(\frac{\left.\sqrt{3}-\frac{f_{-1}}{t_{-1}}\right)}{\sqrt{3}-1}\right)$ & 1 \\
\hline$\delta$ & $\cos (2 \delta)=\frac{-2+\sqrt{4-4\left(\frac{1}{s^{2}-3}\right)\left(5-\frac{1}{s^{2}}-4 s^{2}\right)}}{2\left(5-\frac{1}{s^{2}}-4 s^{2}\right)}$ & 0 \\
\hline$k$ & 0 & $k=9\left(s^{2}-1\right)$ \\
\hline$\lambda$ & $\lambda=\sqrt{\cos ^{2}(2 \delta) s^{2}+\sin ^{2}(2 \delta)}$ & $s$ \\
\hline
\end{tabular}

Vale destacar que para aços tipicamente trabalharemos com a segunda coluna onde a relação dos limites de resistência à fadiga em torção e flexão está compreendida entre $\frac{1}{\sqrt{3}} \leq \frac{t_{-1}}{f_{-1}} \leq 1$, o que impõe que $k$ será nulo, tornando a equação do modelo de Liu \& Mahadevan insensível à amplitude da tensão hidrostática. 


\subsubsection{Papadopoulos}

O modelo de Papadopoulos analisa a fadiga de metais em uma escala intermediária entre a microscópica e a macroscópica chamada de escala mesoscópica, que é do tamanho dos grãos e agregados metálicos. Segundo o autor, ainda que o carregamento externo preserve no componente um comportamento macroscópico elástico, grãos metálicos podem sofrer deslizamentos plásticos que podem culminar na iniciação de trincas por fadiga.

A deformação plástica acumulada na direção do deslizamento induzida por carregamentos cíclicos em um volume elementar $V$ é aproximadamente igual à amplitude do módulo do vetor da tensão cisalhante resolvida quando o número de ciclos tende a infinito. Isto pode ser colocado matematicamente conforme o apresentado na equação (89).

$$
T_{a} \approx \Sigma^{\infty} \Delta y^{p}
$$

Na equação (89), $T_{a}$ se refere à amplitude do módulo do vetor da tensão cisalhante resolvida e $\Sigma^{\infty} \Delta y^{p}$ é o somatório das deformações plásticas ao longo da direção do deslizamento.

Sendo assim, o importante é buscar modelar um critério que observe que a deformação plástica acumulada não pode exaurir a ductilidade do material, e que consequentemente venha a prevenir a formação de uma trinca de fadiga. Desse modo, o critério de fadiga deverá ser baseado em um valor médio da deformação plástica acumulada em todos os cristais dentro do volume elementar $V$. Em outras palavras, deve-se buscar um valor médio para $T_{a}$, que pode ser obtido através de seu valor médio quadrático apresentado na equação (90), e suas equações auxiliares (91) e (92). Os valores de $f, g, p$ e $q$ são fornecidos pelas equações (53), (54), (55) e (56).

$$
\sqrt{T_{a}^{2}}=\sqrt{5} \sqrt{\frac{1}{8 \pi^{2}} \int_{\varphi=0}^{2 \pi} \int_{\theta=0}^{\pi} \int_{\chi=0}^{2 \pi}\left[T_{a}(\varphi, \theta, \chi)\right]^{2} d \chi \sin \theta d \theta d \varphi}
$$


Os ângulos $\varphi$ e $\theta$ são referentes ao sistema de coordenadas esféricas, $\chi$ é o ângulo associado às direções de deslizamento. As variáveis $f, g, p$ e $q$ são funções auxiliares referentes aos parâmetros de carregamento bem como e ângulos associados ao sistema de referência e de sua rotação.

$$
\begin{aligned}
& T_{a}=\sqrt{a^{2} \cos ^{2} \chi+b^{2} \sin ^{2} \chi} \\
& a, b=\sqrt{\frac{f^{2}+g^{2}+p^{2}+q^{2}}{2} \pm \sqrt{\left(\frac{f^{2}+g^{2}+p^{2}+q^{2}}{2}\right)^{2}-(f q-g p)^{2}}}
\end{aligned}
$$

Considerando a fratura de alguns cristais isolados dentro do volume elementar $V$, trincas embrionárias afetam a resistência do material à fadiga. Essa influência está relacionada à tensão hidrostática máxima correspondente ao ciclo de carregamento. Deste modo, o critério de fadiga de Papadopoulos inclui essa influência por meio de uma constante de proporcionalidade $\alpha$, avaliada por uma relação que envolve os limites de resistência à fadiga em flexão e torção. O modelo de Papadopoulos é apresentado na equação (93).

$$
\sqrt{T_{a}^{2}}+\alpha \sigma_{H, \max } \leq t_{-1}
$$

Substituindo os valores de $a, b$ obtidos através da equação (92), substituindo na equação (93) para calcular $T_{a}$ e integrando a função da equação (90) para se obter o valor médio quadrático da amplitude do módulo do vetor da tensão cisalhante resolvida, obtém-se a equação (94) e seu desdobramento apresentado na equação (95).

$$
\begin{gathered}
\sqrt{T_{a}^{2}}=\sqrt{5} \sqrt{\frac{1}{8 \pi^{2}} \int_{\varphi=0}^{2 \pi} \int_{\theta=0}^{\pi} \pi\left(a^{2}+b^{2}\right) \sin \theta d \theta d \varphi} \\
\sqrt{T_{\varphi=0}^{2}}=\sqrt{5} \sqrt{\frac{1}{8 \pi} \int_{\varphi=8 \pi}^{2 \pi} \int_{\theta=0}^{\pi}\left(f^{2}+g^{2}+p+q^{2}\right) \sin \theta d \theta d \varphi}
\end{gathered}
$$


Ainda que as etapas dos cálculos intermediários sejam complicadas, a conclusão é relativamente simples e está apresentada na equação (96), onde $\sigma_{a}$ e $\tau_{a}$ são a amplitude de tensão normal e a amplitude de tensão cisalhante aplicadas macroscopicamente no componente mecânico.

$$
\sqrt{T_{a}^{2}}=\sqrt{\frac{\sigma_{a}^{2}}{3}+\tau_{a}^{2}}
$$

Com isso, é possível substituir a tensão cisalhante resolvida obtido na equação (96) no equacionamento do modelo de Papadopoulos, apresentado na equação (93), para se obter a equação (97).

$$
\sqrt{\left(\frac{\sigma_{a}^{2}}{3}+\tau_{a}^{2}\right)}+\alpha \sigma_{H, \max } \leq t_{-1}
$$

Sabe-se que a máxima tensão hidrostática $\sigma_{H, \max }$ pode ser calculada pela equação (98), e a constante de proporcionalidade $\alpha$ é dada pela equação (99).

$$
\begin{gathered}
\sigma_{H, \max }=\frac{\sigma_{a}+\sigma_{m}}{3} \\
\alpha=\frac{t_{-1}-\left(\frac{f_{-1}}{\sqrt{3}}\right)}{\frac{f_{-1}}{3}}
\end{gathered}
$$

Com isso, obtém-se o resultado final do equacionamento do modelo de Papadopoulos, apresentado na equação (100).

$$
\sqrt{\left(\frac{\sigma_{a}^{2}}{3}+\tau_{a}^{2}\right)}+\alpha \frac{\sigma_{a}+\sigma_{m}}{3} \leq t_{-1}
$$

É importante mencionar que esse modelo não depende de determinação de plano crítico, tampouco da tensão cisalhante média $\tau_{m}$ e do ângulo de defasagem $\beta$ entre os carregamentos de flexão e torção. A constante $\alpha$ pode ser determinada 
testando a condição uniaxial de flexão pura totalmente reversível (ou seja, tensão média nula), onde a criticalidade é atingida quando $\sigma_{a}$ assume o valor de $f_{-1}$. Com $\tau_{a}$ nulo, substitui-se $f_{-1}$ no lugar de $\sigma_{a}$ na equação (100), obtendo-se a equação (101) e seus desdobramentos nas equações (102), (103), (104) e (105) (Papadopoulos, 1997).

$$
\begin{gathered}
\frac{f_{-1}}{\sqrt{3}}+\alpha \frac{f_{-1}}{3}=t_{-1} \\
\frac{f_{-1}}{3}(\sqrt{3}+\alpha)=t_{-1} \\
(\sqrt{3}+\alpha)=\frac{t_{-1}}{(1 / 3) f_{-1}} \\
\alpha=\frac{t_{-1}}{(1 / 3) f_{-1}}-\sqrt{3} \\
\alpha=\frac{t_{-1}-\left(f_{-1} / \sqrt{3}\right)}{f_{-1} / 3}
\end{gathered}
$$




\section{Materiais e Metodologia de Pesquisa e de Ensaios}

Um eixo virabrequim é um componente estrutural que converte força recebida através das bielas conectadas aos seus pistões em torque transmitido aos demais componentes acoplados nas extremidades do próprio eixo. Especificamente no caso de usinas termoelétricas, a energia química liberada da reação exotérmica de combustão é convertida, no fim de todo o processo, em energia elétrica. Esse processo de combustão ocorre dentro dos pistões que estão ligados às bielas, proporcionando um torque nos mancais, culminando na rotação de um eixo como um todo. As Fig. 24 e 25 apresentam esquematicamente um trecho de um eixo virabrequim indicando a defasagem de posição angular entre os mancais, enquanto a Fig. 26 apresenta esquematicamente um mancal com suas bielas.

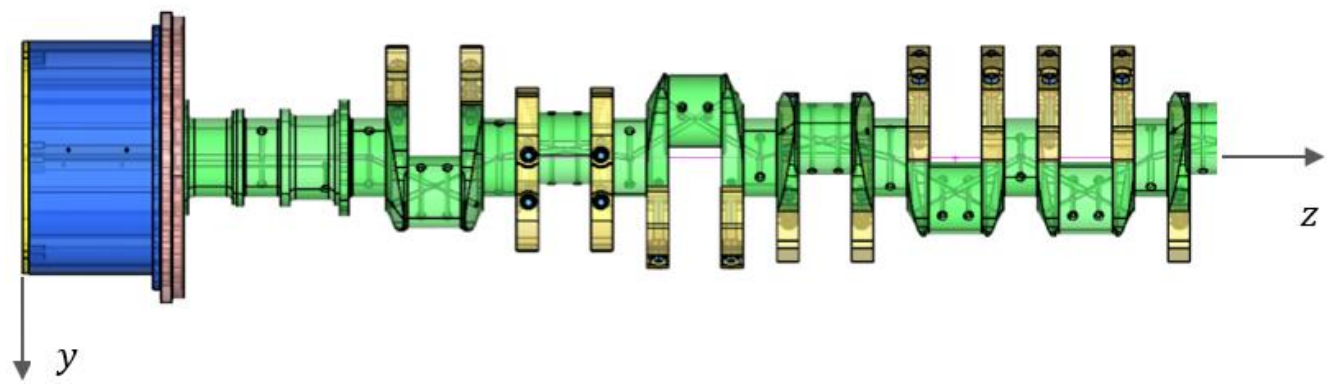

Figura 24 - Ilustração de eixo virabrequim (Fonte: Schwaben Engineering)

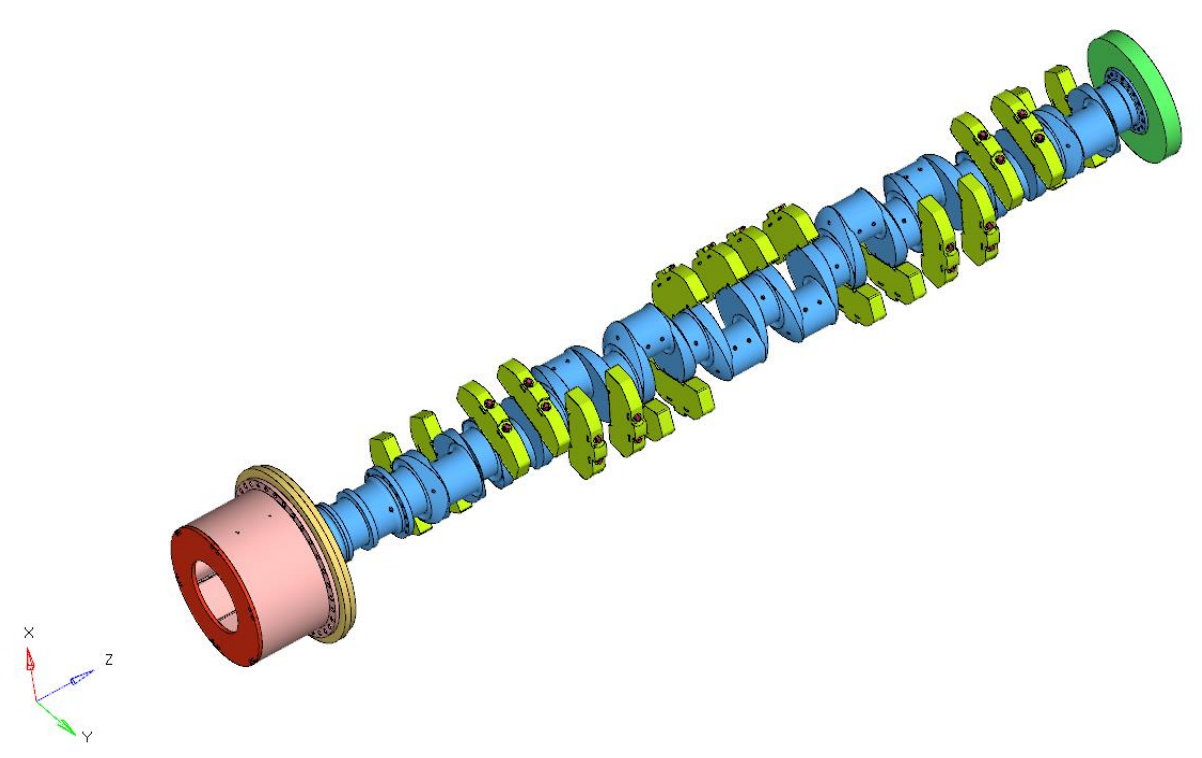

Figura 25 - Geometria complexa com defasagem angular entre os mancais do eixo (Fonte: Schwaben Engineering) 


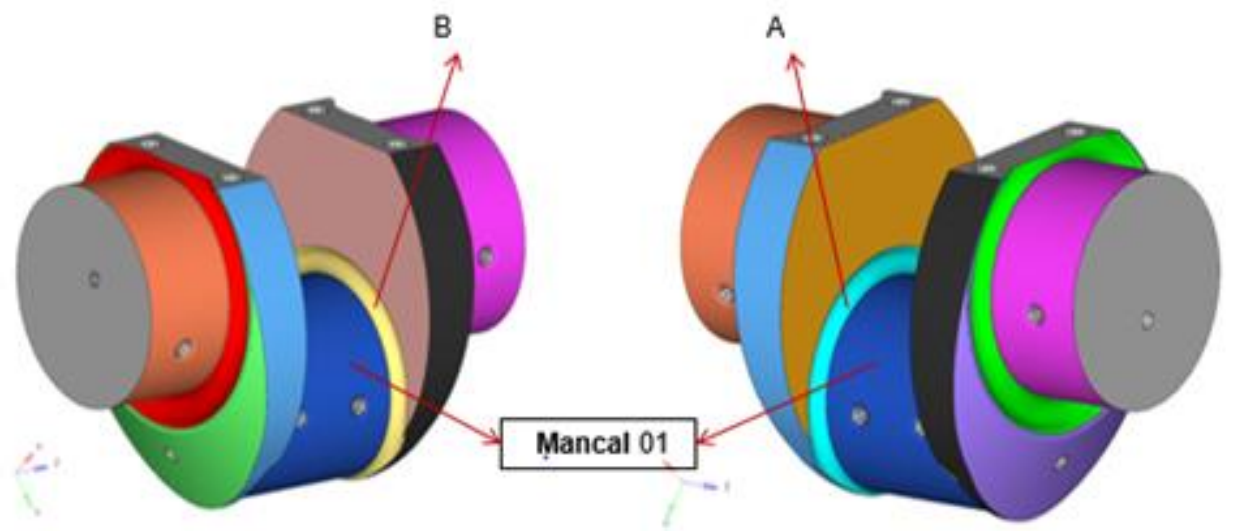

Figura 26 - Representação do mancal 01 e de suas bielas A e B (Fonte: Schwaben Engineering)

A defasagem da posição angular entre os mancais garante uma cronologia sequencial de combustão bem definida, o que impõe torques consecutivos ao eixo, garantindo sua movimentação. A sequência de disparo referente ao eixo estudado com dez mancais e duas bielas e dois pistões por mancal é apresentada de acordo com o esquema disponível na Fig. 27.

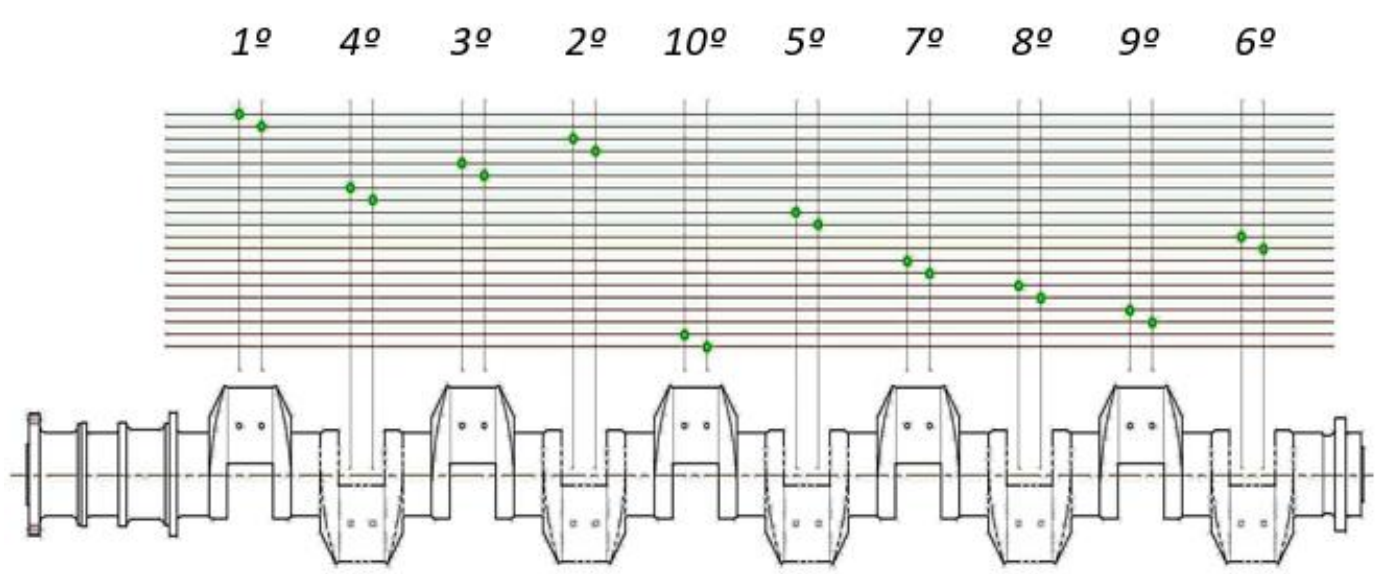

Figura 27 - Sequencia de disparo dos pistões do eixo virabrequim (Fonte: Schwaben Engineering)

Os consecutivos torques impõem também tensões e deformações de natureza macroscopicamente elásticas em todo o eixo, e os esforços foram calculados por terceiros através de uma análise numérica por elementos finitos, que avalia as tensões em cada uma das vinte bielas distribuídas por seus dez mancais. A análise por elementos finitos determinou as três componentes de tensões normais, as três componentes de tensões cisalhantes, o valor das três tensões principais e a tensão de von Mises para cada posição angular do eixo virabrequim. É importante 
pontuar que, para que o eixo retorne à posição inicial com os seus pistões também na posição inicial, o ciclo total tem $720^{\circ}$ (avaliado de $-109^{\circ}$ a 610 graus), e a análise por elementos finitos considerou um passo de $1^{\circ}$. A Fig. 28 apresenta um trecho do resultado da análise para a biela 01 do mancal A e a Fig. 29 apresenta a variação das tensões principais S1, S2 e S3 ao longo de todo o ciclo de carregamento de $720^{\circ}$.

\begin{tabular}{|c|c|c|c|c|c|c|c|c|c|c|c|c|}
\hline 4 & A & B & C & D & $\mathrm{E}$ & $\mathrm{F}$ & G & H & 1 & J & K & L \\
\hline 1 & & \multicolumn{11}{|c|}{ A01 } \\
\hline 2 & Ângulo & node & VonMises & $\sigma x x$ & oyy & $\sigma 22$ & $\tau x y$ & туz & $\tau x z$ & S1 & S2 & S3 \\
\hline 3 & -109 & 16617668 & 104,598 & $-5,892$ & 43,939 & 31,993 & 19,29 & 40,224 & 31,305 & 91,429 & 2,364 & $-23,753$ \\
\hline 4 & -108 & 16617668 & 101,288 & $-5,724$ & 42,54 & 31,01 & 18,67 & 38,947 & 30,316 & 88,534 & 2,3 & $-23,009$ \\
\hline 5 & -107 & 16617668 & 98,092 & $-5,561$ & 41,189 & 30,059 & 18,071 & 37,714 & 29,361 & 85,738 & 2,238 & $-22,29$ \\
\hline 6 & -106 & 16617668 & 95,027 & $-5,405$ & 39,893 & 29,146 & 17,497 & 36,532 & 28,445 & 83,057 & 2,178 & $-21,601$ \\
\hline 7 & -105 & 16617668 & 92,105 & $-5,256$ & 38,658 & 28,275 & 16,951 & 35,404 & 27,572 & 80,501 & 2,121 & $-20,945$ \\
\hline 8 & -104 & 16617668 & 89,35 & $-5,115$ & 37,494 & 27,454 & 16,435 & 34,341 & 26,749 & 78,091 & 2,067 & $-20,325$ \\
\hline 9 & -103 & 16617668 & 86,783 & $-4,983$ & 36,41 & 26,688 & 15,956 & 33,351 & 25,982 & 75,846 & 2,017 & $-19,748$ \\
\hline 10 & -102 & 16617668 & 84,4 & $-4,859$ & 35,403 & 25,977 & 15,511 & 32,431 & 25,27 & 73,762 & 1,97 & $-19,211$ \\
\hline 11 & -101 & 16617668 & 82,203 & $-4,745$ & 34,476 & 25,321 & 15,101 & 31,584 & 24,614 & 71,841 & 1,927 & $-18,716$ \\
\hline 12 & -100 & 16617668 & 80,197 & $-4,64$ & 33,629 & 24,721 & 14,728 & 30,81 & 24,015 & 70,087 & 1,887 & $-18,264$ \\
\hline 13 & -99 & 16617668 & 78,391 & $-4,544$ & 32,868 & 24,18 & 14,392 & 30,113 & 23,476 & 68,509 & 1,851 & $-17,856$ \\
\hline
\end{tabular}

Figura 28 - Segmento da análise por elementos finitos (Fonte: Schwaben Engineering)

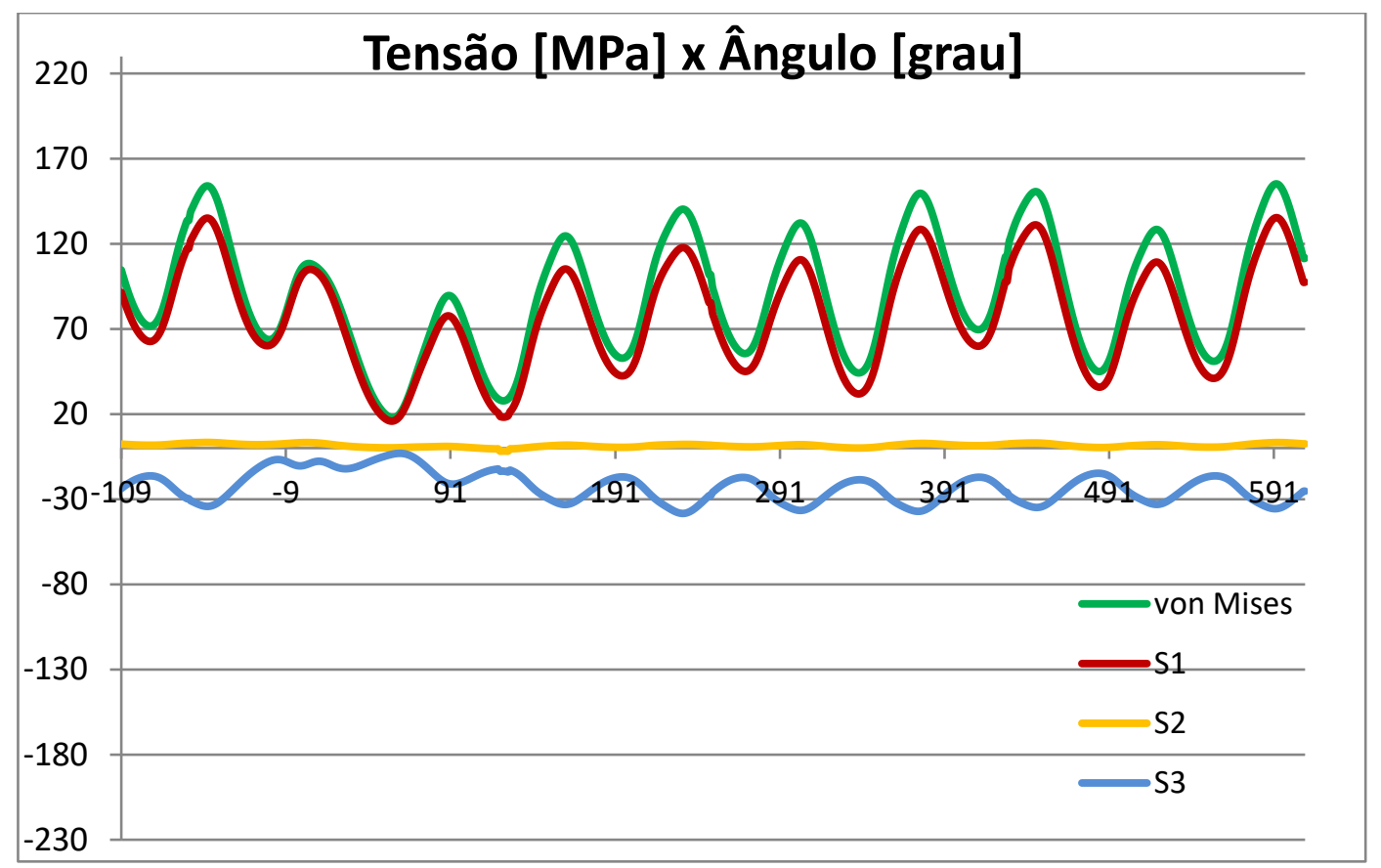

Figura 29 - Variação das tensões principais e tensão de von Mises para todo o ciclo de carregamento (Fonte: Schwaben Engineering) 
Os eixos apresentaram fratura por fadiga conforme apresentado nas Figs. 30, 31, 32 e 33, motivando o presente estudo.

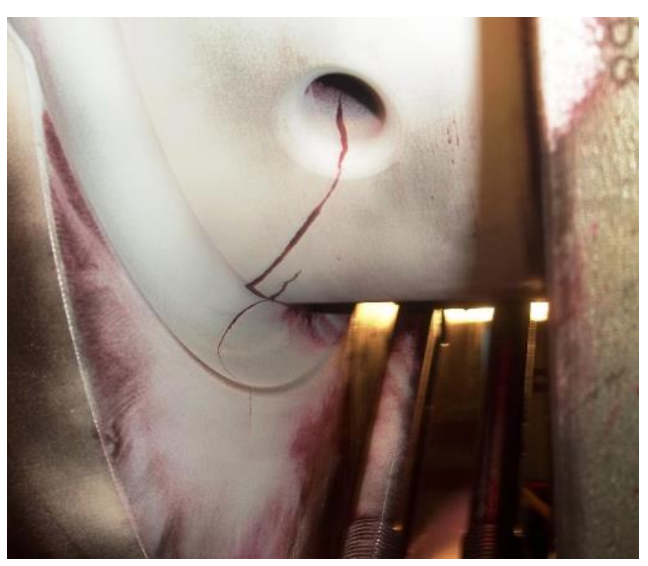

Figura 30 - Fotografia de fratura 01 (Fonte: Linhares Engenharia)

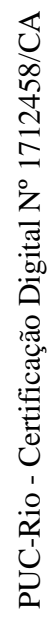

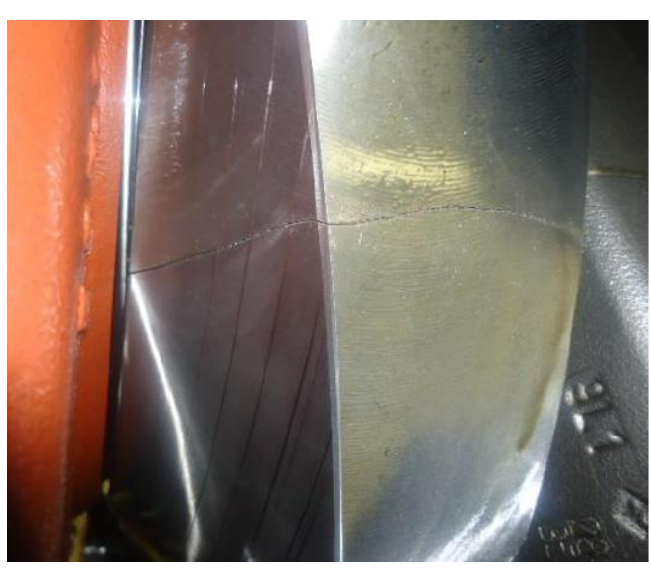

Figura 31 - Fotografia de fratura 02 (Fonte: Linhares Engenharia)

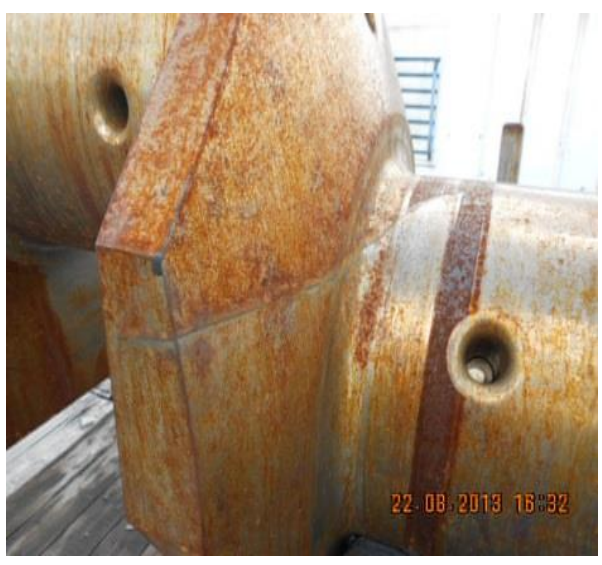

Figura 33 - Fotografia de fratura 04 (Fonte: Linhares Engenharia) 


\subsection{Composição Química do Material}

Os eixos em questão são forjados, e podem ser fabricados a partir dos aços 42CrMo4 e 34CrNiMo6, cujas composições são apresentadas nas Tabelas 2 e 3.

Tabela 2 - Composição química do 42CrMo4 (Peixoto, 2018)

\begin{tabular}{ccccccccc}
\hline \multicolumn{7}{c}{ Aço DIN 42CrMo4 } \\
\hline $\mathrm{Fe}(\%)$ & $\mathrm{C}(\%)$ & $\mathrm{Mn}(\%)$ & $\mathrm{Si}(\%)$ & $\mathrm{Cu}(\%)$ & $\mathrm{Cr}(\%)$ & $\mathrm{V}(\%)$ & $\mathrm{Mo}(\%)$ & $\mathrm{Ni}(\%)$ \\
\hline \hline 96,9 & 0,38 & 0,85 & 0,27 & 0,18 & 0,97 & 0,01 & 0,2 & --
\end{tabular}

Tabela 3 - Composição química do 34CrNiMo6 (Peixoto, 2018)

\begin{tabular}{ccccccccc}
\hline \multicolumn{7}{c}{ Aço DIN 34CrNiMo6 } \\
\hline $\mathrm{Fe}(\%)$ & $\mathrm{C}(\%)$ & $\mathrm{Mn}(\%)$ & $\mathrm{Si}(\%)$ & $\mathrm{Cu}(\%)$ & $\mathrm{Cr}(\%)$ & $\mathrm{V}(\%)$ & $\mathrm{Mo}(\%)$ & $\mathrm{Ni}(\%)$ \\
\hline \hline 96,4 & 0,38 & 0,77 & 0,09 & 0,12 & 1,07 & 0,13 & 0,29 & 0,72
\end{tabular}

Estando o aço DIN 42CrMo4 disponível no momento do estudo, o mesmo concentrou esforços no aço em questão. Em uma primeira abordagem, é interessante conhecer as impurezas presentes na liga pois a presença de materiais indesejados influencia na posição do $\Delta K_{t h}$ na curva $d a / d N$ deslocando o mesmo para a esquerda, favorecendo uma mais precoce propagação de trinca (Peixoto, 2018). Amostras do aço DIN 42CrMo4 foram utilizadas para realizar uma microscopia eletrônica de varredura (MEV) a fim de verificar a presença de contaminantes no material. O mosaico formado por imagens do DIN 42CrMo4 apresentado na Fig. 34 indicou a quantidade de 95 partículas $/ \mathrm{mm}^{2}$, resultando em uma média de 5,01 partículas/ $\mu \mathrm{m}^{2}$ (Peixoto, 2018). 

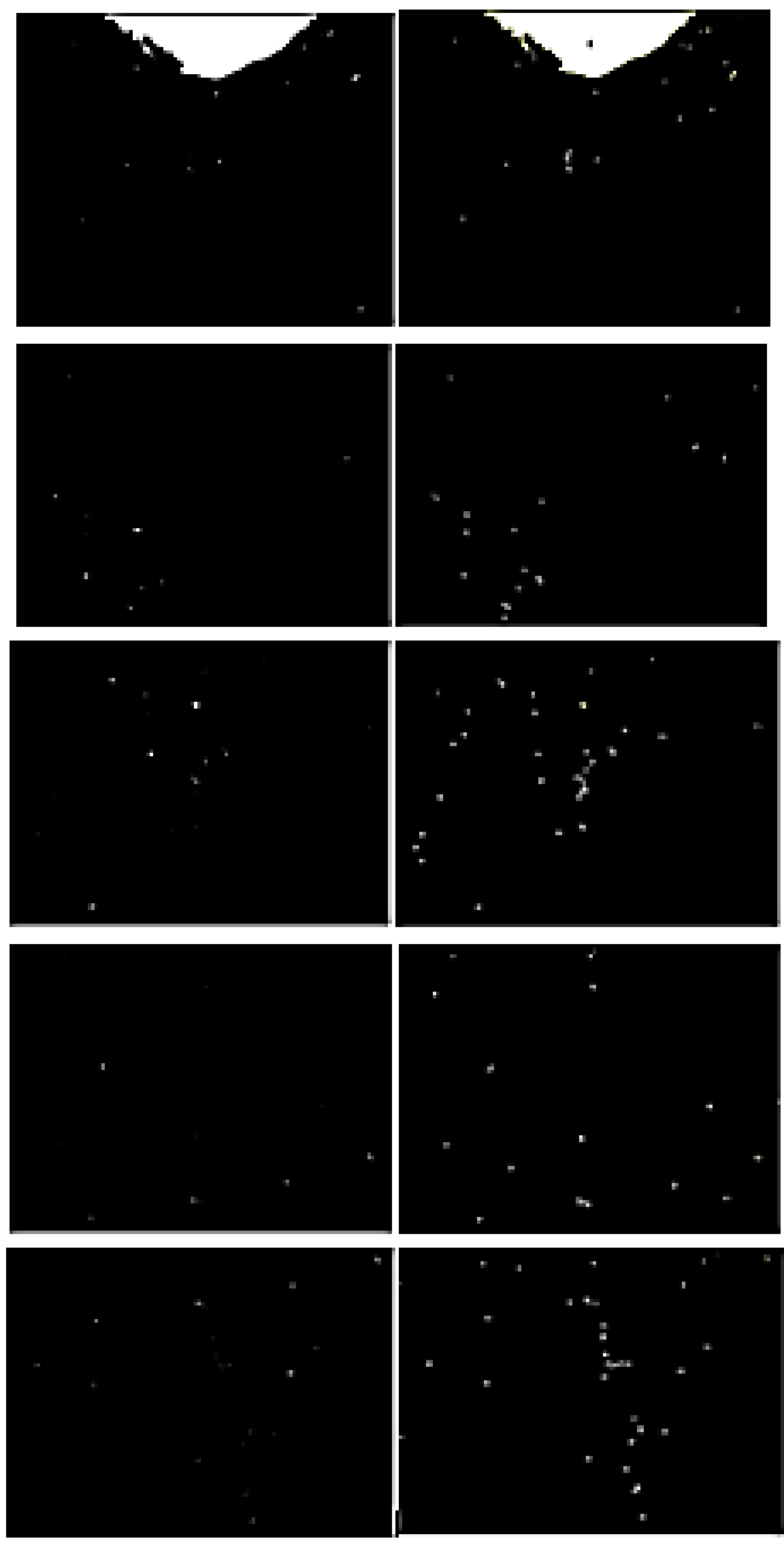

Figura 34 - Mosaico de Imagens do aço DIN 42CrMo4 (Peixoto, 2018) 


\subsection{Características Mecânicas do DIN 42CrMo4}

Ensaios de tração permitem a determinação de características mecânicas do material. A Fig. 35 apresenta um ensaio monotônico de força-deslocamento realizado no Laboratório de Ensaios Mecânicos do Departamento de Engenharia Civil da PUC-Rio.

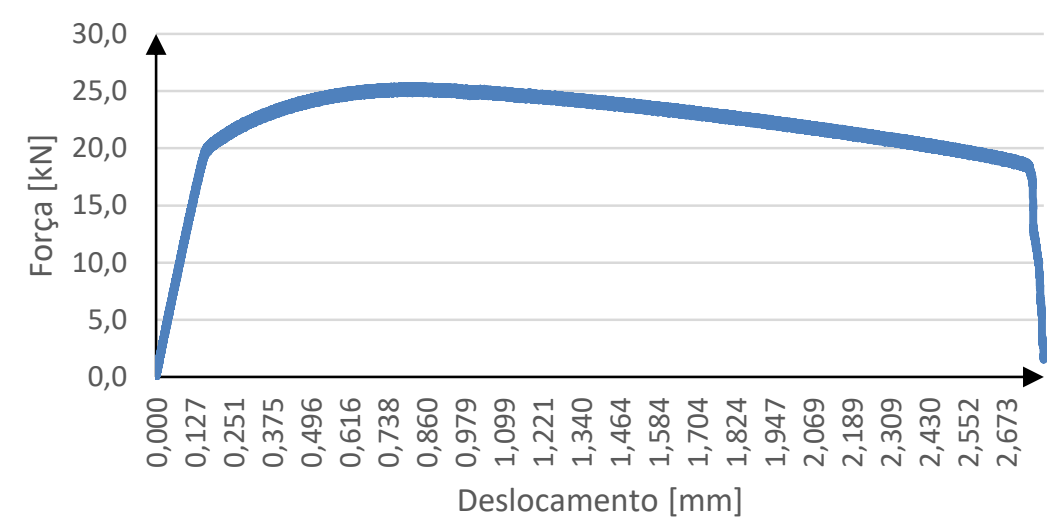

Figura 35 - Curva de força $[\mathrm{kN}]$ vs. deslocamento $[\mathrm{mm}]$ (autor)

O módulo de elasticidade $E$ é propriedade do material e tem seu valor conhecido, entre 206 GPa e 212 GPa. Aceita-se 210 GPa como um valor médio razoável para o módulo de elasticidade $E$. Analogamente, o limite de escoamento $\sigma_{y}$ e limite de resistência mecânica $\sigma_{u}$ dependem do tratamento térmico ao qual o aço é submetido, mas para esse material específico esses valores foram ensaiados e calculados em um serviço previamente terceirizado. Neste trabalho, os valores admitidos serão $715 \mathrm{MPa}$ para o limite de escoamento $\sigma_{y}$ e $906 \mathrm{MPa}$ para o limite de resistência mecânica $\sigma_{u}$.

Por fim, o limite de resistência à fadiga em tração $f_{-1}$ e limite de resistência à fadiga em torção $t_{-1}$ foram aferidos a partir da extrapolação de curvas de Wöhler determinadas experimentalmente. $\mathrm{O}$ detalhamento dos resultados das curvas de Wöhler será discutido mais à frente nesse estudo, entretanto já é possível adiantar que foi considerado como limite de resistência à fadiga valores de tensão associados a um número de ciclos $N_{f}$ equivalente a $2 \times 10^{6}$ ciclos, onde obtivemos derivadas $d \sigma / d N_{f}$ com módulos da ordem de $10^{-4}$ para torção e $10^{-5}$ para tração. 
A Tabela 4 apresenta valores referentes às propriedades mecânicas do DIN 42 CrMo4. Destaca-se que $f_{-1}$ e $t_{-1}$ foram determinados experimentalmente.

Tabela 4 - Tabela com propriedades mecânicas do DIN 42CrMo4 (Giovani)

\begin{tabular}{|c|c|}
\hline Propriedade Mecânica & Valor Calculado \\
\hline$\sigma_{y}$ & $715 \mathrm{MPa}$ \\
\hline$\sigma_{u}$ & $906 \mathrm{MPa}$ \\
\hline$E$ & $210 \mathrm{GPa}$ \\
\hline$f_{-1}$ & $365 \mathrm{MPa}$ \\
\hline$t_{-1}$ & $227 \mathrm{MPa}$ \\
\hline
\end{tabular}

\subsection{Características da Máquina Utilizada para Ensaio}

Duas máquinas foram utilizadas para realizar os experimentos. A primeira e mais utilizada é uma Instron servo-hidráulica modelo 8874, capaz de realizar ensaios de fadiga em tração-compressão e torção-torção, com ou sem tensão média. A máquina tem capacidade para $25 \mathrm{kN}$ de força axial e 100 N.m para torque, sendo capaz de conduzir ensaios com frequências variadas, desde $1 \mathrm{~Hz}$ a $3 \mathrm{~Hz}$, a depender do carregamento aplicado. Fotografias da máquina estão disponíveis nas Figs. 36 e 37.

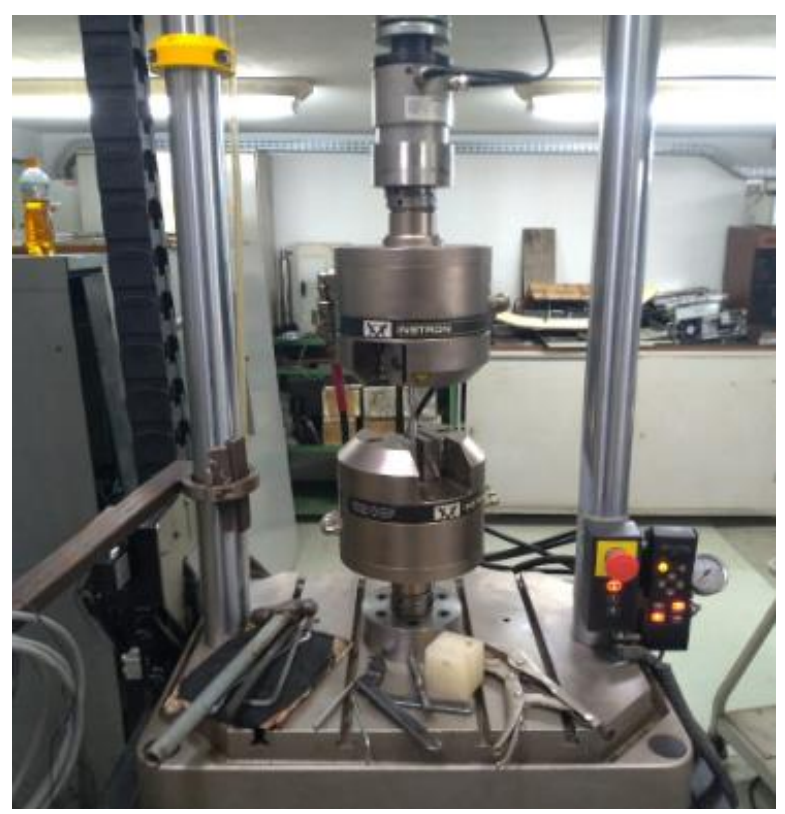

Figura 36 - Fotografia da Máquina Instron servo-hidráulica modelo 8874 (autor) 


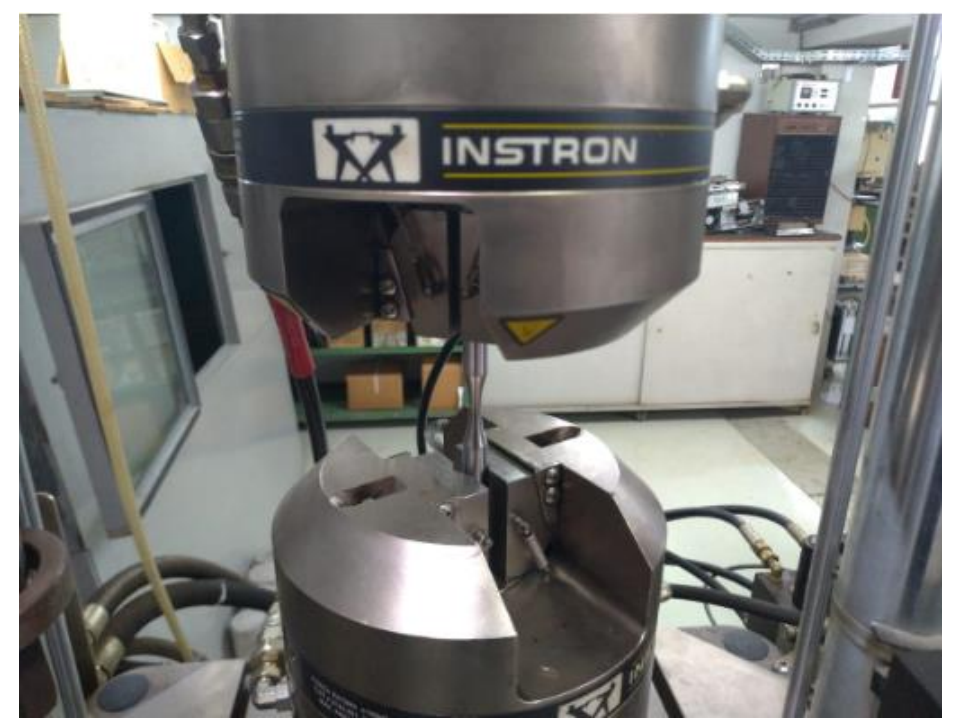

Figura 37 - Fotografia da Máquina Instron servo-hidráulica modelo 8874 (autor)

A outra máquina utilizada foi uma MTS modelo 311, capaz de realizar apenas tração e compressão, com capacidade máxima de 1000 kN. Esta máquina foi capaz de conduzir ensaios em até $8 \mathrm{~Hz}$. Embora tenha em sua especificação a capacidade de conduzir ensaios em frequências superiores (até $20 \mathrm{~Hz}$ ), experimentos mostraram que o controle de força se revelou impreciso, estabilizando-se assertivamente em valores entre $6 \mathrm{~Hz}$ e $8 \mathrm{~Hz}$. Fotografias da máquina em questão estão disponíveis nas Figs. 38 e 39.

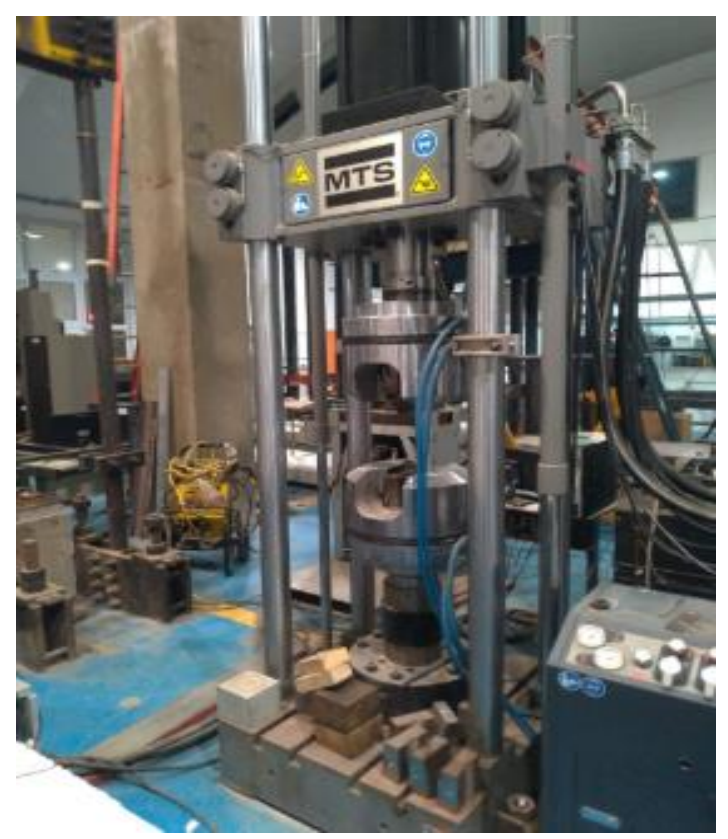

Figura 38 - Fotografia da máquina MTS 311 (autor) 


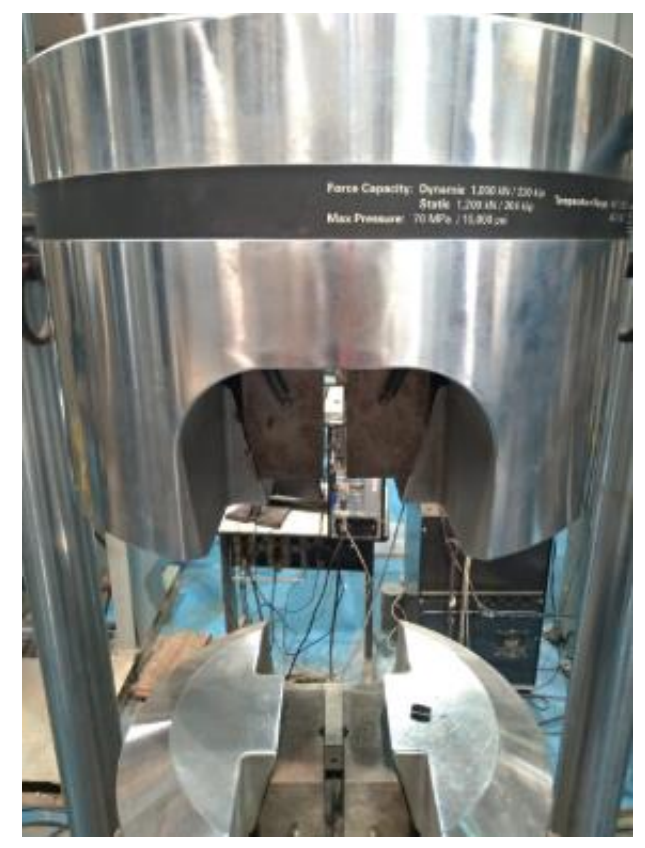

Figura 39 - Fotografia da máquina MTS 311 (autor)

\subsection{Determinação da Geometria do Corpo de Provas}

Usando como referência a norma ASTM E466-15 Standard Practice for Conducting Force Controlled Constant Amplitude Axial Fatigue Tests of Metallic Materials, a geometria descrita na Fig. 40 era possível de ser executada no laboratório de ensaios mecânicos do Departamento de Engenharia Civil da própria PUC-Rio. Trata-se de uma geometria cilíndrica com redução da área de seção reta com raio de redução da seção transversal constante $R$, onde as relações entre as grandezas raio de redução da seção transversal $R$, comprimento da região de raio reduzido $L$, diâmetro da menor seção transversal $D$ e diâmetro da maior seção transversal $D^{\prime}$ são descritas, bem como suas eventuais tolerâncias.

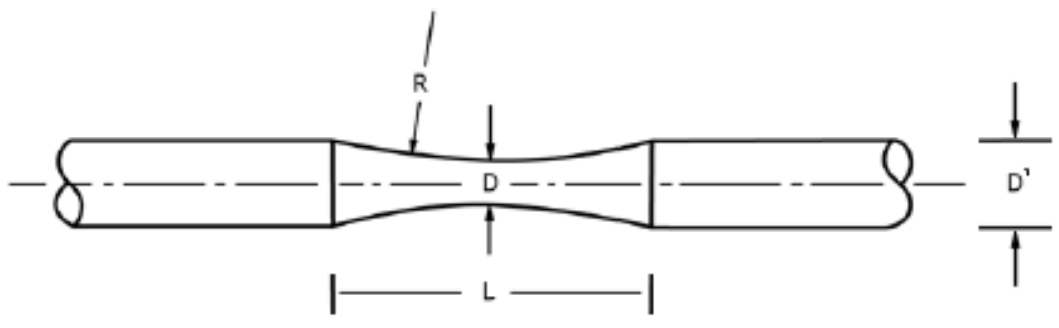

Figura 40 - Geometria proposta pela norma ASTM E466-15

Segundo a norma, $D^{\prime}$ deve ser superior ao mínimo diâmetro da região útil $D$ por um fator de pelo menos 1,5 . O comprimento da região de área reduzida $L$ deve 
medir pelo menos 3 vezes o valor do menor diâmetro $D$, enquanto o raio de curvatura $R$ deverá medir pelo menos 8 vezes o cumprimento de $D$.

Considerando que as garras da máquina utilizada para ensaio admitem uma seção transversal máxima de 0,5 pol $(12,7 \mathrm{~mm})$, optou-se por uma medida de $D^{\prime}$ no valor de $12,5 \mathrm{~mm}$. Os demais valores foram determinados a partir de $D^{\prime}$, mas seria necessário verificar também se a máquina seria capaz de fraturar um corpo de provas com essas dimensões tanto em tração quanto em torção. Os valores avaliados consideram as dimensões do corpo de provas apresentados na Fig. 42.

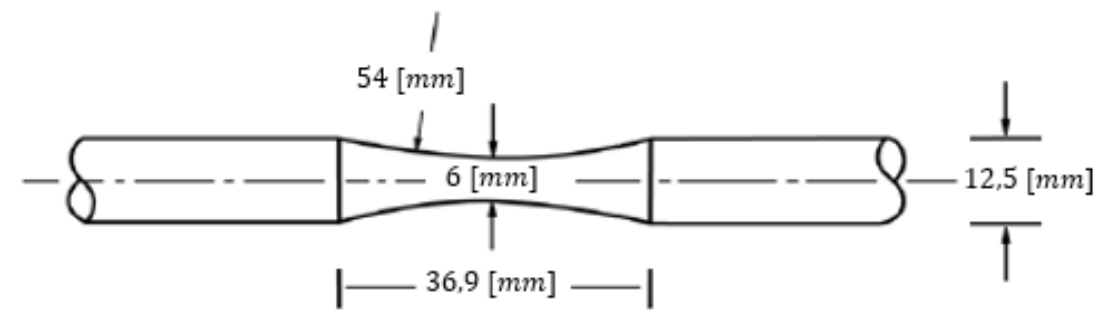

Figura 41 - Dimensões finais do corpo de provas (modificado de norma ASTM E466-15)

Para garantir que a máquina será capaz de fraturar o corpo de provas com as referidas dimensões, considerou-se $80 \%$ do valor de carga máxima que a máquina poderia oferecer para garantir uma certa margem de segurança. Ciente de que tais valores são $25 \mathrm{kN}$ e $100 \mathrm{Nm}$, consideramos a carga axial trativa no valor de $20 \mathrm{kN}$ e o momento torção no valor de $80 \mathrm{Nm}$. É razoável supor que se a máquina é capaz de fraturar o corpo de provas na condição uniaxial, então a mesma máquina terá condições de fraturar o mesmo corpo de provas em um carregamento na condição biaxial, dado que irá impor ao corpo de provas um estado de tensões ainda mais severo. Sendo assim, se satisfeitas as condições uniaxiais, naturalmente condições biaxiais também estarão satisfeitas. É também razoável supor que ensaios de fadiga que imponham uma amplitude de tensão aproximadamente igual ao limite de escoamento devem ser relativamente curtos, pois o corpo de provas não deve suportar um número de ciclos muito grande até atingir a falha.

Para a condição de tração, seja $A$ a área da seção transversal, $P$ a força axial aplicada, $\sigma$ a tensão aplicada, $\sigma_{y}$ o limite de escoamento e $r_{t}$ o raio da mínima seção transversal, verifica-se o apresentado nas equações (106), (107) e (108).

$$
\sigma=\frac{P}{A}, \quad \operatorname{com} \sigma=\sigma_{y}
$$




$$
\begin{gathered}
r_{t}^{2}=\frac{P}{\pi \sigma_{y}} \\
r_{t}=\sqrt{\frac{2 \times 10^{4} \mathrm{~N}}{\pi 715 \times 10^{6} \mathrm{~Pa}}}=0,00298 \mathrm{~m}=2,98 \mathrm{~mm}
\end{gathered}
$$

Para a situação de torção, seja $T$ o torque, $I$ o momento de inércia de área da mínima seção transversal, $\tau$ a tensão cisalhante aplicada, $\sigma_{y}$ o limite de escoamento e $r_{T}$ o raio da mínima seção transversal, verifica-se o apresentado nas equações (109), (110), (111) e (112).

$$
\begin{gathered}
\tau=\frac{T \cdot r_{T}}{I}, \quad \operatorname{com} \tau=\sigma_{y} \\
\sigma_{y}=\frac{T \cdot r_{T}}{(1 / 2) \pi r_{T}^{4}} \\
r_{T}^{3}=\frac{T}{(1 / 2) \pi \sigma_{y}} \\
r_{T}=\sqrt[3]{\frac{80 N m}{(1 / 2) \pi 715 \times 10^{6} P a}}=0,00414 \mathrm{~m}=4,14 \mathrm{~mm}
\end{gathered}
$$

Aproximando valores, as dimensões de raios calculados para as condições de fadiga em tração pura e fadiga em torção pura são de $3 \mathrm{~mm} \mathrm{e} 4 \mathrm{~mm}$, respectivamente. Dado que a fratura é um evento experimental desejável, é natural que se opte pela geometria de menor dimensão, pois este é o cenário em que o carregamento será mais crítico, pois as tensões serão maiores para um determinado valor de carga axial ou de torção. Além disso, há um outro motivo que aponte no sentido da escolha do raio da mínima seção transversal igual a $3 \mathrm{~mm}$ colocado na própria norma, que é o fato de que o diâmetro da maior seção (região a ser engastada pelas garras da máquina) deverá ser superior ao diâmetro da menor seção reta por um fator de pelo menos 1,5. Entretanto, a garra disponível admite apenas 12,5 mm de diâmetro, e apesar de ambas as condições atenderem ao fator mínimo de 1,5, a escolha do raio menor permite incrementar esse fator que relaciona $D$ e $D^{\prime}$, assegurando que as relações de dimensões sejam atendidas mesmo na ocorrência de tolerâncias nas medidas naturais ao processo de torneamento. 


\subsection{Metodologia de Pesquisa}

Todos os modelos de fadiga multiaxial abordados na revisão bibliográfica limitam-se a discutir apenas se o carregamento multiaxial imposto levará o material à falha, não procurando prever a quantidade de ciclos que levariam o material à fratura. Entretanto, Carpinteri \& Spagnoli apresentaram em 2012 uma publicação sugerindo uma modificação em seu próprio critério, permitindo prever extensão da vida em fadiga de um material sujeito a um determinado carregamento multiaxial. Sendo assim, reapresenta-se o equacionamento para o modelo de Carpinteri \& Spagnoli, previamente discutido na equação (65).

$$
\sqrt{N_{\text {max }}^{2}+\left(\frac{f_{-1}}{t_{-1}}\right)^{2} C_{a}^{2}} \leq f_{-1}
$$

Para previsão de vida em fadiga finita, os limites de resistência à fadiga em flexão $f_{-1}$ e torção $t_{-1}$ deverão ser substituídos por suas correspondentes resistências à fadiga $f_{-1}^{\prime}$ e $t_{-1}^{\prime}$ para vida finita, respectivamente. Tais modificações são apresentadas nas equações (113) e (114).

$$
\begin{aligned}
& f_{-1}^{\prime}=f_{-1}\left(\frac{N_{f}}{N_{0}}\right)^{m} \\
& t_{-1}^{\prime}=t_{-1}\left(\frac{N_{f}}{N_{0}}\right)^{m *}
\end{aligned}
$$

A saber, $N_{f}$ é o número de ciclos para falha em vida finita, $N_{0}$ é um número de ciclos de referência (Carpinteri \& Spagnoli referenciam $N_{0}$ como $2 \times 10^{6}$ ciclos), $m$ é o expoente da equação de Basquin conforme apresentado na equação (1) e coeficiente angular da curva de Wöhler para ensaio de tração-compressão totalmente reversível quando plotada em escala log-log e $m *$ é o expoente da equação de Basquin conforme apresentado na equação (1) e o coeficiente angular da curva de Wöhler para ensaio de torção totalmente reversível quando plotada em escala log-log (Carpinteri\&Spagnoli, Structural integrity assessment of metallic components under multiaxial fatigue: the C-S criterion and its evolution, 2013). 
Com isso, apresenta-se o equacionamento para o critério de Carpinteri \& Spagnoli para previsão de vida em fadiga finita na equação (115).

$$
\sqrt{\left[N_{\max }^{2}+\left(\frac{f_{-1}}{t_{-1}}\right)^{2}\left(\frac{N_{f}}{N_{0}}\right)^{2 m}\left(\frac{N_{0}}{N_{f}}\right)^{2 m *} C_{a}^{2}\right]}=f_{-1}\left(\frac{N_{f}}{N_{0}}\right)^{m}
$$

Naturalmente, para que se possa aplicar a equação (115), é necessário determinar $m$ e $m *$, que precisam ser calculados a partir de curvas de Wöhler de tração e torção, respectivamente. Para isso, pelo menos 6 ensaios de fadiga em tração-compressão e pelo menos 6 ensaios de fadiga torção-torção são conduzidos, de modo a encontrar as curvas de Wöhler pertinentes e suas respectivas equações. Uma vez determinados os parâmetros $m$ e $m *$, todos os termos da equação (115) são conhecidos, de modo que é possível solucioná-la para encontrar o valor de $N_{f}$.

\subsubsection{Determinação dos parâmetros $m \mathrm{e} m$ *}

A rigor, os parâmetros $m$ e $m *$ são os coeficientes angulares das curvas de Wöhler para tração e torção totalmente reversíveis, respectivamente, ambas plotadas em escala log-log. Para obtenção desses valores, utiliza-se dois pontos mais precisos da curva de S-N levantada experimentalmente, cuja equação formulação típica é apresentada na equação (1) deste texto.

Sejam dois pontos da curva de Wöhler que relacionam amplitude de tensão e número de ciclos para falha conforme apresentado nas equações (116) e (117). Como ambos os pontos pertencem à mesma curva, amplitude de tensão e número de ciclos para falha se relacionam através dos mesmos parâmetros, ainda desconhecidos, $A$ e $B$.

$$
\begin{aligned}
& \sigma_{1}=A N_{1}^{B} \\
& \sigma_{2}=A N_{2}^{B}
\end{aligned}
$$

Dividindo uma equação pela outra e tomando o logaritmo dos dois lados da igualdade, tem-se o exposto nas equações (118) e (119). 


$$
\begin{aligned}
& \log \left(\frac{\sigma_{1}}{\sigma_{2}}\right)=\log \left(\frac{N_{1}}{N_{2}}\right)^{B} \\
& \log \left(\frac{\sigma_{1}}{\sigma_{2}}\right)=B \log \left(\frac{N_{1}}{N_{2}}\right)
\end{aligned}
$$

Observa-se que o expoente da curva de Basquin é justamente o coeficiente angular $m$ desejado para uma curva de Wöhler de tração totalmente reversível. A equação (120) apresenta a equação final para o cálculo de $m$ e a equação (121) apresenta o equacionamento final para um processo análogo referente ao cálculo de $m *$.

$$
\begin{gathered}
m=\frac{\log \left(\sigma_{1}\right)-\log \left(\sigma_{2}\right)}{\log \left(N_{1}\right)-\log \left(N_{2}\right)} \\
m *=\frac{\log \left(\tau_{1}\right)-\log \left(\tau_{2}\right)}{\log \left(N_{1}\right)-\log \left(N_{2}\right)}
\end{gathered}
$$

Uma vez determinado o parâmetro $m$ e $m *$, é possível obter o coeficiente $A$ e $A^{\prime}$ da curva de Basquin substituindo os valores de qualquer amplitude de tensão e seu correspondente número de ciclos para falha, obtido experimentalmente, na equação própria equação de Basquin. Os equacionamentos de interesse estão disponíveis nas equações (122) e (123). As soluções dessas equações fornecem o último parâmetro faltante da equação de Basquin. Observe que o sub índice 1 denota um ponto genérico para o ensaio de tração enquanto o sub índice 1' denota um ponto genérico para ensaio de torção.

$$
\begin{gathered}
\sigma_{1}=A\left(N_{1}\right)^{m} \\
\tau_{1^{\prime}}=A^{\prime}\left(N_{1 \prime}\right)^{m *}
\end{gathered}
$$

Cabe ressaltar que o procedimento acima relaciona apenas dois pontos da curva experimental, e pode não ser representativo para toda a curva visto que relacionando outros dois pontos pode produzir resultados ligeiramente diferentes. Sendo assim, $A$ e $B$ precisam ser calculados para várias combinações de pontos experimentais, e a equação da curva final deverá ser aquela que melhor se ajusta aos pontos coletados. Naturalmente, softwares de computador são capazes de 
realizar o melhor ajuste para uma coleção de pontos experimentais, fornecendo a equação final de maneira assertiva. A partir das equações das curvas de Wöhler para tração e torção fornecidas pelo software, os parâmetros $m$ e $m *$ serão os expoentes dessas curvas.

Por fim, convém salientar que $m$ e $m *$ são valores constantes para toda a extensão da curva de Wöhler. Sendo assim, os ensaios realizados para a obtenção de uma coleção de pontos que culminará no melhor ajuste de uma equação exponencial podem ser relativamente curtos, aplicando altas amplitudes de tensão para obter um pequeno número de ciclos para falha. Isso é conveniente porque pode abreviar o procedimento para obtenção dos parâmetros em questão.

\subsubsection{Determinação dos parâmetros $N_{0}, f_{-1}$ e $t_{-1}$}

O limite de resistência à fadiga é um parâmetro de interesse, associando um determinado valor de amplitude de tensão a uma vida infinita do componente mecânico em operação. Uma amplitude de tensão aplicada suficientemente pequena, menor do que o limite de resistência à fadiga, levaria um equipamento a operar por toda a sua vida útil sem que o mesmo falhe por fadiga.

Carpinteri \& Spagnoli propõem em sua publicação de 2012 uma modificação em seu próprio critério, fazendo com que o modelo, que outrora avaliava se um carregamento combinado de torção e tração levaria um determinado material para falha ou vida infinita, passasse a prever quantos ciclos o componente mecânico suportaria até falhar por fadiga (Carpinteri\&Spagnoli, Structural integrity assessment of metallic components under multiaxial fatigue: the C-S criterion and its evolution, 2013).

Nessa mesma publicação, Carpinteri \& Spagnoli sugerem um valor de referência para $N_{0}$ igual a $2 \times 10^{6}$ ciclos, e por esse motivo, foi considerado o valor de resistência à fadiga aqueles valores de amplitude de tensão associados a $2 \times 10^{6}$ ciclos. Como nenhum ensaio será conduzido até esse número de ciclos, as curvas de Wöhler obtidas serão extrapoladas para que se obtenha o valor da amplitude de tensão desejado, associado a $2 \times 10^{6}$ ciclos. 


\subsubsection{Previsão de Vida em Fadiga}

\subsubsection{Equacionamento}

Uma vez conhecidos os limites de resistência à fadiga $f_{-1}$ e $t_{-1}$, o valor dos parâmetros $m$ e $m *$, o valor de $N_{0}$ e os valores de $N_{\text {max }}$ e $C_{a}$ associados ao plano crítico, então a única incógnita da equação (115) é a variável $N_{f}$. Para se determinar analiticamente o resultado de $N_{f}$, é necessário realizar alguma manipulação na equação (115), sendo o primeiro passo elevar ao quadrado os dois lados da igualdade, obtendo o apresentado na equação (124).

$$
N_{\text {max }}^{2}+\left[\left(\frac{f_{-1}}{t_{-1}}\right)^{2}\left(\frac{N_{f}}{N_{0}}\right)^{2 m}\left(\frac{N_{0}}{N_{f}}\right)^{2 m *}\right] C_{a}^{2}=f_{-1}^{2}\left(\frac{N_{f}}{N_{0}}\right)^{2 m}
$$

Agrupando os termos constantes para reorganizar a equação, tem-se o exposto na equação (125), culminando em seu desdobramento apresentado na equação (126).

$$
\begin{gathered}
N_{\text {max }}^{2}+\left\{\left[\left(\frac{f_{-1}}{t_{-1}}\right)^{2} N_{0}^{2(m *-m)}\right] C_{a}^{2}\right\} N_{f}^{2(m-m *)}=\left(\frac{f_{-1}}{N_{0}^{m}}\right)^{2} N_{f}^{2 m} \\
N_{\text {max }}^{2}+\left\{\left[\left(\frac{f_{-1}}{t_{-1}}\right)^{2} N_{0}^{2(m *-m)}\right] C_{a}^{2}\right\} N_{f}^{2(m-m *)}-\left(\frac{f_{-1}}{N_{0}^{m}}\right)^{2} N_{f}^{2 m}=0
\end{gathered}
$$

Podemos então reduzir a equação substituindo as constantes por parâmetros mais simples, conforme o indicado na Tabela 5, obtendo o equacionamento final apresentado na equação (127). 
Tabela 5 - Substituição de parâmetros para o critério de vida finita de Carpinteri \& Spagnoli

\begin{tabular}{|c|c|}
\hline$N_{\max }^{2}$ & $P$ \\
\hline$\left[\left(f_{-1} / t_{-1}\right)^{2} N_{0}^{2(m *-m)}\right] C_{a}^{2}$ & $Q$ \\
\hline$\left(f_{1} / N_{0}^{m}\right)^{2}$ & $R$ \\
\hline $2(m-m *)$ & $S$ \\
\hline $2 m$ & $T$ \\
\hline
\end{tabular}

$$
P+Q N_{f}^{S}-R N_{f}^{T}=0
$$

Sendo $S$ e $T$ expoentes da variável $N_{f}$ e diferentes entre si, não existe solução analítica para o problema. Entretanto, essa equação polinomial pode ser solucionada numericamente e o valor de $N_{f}$ que atender à equação será a solução do problema e fornecerá o número de ciclos para falha associado a um determinado carregamento aplicado a um determinado material segundo o critério modificado de Carpinteri \& Spagnoli.

\subsubsection{Solução Numérica}

Os modelos alternativos ao critério de Carpinteri \& Spagnoli modificado são todos voltados para uma análise considerando vida infinita. O critério de Papadopoulos merece especial destaque porque seu modelo é compacto e de fácil aplicação, pois não depende de determinação de plano crítico, mas dos seus valores de carregamento externos. Além de sua elegância, o critério de Papadopoulos é atrativo porque apresenta menores índices de erro se comparado aos demais modelos apresentados no presente estudo (Feiferis, 2018).

Já o critério de Carpinteri \& Spagnoli, por sua vez, envolve uma complexidade significativamente maior em sua aplicação, e isso se deve ao fato de que o modelo não depende diretamente de $\sigma_{a}$ e $\tau_{a}$, mas de $N_{\max }$ e de $C_{a}$, cujos 
equacionamentos dependem da determinação do plano crítico. Adicionalmente, as próprias equações para determinação de $N_{\max }$ e de $C_{a}$ são razoavelmente complexas, dependendo elas próprias de um apanhado de funções auxiliares.

No entanto, a possibilidade de estimar a vida de um componente estrutural sob carregamento que deve culminar em falha por fadiga é algo extremamente valioso, a ponto de motivar pesquisas no sentido de medir a acuracidade do modelo em questão.

Sendo assim, a equação (126) oferece condições de se prever uma estimativa para o número de ciclos para falha de um componente estrutural sob solicitação mecânica que combine tração e torção. Embora em um primeiro momento aparente ter três informações desconhecidas $\left(N_{\max }, C_{a}\right.$ e $\left.N_{f}\right)$ e apenas uma equação, a determinação de $N_{\max }$ e de $C_{a}$ dependem apenas do carregamento externo e da orientação do plano crítico (que, por sua vez, depende do carregamento externo e de propriedades materiais). Embora seja um processo trabalhoso, na prática, se definida uma condição de carregamento, a equação (126) possui uma única variável a ser determinada, cuja solução fornece uma estimativa para no número de ciclos para falha do material.

$$
N_{\text {max }}^{2}+\left\{\left[\left(\frac{f_{-1}}{t_{-1}}\right)^{2} N_{0}^{2(m *-m)}\right] C_{a}^{2}\right\} N_{f}^{2(m-m *)}-\left(\frac{f_{-1}}{N_{0}^{m}}\right)^{2} N_{f}^{2 m}=0
$$

Embora não seja possível isolar a variável $N_{f}$ para determinar analiticamente o seu valor, os demais parâmetros são tratados como constantes para um carregamento e um material determinado, fazendo com que a equação possa ser resolvida numericamente. Define-se então, para o lado esquerdo da igualdade, uma função genérica $y=F\left(N_{f}\right)$, onde a $F\left(N_{f}\right)$ está representado na equação (128).

$$
N_{\text {max }}^{2}+\left\{\left[\left(\frac{f_{-1}}{t_{-1}}\right)^{2} N_{0}^{2(m *-m)}\right] C_{a}^{2}\right\} N_{f}^{2(m-m *)}-\left(\frac{f_{-1}}{N_{0}^{m}}\right)^{2} N_{f}^{2 m}=y
$$

Sendo assim, a raiz dessa equação será o valor $N_{f}$ que irá satisfazer a equação (126) e, portanto, será a previsão do número de ciclos para falha segundo o critério de Carpinteri \& Spagnoli. 
Por exemplo, seja um carregamento biaxial de $\sigma_{a}=350 \mathrm{MPa}$ de amplitude de tensão normal e $\tau_{a}=250 \mathrm{MPa}$ tal que, após todos os cálculos de orientação do plano crítico, bem como valores de $N_{\max }$ e $C_{a}$, produz a equação (129) prevendo 53262 ciclos para falha, conforme indicado no gráfico da Fig. 42.

$$
45593,35+108174,22 x^{0,054}-1400908,96 x^{-0,162}=0
$$

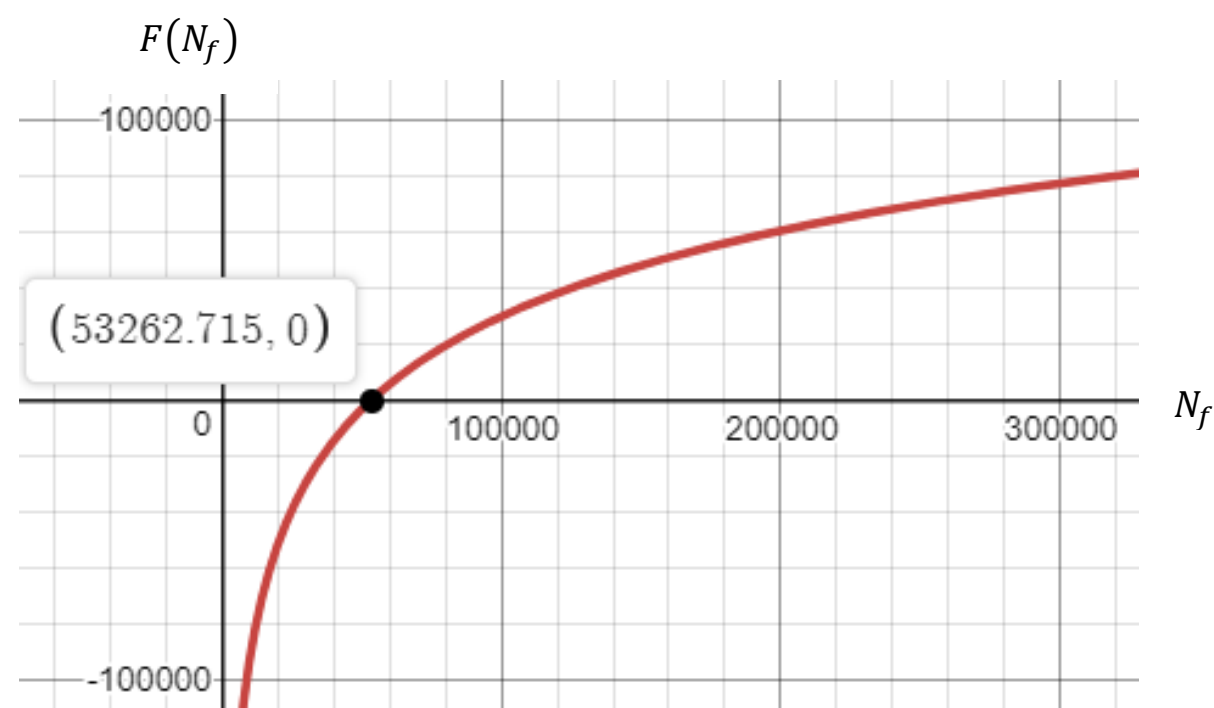

Figura 42 - Solução para equação do modelo de Carpinteri \& Spagnoli para um carregamento genérico

É claro que o resultado proposto pela equação pode entregar um número não inteiro. Mas para fins de valores de referência para uma previsão de vida em fadiga, é perfeitamente razoável considerar uma aproximação do valor obtido o número de ciclos para falha para o número inteiro mais próximo.

Destaca-se que qualquer software matemático capaz de plotar curvas atende à demanda necessária. Para o presente estudo, as curvas foram plotadas através do Desmos, software online disponível no endereço www.desmos.com/calculator. 


\section{Resultados e Discussão}

\subsection{Curvas de Wöhler Experimentais para Tração e Torção}

Para se obter as curvas de Wöhler para tração e torção totalmente reversíveis, foram conduzidos sete ensaios de tração-compressão e seis ensaios de torção-torção para diferentes valores de amplitudes de tensão. O número de ciclos para falha de cada ensaio foi coletado e duas curvas foram determinadas considerando o melhor ajuste para cada tipo de ensaio. A Tabela 6 e a Tabela 7 apresentam os valores de tensões ensaiados, enquanto as Figs. 43 e 44 apresentam a dispersão dos pontos coletados.

Tabela 6 - Valor de tensão normal totalmente reversível e número de ciclos obtido para cada ensaio

\begin{tabular}{|c|c|}
\hline $\boldsymbol{\sigma}_{\boldsymbol{a}}[\mathbf{M P a}]$ & $\boldsymbol{N}_{\boldsymbol{f}}[$ ciclos $]$ \\
\hline 642,49 & 1.400 \\
\hline 608,50 & 3.395 \\
\hline 572,52 & 11.598 \\
\hline 536,63 & 34.698 \\
\hline 503,12 & 64.748 \\
\hline 465,72 & 72.000 \\
\hline 428,33 & 156.280 \\
\hline
\end{tabular}

Tabela 7 - Valor de tensão cisalhante totalmente reversível e número de ciclos obtido para cada ensaio

\begin{tabular}{|c|c|}
\hline $\boldsymbol{\tau}_{\boldsymbol{a}}[\mathbf{M P a}]$ & $\boldsymbol{N}_{\boldsymbol{f}}[$ ciclos $]$ \\
\hline 499,92 & 1.192 \\
\hline 444,37 & 5.493 \\
\hline 413,27 & 9.574 \\
\hline 392,47 & 11.805 \\
\hline 371,81 & 12.261 \\
\hline 351,16 & 37.193 \\
\hline
\end{tabular}




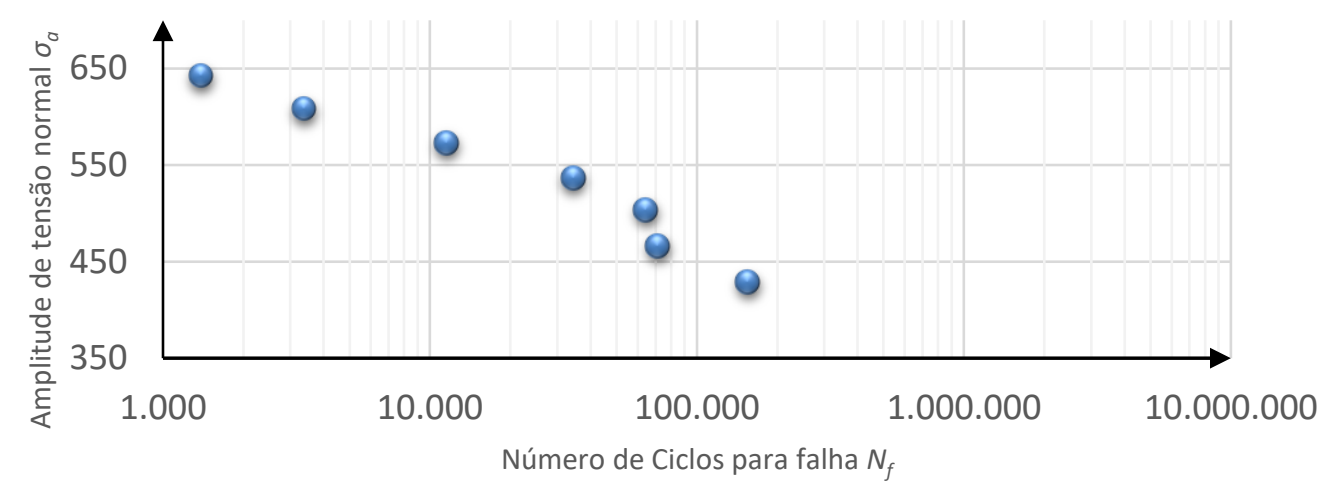

Figura 43 - Dispersão de pontos para curva de Wöhler de tração-compressão

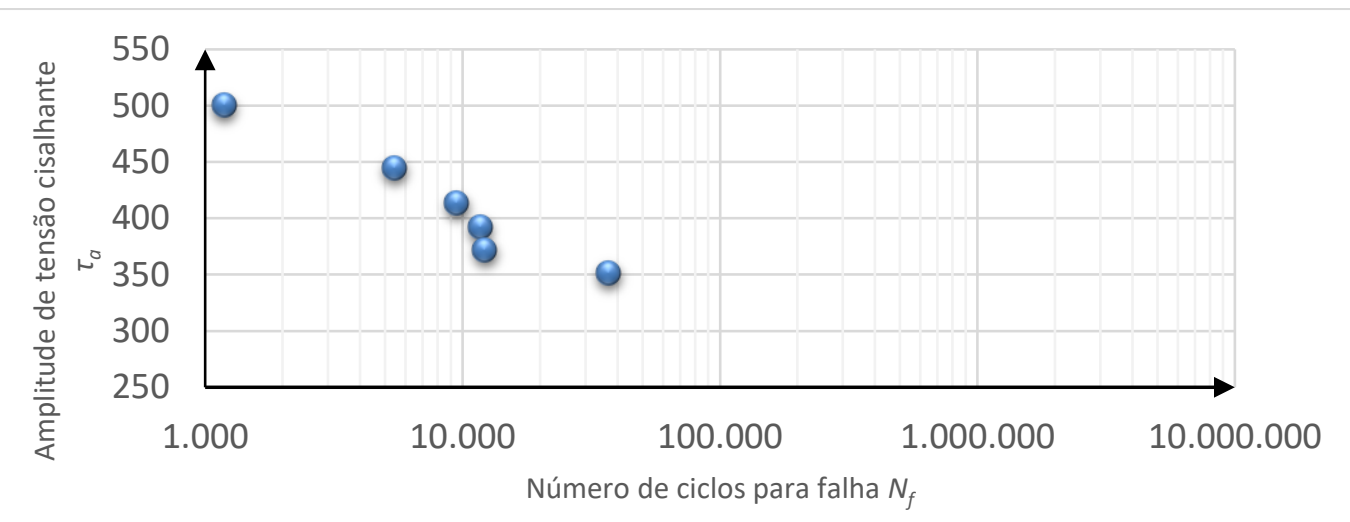

Figura 44 - Dispersão de pontos para curva de Wöhler de torção

Com base na dispersão obtida, foi possível obter o equacionamento que representa o melhor ajuste através do Excel. O referido equacionamento da curva de tração-compressão está apresentado na equação (130) assim como o equacionamento da curva de torção-torção está apresentado na equação (131), e as curvas ficaram conforme apresentado nas Figs. 45, 46, 47 e 48. Destaca-se que as mesmas curvas foram extrapoladas para $10^{7}$ ciclos com o intuito de prever os limites de resistência à fadiga.

$$
\begin{gathered}
\sigma_{a}=1183,6\left(N_{f}\right)^{-0,081} \\
\tau_{a}=1089,4\left(N_{f}\right)^{-0,108}
\end{gathered}
$$




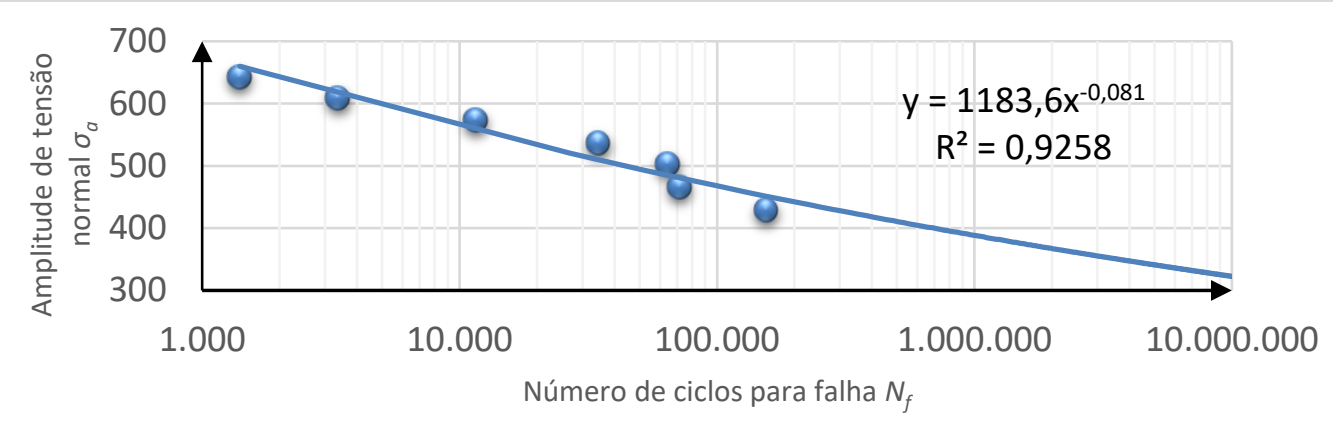

Figura 45 - Curva de Wöhler para tração com número de ciclos para falha em escala log

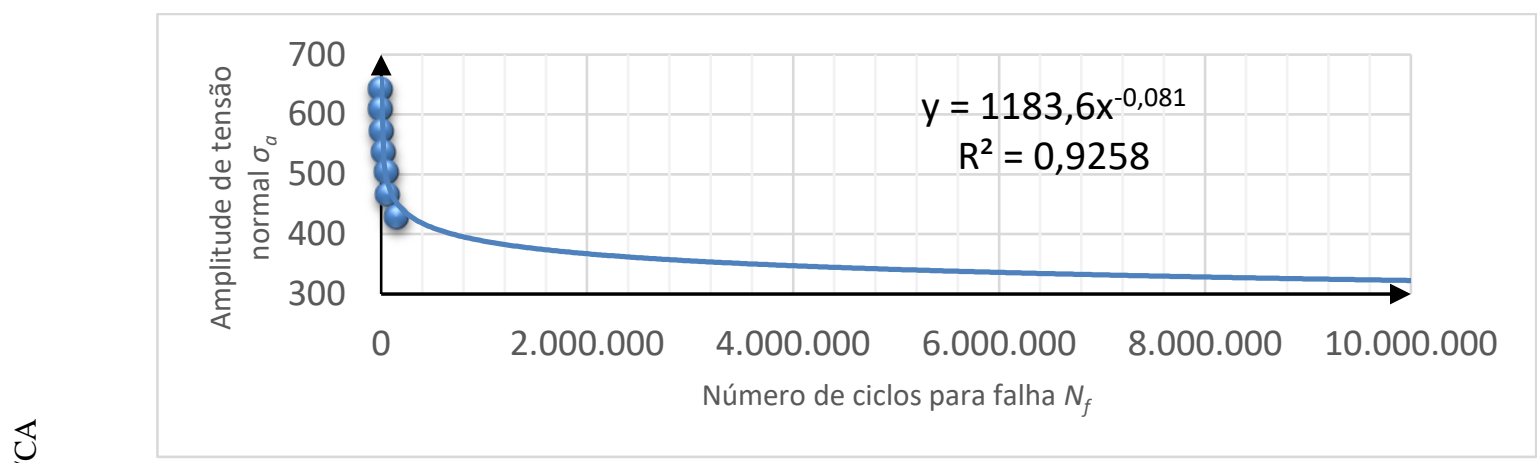

Figura 46 - Curva de Wöhler para tração com número de ciclos para falha em escala linear

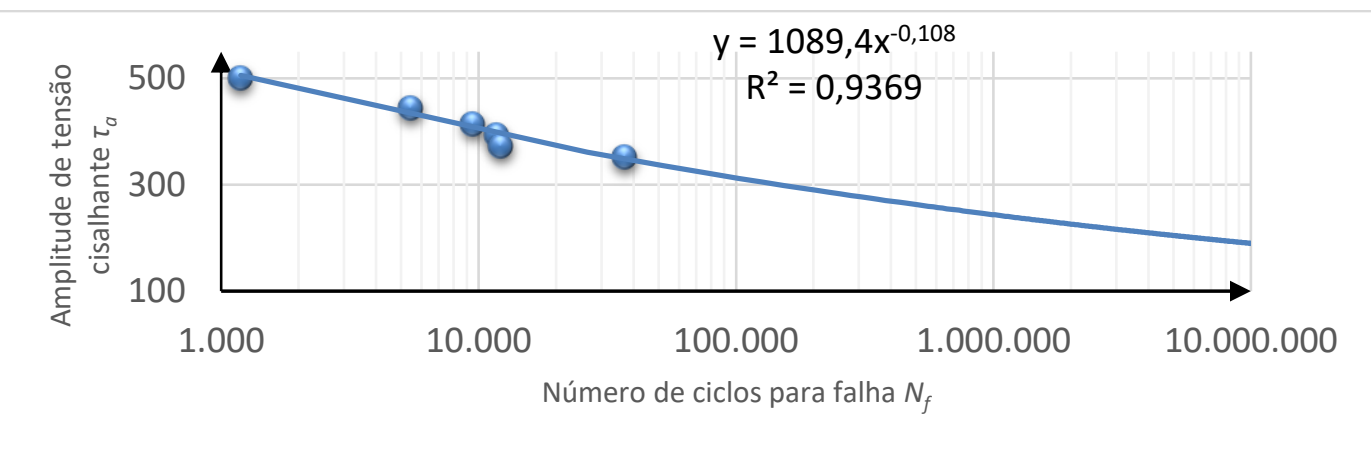

Figura 47 - Curva de Wöhler para torção com número de ciclos para falha em escala log

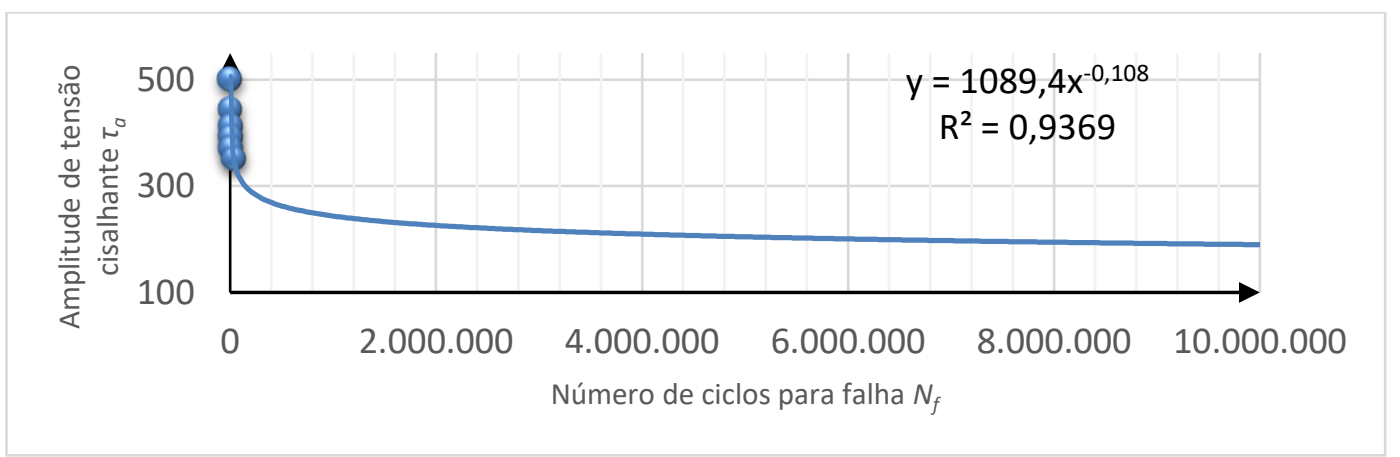

Figura 48 - Curva de Wöhler para torção com número de ciclos para falha em escala linear 
Uma vez de posse das equações para as curvas de Wöhler, os parâmetros $m$ e $m *$ são os expoentes das curvas determinadas, sendo $m$ para os ensaios de tração e $m *$ para os ensaios de torção. Os mesmos estão disponíveis nas equações (132) e (133).

$$
\begin{gathered}
m=-0,081 \\
m *=-0,108
\end{gathered}
$$

Carpinteri \& Spagnoli indicam ainda que o número de ciclos de referência $N_{0}$, a partir do qual podemos considerar que o material não irá fraturar, deve ser $2 \times 10^{6}$. Por esse motivo, os limites de resistência à fadiga considerados serão aqueles associados a esse número de ciclos pois, uma vez aplicadas amplitudes de tensões inferiores a esses valores, o material deverá resistir por um número de ciclos superior a $N_{0}$. Com isso, tem-se o disposto nas equações (134), (135) e (136).

$$
\begin{gathered}
N_{0}=2 \times 10^{6} \\
f_{-1}=365,44 \mathrm{MPa} \\
t_{-1}=227,34 \mathrm{MPa}
\end{gathered}
$$

A consistência desses valores pode ser verificada comparando os valores fornecidos na publicação de 1945 de Nishihara e Kawamoto (Nishihara\&Kawamoto, 1945), disponíveis na Tabela 8.

Tabela 8 - Propriedades de materiais referentes aos ensaios de Nishihara e Kawamoto (Nishihara\&Kawamoto, 1945)

\begin{tabular}{lccccc}
\hline Material & $f_{-1}[\mathrm{MPa}]$ & $t_{-1}[\mathrm{MPa}]$ & $t_{-1} / f_{-1}$ & $\sigma_{u}[\mathrm{MPa}]$ & $m_{\sigma}$ \\
\hline Hard steel & 313,9 & 196,2 & 0,63 & 704,1 & 8,7 \\
Mild steel & 235,4 & 137,3 & 0,58 & 518,8 & 18,2 \\
Cast iron & 96,1 & 91,2 & 0,95 & 230 & 19,4 \\
\hline
\end{tabular}

Os valores de resistência à fadiga obtidos experimentalmente são cerca de $16 \%$ acima dos valores indicados por Nishihara \& Kawamoto, o que de fato coloca o material em questão na categoria de hard steel. Além disso, a relação entre os limites de resistência à fadiga calculada foi de 0,62 , o que também está coerente e 
dentro do esperado. O limite de resistência mecânica é propriedade conhecida desse material, e é tratado nesse estudo como $906 \mathrm{MPa}$, sendo consistente com o esperado. Por fim, os valores de $m_{\sigma}$ e $m_{\sigma *}$ são fornecidos pelas equações (135) e (136), e seus valores estão disponíveis nas equações (137) e (138). Esses valores são coerentes com a categorização de hard steel.

$$
\begin{gathered}
m_{\sigma}=-1 / m \\
m_{\sigma *}=-1 / m * \\
m_{\sigma}=12,345 \\
m_{\sigma *}=9,259
\end{gathered}
$$

\subsection{Previsão de vida em Fadiga vs. Experimentos}

\subsubsection{Previsão de Vida em Fadiga para ensaios Biaxiais}

Dos 16 ensaios conduzidos, três condições de carregamento multiaxiais diferentes foram testadas. Duas previsões teóricas se mostraram razoavelmente consistentes quando comparadas ao resultado experimental, enquanto o outro experimento mostrou-se bastante discrepante.

\subsubsection{Corpo de Prova A (CP-A)}

Como uma primeira tentativa para levar o corpo de prova à fratura, foi utilizado um carregamento de $\sigma_{a}=0,6 \sigma_{y}$ e $\tau_{a}=0,35 \sigma_{y}$. Esses valores resultam numericamente em $\sigma_{a}=429,33 \mathrm{MPa}$ e $\tau_{a}=247,88 \mathrm{MPa}$, proporcionando os seguintes resultados parciais, apresentados na Tabela 9.

Tabela 9 - Cálculos parciais para carregamento de $\sigma_{a}=429,33 \mathrm{MPa}$ e $\tau_{a}=247,88 \mathrm{MPa}$

\begin{tabular}{|c|c|c|c|c|}
\hline$\sigma_{a}=429,33 \mathrm{MPa}$ & $\tau_{a}=247,88 \mathrm{MPa}$ & $\varphi_{f}=65,40^{\circ}$ & $\delta=41,38^{\circ}$ & $\varphi_{c}=24,02^{\circ}$ \\
\hline$a=255,49 \mathrm{MPa}$ & $b=0 \mathrm{MPa}$ & $N_{a}=255,49 \mathrm{MPa}$ & $N_{m}=0 \mathrm{MPa}$ & $N_{\max }=255,49 \mathrm{MPa}$ \\
\hline$f=0 \mathrm{MPa}$ & $g=0 \mathrm{MPa}$ & $p=325,35 \mathrm{MPa}$ & $q=0 \mathrm{MPa}$ & $C_{a}=325,35 \mathrm{MPa}$ \\
\hline
\end{tabular}


Tais parâmetros fornecem a equação (139) para determinação da vida em fadiga do corpo de provas, fornecendo a previsão de ciclos da Fig. 49.

$$
65274,39082+124956,1744 x^{0,054}-1400908,96 x^{-0,162}=0
$$

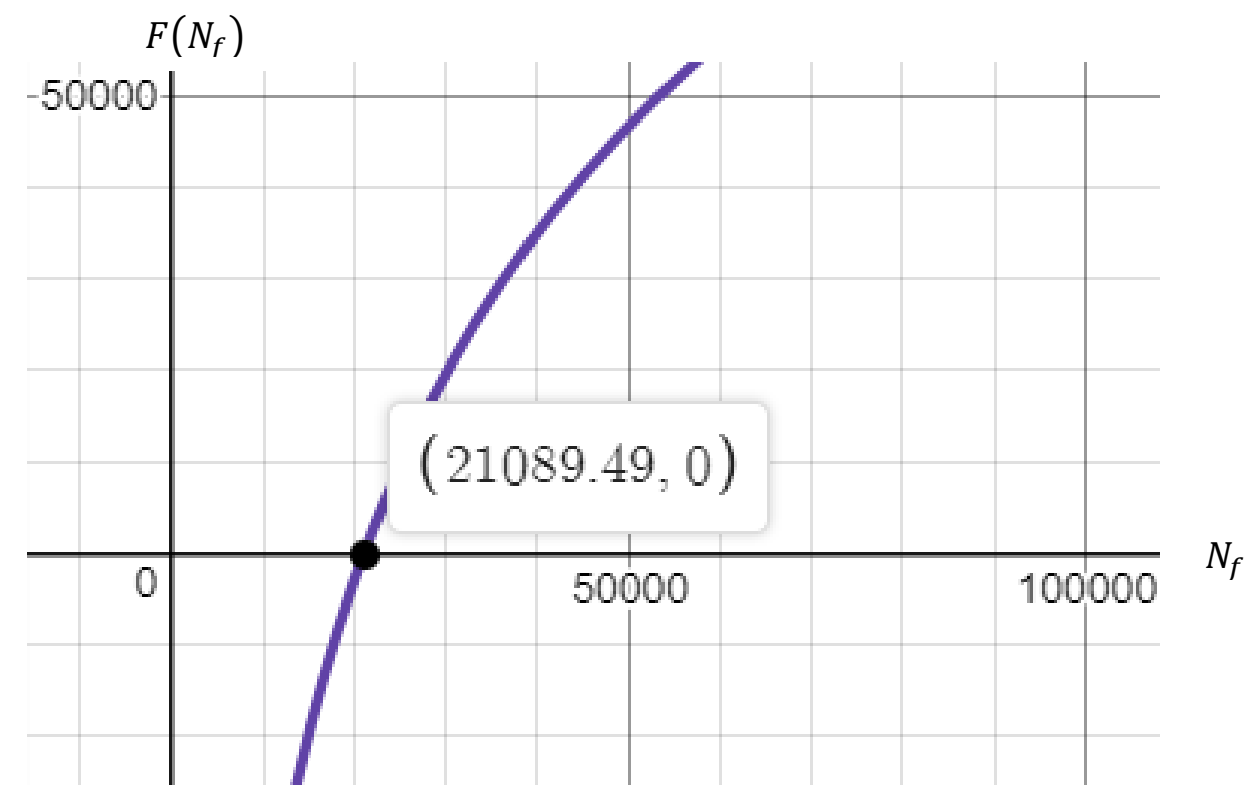

Figura 49 - Previsão de vida em fadiga sob carregamento de $\sigma_{a}=429,33 \mathrm{MPa}$ e $\tau_{a}=247,88 \mathrm{MPa}$

Comparando a previsão teórica com o resultado experimental, temos:

- Previsão teórica: 21.089 ciclos;

- Resultado experimental: 28.941 ciclos.

- Variação Percentual: $\quad 37 \%$

O modelo apresentou alguma margem de erro, mas manteve-se conservador em sua previsão. Isto é positivo porque indica a possibilidade de o modelo poder ser usado para projetos estruturais de engenharia uma vez que a vida final é $37 \%$ superior à vida prevista. Cientes de que fadiga é um fenômeno que apresenta enorme espalhamento, é razoável inferir que o modelo teórico nesse caso descreve relativamente bem o fenômeno. 


\subsubsection{Corpo de Prova B (CP-B)}

Buscando fazer com que o ensaio culmine em fratura, a próxima combinação de valores foi escolhida buscando uma pequena redução de $\sigma_{a}$ e um pequeno incremento de $\tau_{a}$.Para um carregamento de $\sigma_{a}=0,5 \sigma_{y}=350,17 \mathrm{MPa}$ e $\tau_{a}=0,4 \sigma_{y}=278,74 M P a$, obteve-se os seguintes resultados parciais, apresentados na Tabela 10 .

Tabela 10 - Cálculos parciais para carregamento de $\sigma_{a}=350,17 \mathrm{MPa}$ e $\tau_{a}=278,74 \mathrm{MPa}$

\begin{tabular}{|c|c|c|c|c|}
\hline$\sigma_{a}=350,17 \mathrm{MPa}$ & $\tau_{a}=227,74 \mathrm{MPa}$ & $\varphi_{f}=61,10^{\circ}$ & $\delta=41,38^{\circ}$ & $\varphi_{c}=19,72^{\circ}$ \\
\hline$a=216,97 \mathrm{MPa}$ & $b=0 \mathrm{MPa}$ & $N_{a}=216,97 \mathrm{MPa}$ & $N_{m}=0 \mathrm{MPa}$ & $N_{\text {max }}=216,97 \mathrm{MPa}$ \\
\hline$f=0 \mathrm{MPa}$ & $g=0 \mathrm{MPa}$ & $p=326,49 \mathrm{MPa}$ & $q=0 \mathrm{MPa}$ & $C_{a}=325,35 \mathrm{MPa}$ \\
\hline
\end{tabular}

Tais parâmetros fornecem a equação (140) para determinação da vida em fadiga do corpo de provas, fornecendo a previsão de ciclos da Fig. 50.

$$
47076,28226+125827,3833 x^{0,054}-1400908,96 x^{-0,162}=0
$$

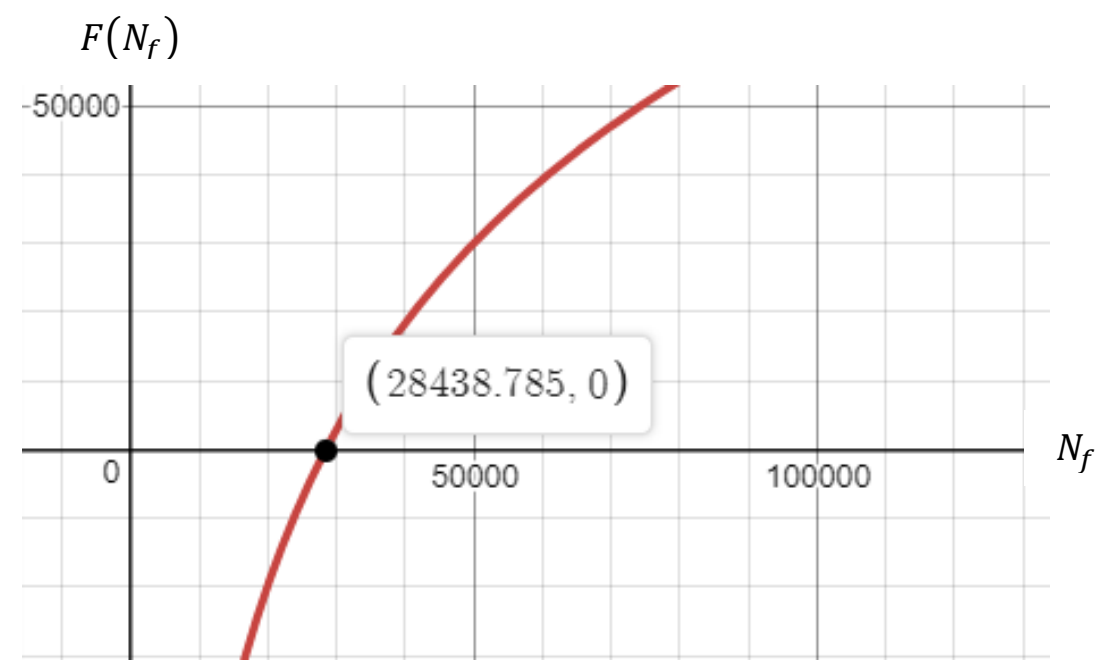

Figura 50 - Previsão de vida em fadiga sob carregamento de $\sigma_{a}=350,17 \mathrm{MPa}$ e $\tau_{a}=278,74 \mathrm{MPa}$

Comparando a previsão teórica com o resultado experimental, temos:

- Previsão teórica:

28.438 ciclos;

- Resultado experimental: 75.769 ciclos.

- Variação Percentual: $\quad 166 \%$ 
O resultado experimental obtido foi substancialmente maior do que a previsão teórica. Embora essa variação percentual elevada indique uma inconsistência do modelo, é sabido que o fenômeno de fadiga tem associado a si um elevado grau de espalhamento. Então, apesar da discrepância, o fato de o modelo ter previsto nos dois casos uma vida em fadiga menor do que a vida em fadiga observada experimentalmente é positivo, porque também sugere um comportamento conservador do modelo. Caso esse conservadorismo venha a se confirmar em outros experimentos, isso pode ser um comportamento bem-vindo para projetos de engenharia, desde que o a imprecisão não seja demasiada.

\subsubsection{Corpo de Prova C (CP-C)}

Para um novo carregamento combinado de $\sigma_{a}=0,63 \sigma_{y}=450 \mathrm{MPa}$ e $\tau_{a}=0,24 \sigma_{y}=174,71 \mathrm{MPa}$, obteve-se os seguintes resultados parciais, apresentados na Tabela 11.

Tabela 11 - Cálculos parciais para carregamento de $\sigma_{a}=450 \mathrm{MPa}$ e $\tau_{a}=174,71 \mathrm{MPa}$

\begin{tabular}{|c|c|c|c|c|}
\hline$\sigma_{a}=450 \mathrm{MPa}$ & $\tau_{a}=174,71 \mathrm{MPa}$ & $\varphi_{f}=71,10^{\circ}$ & $\delta=41,38^{\circ}$ & $\varphi_{c}=29,72^{\circ}$ \\
\hline$a=261,06 \mathrm{MPa}$ & $b=0 \mathrm{MPa}$ & $N_{a}=261,06 \mathrm{MPa}$ & $N_{m}=0 \mathrm{MPa}$ & $N_{\text {max }}=261,06 \mathrm{MPa}$ \\
\hline$f=0 \mathrm{MPa}$ & $g=0 \mathrm{MPa}$ & $p=282,57 \mathrm{MPa}$ & $q=0 \mathrm{MPa}$ & $C_{a}=282,57 \mathrm{MPa}$ \\
\hline
\end{tabular}

Tais parâmetros fornecem a equação (141) para determinação da vida em fadiga do corpo de provas, fornecendo a previsão de ciclos da Fig. 51.

$$
68153,73249+94251,97717 x^{0,054}-1400908,96 x^{-0.162}=0
$$

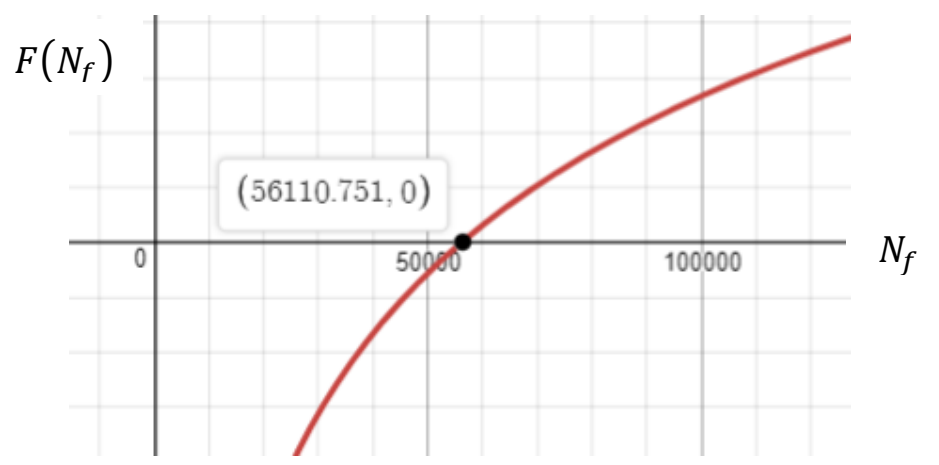

Figura 51 - Previsão de vida em fadiga sob carregamento de $\sigma_{a}=450 \mathrm{MPa}$ e $\tau_{a}=174,71 \mathrm{MPa}$ 
- Previsão teórica: $\quad 56.110$ ciclos;

- Resultado experimental: 37.800 ciclos.

- Variação Percentual: $\quad-32 \%$

Para CP-C, o número de ciclos para falha foi inferior ao previsto teoricamente. E apesar de o resultado apontar no sentido contrário do suposto conservadorismo sugerido nos ensaios anteriores, a discrepância se também se mostrou inferior. Apesar da necessidade de um maior número de experimentos para confirmar uma tendência estatística, é seguro afirmar que o critério para avaliação de fadiga multiaxial de Carpinteri \& Spagnoli modificado é capaz de apresentar previsões de valores de referência, com uma certa margem de erro. Se considerarmos o resultado de CP-B como um outlier estatístico, a janela de erro fica na ordem de $34,5 \%$ para mais ou para menos.

\subsubsection{Testando os limites do modelo}

Embora o modelo seja concebido para uma condição de carregamento multiaxial, uma maneira de avaliar a acuracidade do modelo é testando os seus limites na condição uniaxial. Ainda que seja uma subutilização do modelo para fins práticos, uma boa modelagem deve ser capaz de prever assertivamente condições de carregamentos complexas e também uniaxiais. Ao todo, 13 ensaios uniaxiais foram conduzidos, e a verificação da compatibilidade dos modelos experimental e o modelo teórico serve para verificar a acuracidade do modelo.

Para esses resultados, cálculos intermediários serão omitidos. Os resultados para tração pura estão apresentados na Tabela 12 e na Fig. 52, enquanto os resultados para torção pura estão representados na Tabela 13 e na Fig. 53. 
Tabela 12 - Resultados teóricos e experimentais para ensaios de tração pura

\begin{tabular}{|c|c|c|c|}
\hline$\sigma_{a}[\mathrm{MPa}]$ & $N_{f}$ experimental [ciclos] & $N_{f}$ teórico [ciclos] & Var $(\%)$ \\
\hline 642,49 & 1.400 & 8.131 & $-83 \%$ \\
\hline 608,50 & 3.395 & 14.221 & $-76 \%$ \\
\hline 572,52 & 11.598 & 26.576 & $-56 \%$ \\
\hline 536,63 & 34.698 & 51.563 & $-33 \%$ \\
\hline 503,12 & 64.748 & 99.631 & $-35 \%$ \\
\hline 465,72 & 72.000 & 218.836 & $-67 \%$ \\
\hline 428,33 & 156.280 & 512.183 & $-69 \%$ \\
\hline
\end{tabular}

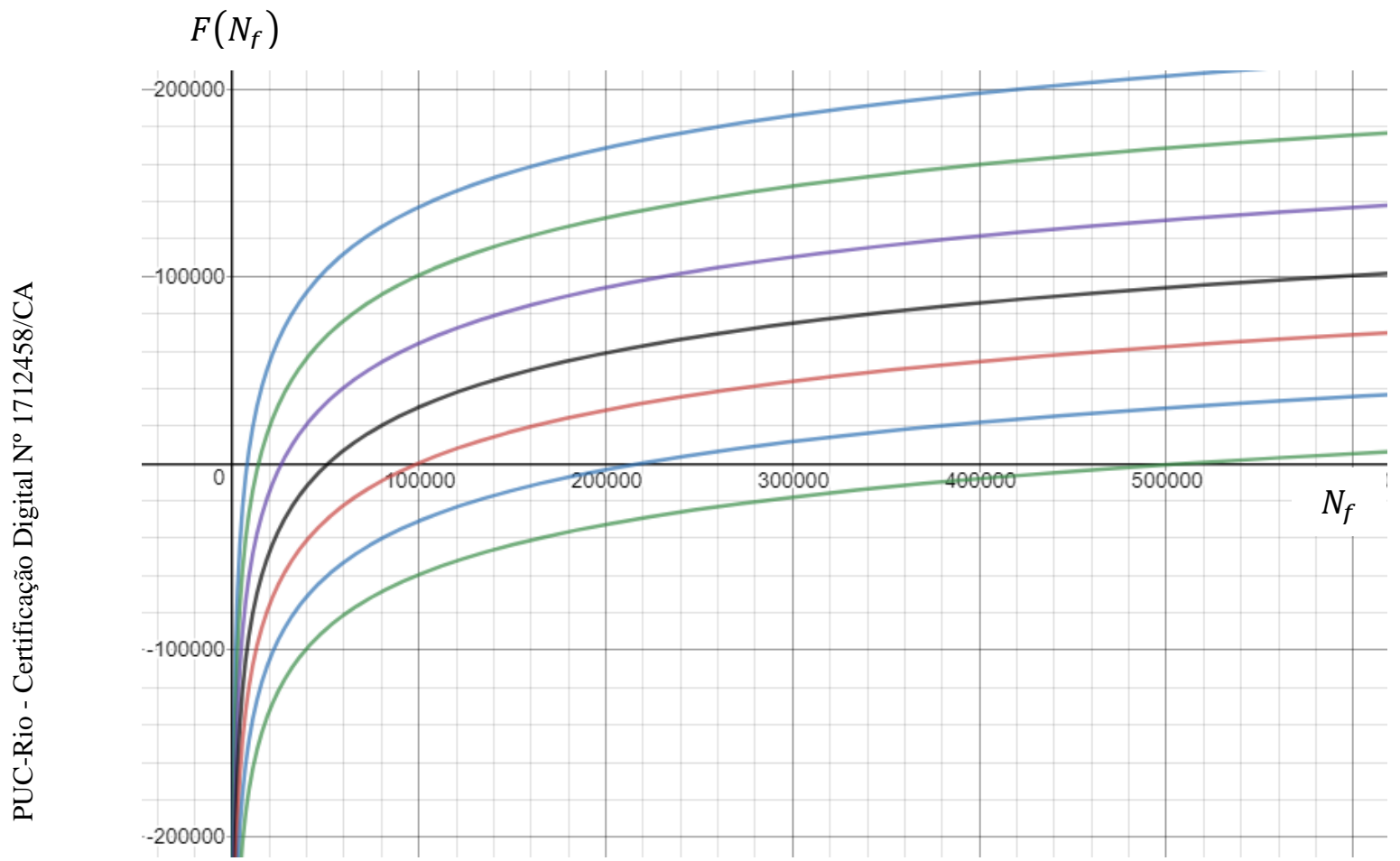

Figura 52 - Curvas para solução dos modelos teóricos para ensaios de tração pura 
Tabela 13 - Resultados teóricos e experimentais para ensaios de torção pura

\begin{tabular}{|c|c|c|c|}
\hline$\tau_{a}[\mathrm{MPa}]$ & $N_{f}$ experimental [ciclos] & $N_{f}$ teórico [ciclos] & Var $(\%)$ \\
\hline 499,92 & 1.192 & 1.400 & $-15 \%$ \\
\hline 444,37 & 5.493 & 4.175 & $32 \%$ \\
\hline 413,27 & 9.574 & 8.187 & $17 \%$ \\
\hline 392,47 & 11.805 & 13.219 & $-11 \%$ \\
\hline 371,81 & 12.261 & 21.830 & $-44 \%$ \\
\hline 351,16 & 37.193 & 37.097 & $0 \%$ \\
\hline
\end{tabular}

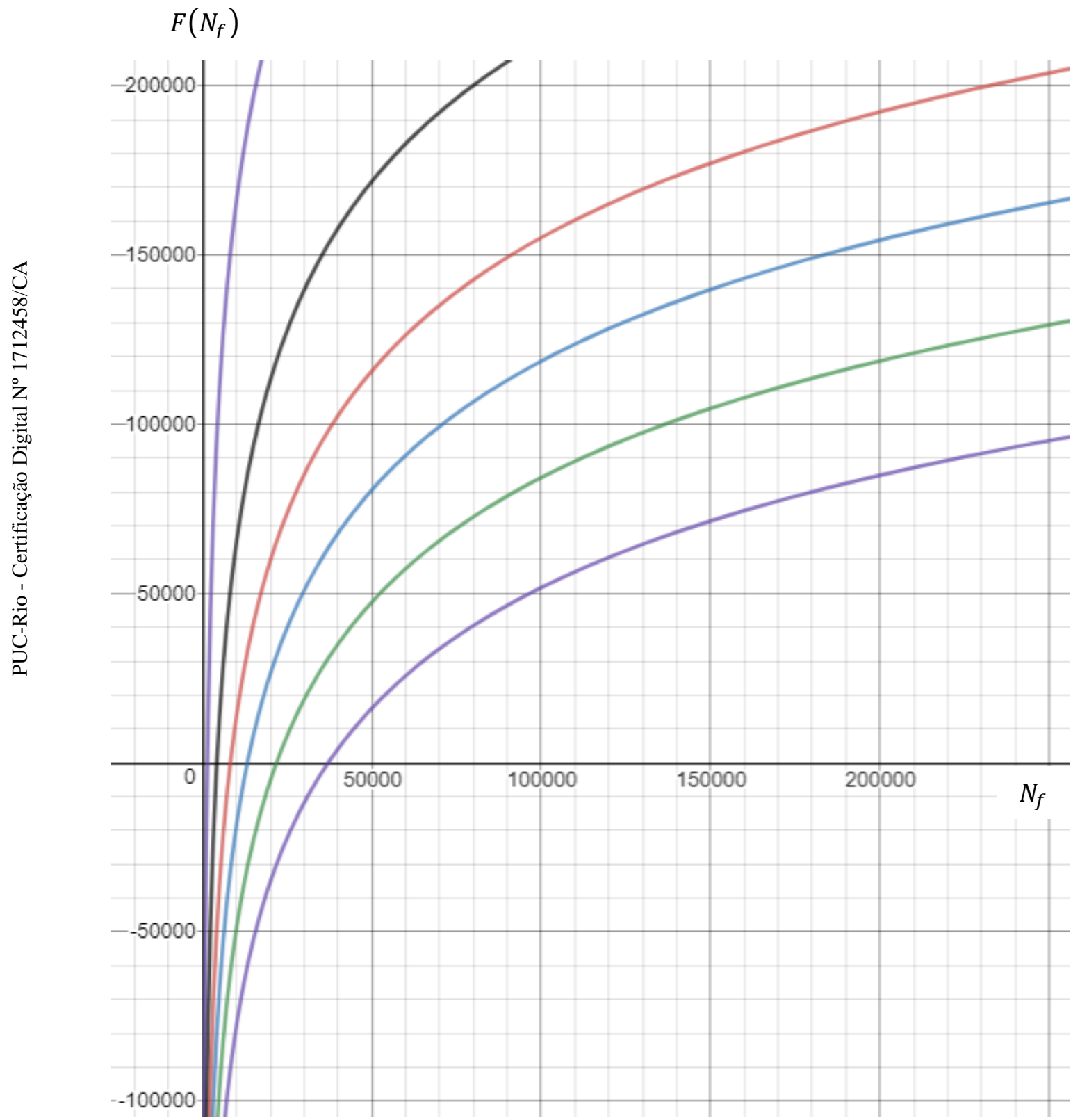

Figura 53 - Curvas para solução dos modelos teóricos para ensaios de torção pura 
Verifica-se que os ensaios em tração-compressão pura, totalmente reversíveis, apresentaram dois pontos consistentes (com erro inferior a 35\% em módulo, destacados em amarelo), enquanto as demais cinco previsões teóricas foram muito discrepantes dos resultados experimentais. Naturalmente, isso pode estar atribuído a fatores externos, como por exemplo uma eventual incapacidade da máquina de controlar o seu carregamento em frequências maiores (ensaios conduzidos na segunda máquina apresentada - MTS 311 - com frequência de ensaio entre $6 \mathrm{~Hz}$ a $8 \mathrm{~Hz}$ ). Isso poderia até justificar uma eventual contribuição para um espalhamento maior, embora as críticas mais naturais à coleção de pontos e ao cenário experimental se devem em parte ao limitado espaço amostral, mas também uma maior imprecisão para condições estritamente axiais.

Apesar da baixa consistência do modelo para os ensaios de tração, é importante destacar que as previsões para os ensaios de torção totalmente reversível se mostraram bastante mais assertivos, com um ponto particularmente preciso (destacado em verde) e apenas um único ponto discrepante.

\subsection{Relacionando diretamente $\sigma_{a}, \tau_{a}$ e $N_{f}$}

A equação (126), que já é um desdobramento do critério de Carpinteri \& Spagnoli modificado, é um interessante avanço em relação aos modelos anteriores, porque é o único modelo matemático que se propõe a estimar o número de ciclos para falha, embora o modelo tenha apresentado consistência apenas parcial. No entanto, a utilização do modelo para fins práticos é trabalhosa, porque depende da determinação de plano crítico por meio de várias funções auxiliares. Nesse sentido, seria muito mais interessante se pudéssemos ter em mãos uma relação direta entre $\sigma_{a}, \tau_{a}$ e $N_{f}$, colocando o número de ciclos para falha $N_{f}$ não mais em função de $N_{\text {max }}$ e de $C_{a}$, que são grandezas obtidas de maneira indireta, mas em função de $\sigma_{a}$ e $\tau_{a}$. Então o objetivo do presente trabalho passa a ser a apresentação de uma contribuição no sentido de identificar uma função teórica que relacione $\sigma_{a}, \tau_{a}$ e $N_{f}$ e que produza resultados similares aos experimentos.

Partindo de um ponto em que a previsão teórica e o resultado experimental tiverem baixa discrepância, a primeira abordagem consiste em buscar uma curva de 
nível no domínio cujo espaço é o plano $\sigma_{a} \tau_{a}$, isto é, um conjunto de pontos $\left(\sigma_{a}, \tau_{a}\right)$ pertencentes ao domínio da função que, quando aplicados a uma função $G\left(\sigma_{a}, \tau_{a}\right)$, entregue o mesmo valor constante de número de ciclos para falha $N_{f}$.

Sendo assim, todo o processo associado à aplicação do Carpinteri \& Spagnoli modificado foi colocado em uma planilha de Excel. Fixando o número de ciclos para falha $N_{f}$ e escolhendo arbitrariamente um valor de $\sigma_{a_{1}}$, foi possível rastrear o valor de $\tau_{a_{1}}$ de tal modo que o par $\left(\sigma_{a_{1}}, \tau_{a_{1}}\right)$ esteja associado ao número de ciclos para falha $N_{f}$ inicialmente escolhido.

Foram obtidas 10 combinações que levam ao mesmo resultado teórico de falha quando submetidos a 37.097 ciclos, estando esses pontos disponíveis na Tabela 14. Com o intuito de assegurar que o procedimento não negligenciou a orientação do plano crítico, a orientação do ângulo $\varphi_{c}$ para cada condição de carregamento também será evidenciada. Por fim, também foi alvo de interesse como viria a variar o valor da tensão equivalente de von Mises $\sigma_{\text {mises }}$ para esses pontos.

Tabela 14 - Pares ordenados teóricos de tensão normal e cisalhante para construção de curva de nível.

\begin{tabular}{ccccc}
$\sigma_{a}[\mathrm{MPa}]$ & $\tau_{a}[\mathrm{MPa}]$ & $\varphi_{c}\left[^{\circ}\right]$ & $\sigma_{\text {mises }}[\mathrm{MPa}]$ & $N_{f}[$ ciclos $]$ \\
\hline 554,18 & 0,00 & 48,62 & 554,18 & 37.097 \\
\hline 546,13 & 58,64 & 42,52 & 555,49 & 37.097 \\
\hline 520,55 & 117,05 & 36,52 & 558,63 & 37.097 \\
\hline 475,44 & 175,58 & 30,42 & 564,38 & 37.097 \\
\hline 405,19 & 234,10 & 24,02 & 573,23 & 37.097 \\
\hline 292,86 & 292,63 & 16,92 & 585,38 & 37.097 \\
\hline 200,00 & 323,02 & 12,22 & 594,17 & 37.097 \\
\hline 132,41 & 337,69 & 9,12 & 599,70 & 37.097 \\
\hline 66,21 & 346,80 & 6,32 & 604,32 & 37.097 \\
\hline 0,00 & 351,16 & 3,62 & 608,22 & \\
\hline
\end{tabular}

A Fig. 54 apresenta a distribuição desses pontos sobre o plano do domínio da função, sugerindo uma curva de nível com tendência a uma elipse, cujos semi eixos têm magnitude de 554,18 $M P a$ e 351,16 $M P a$. 


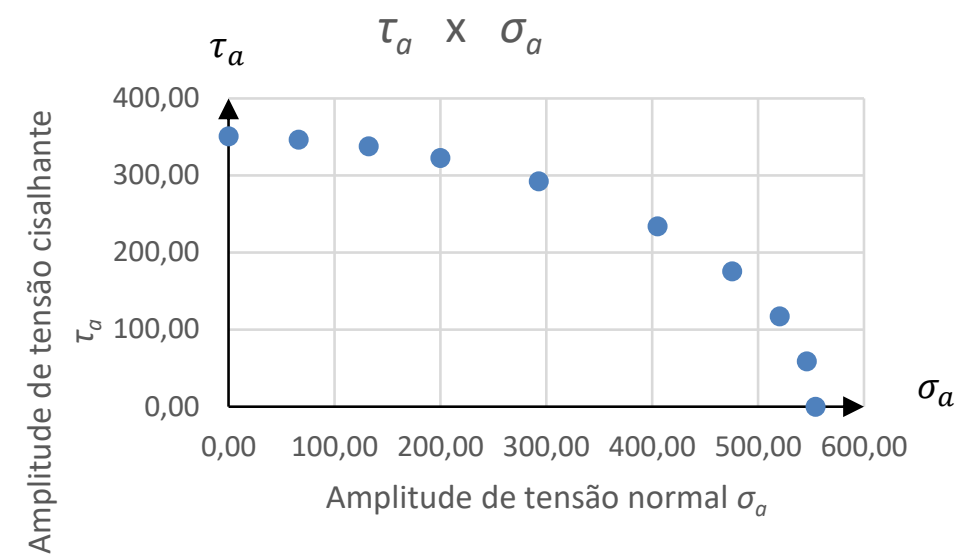

Figura 54 - Distribuição dos pontos teóricos sobre curva de nível no domínio da função

A inspeção conseguinte natural é verificar o grau de precisão com o que se esses pontos recaem sobre a elipse proposta, cujo equacionamento está apresentado na equação (142).

$$
\frac{\sigma_{a}^{2}}{554,18^{2}}+\frac{\tau_{a}^{2}}{351,16^{2}}=1
$$

O resultado pode ser avaliado na Fig. 55. Naturalmente, só faz sentido tratar a respeito de amplitudes de tensões axiais e cisalhantes positivas, então é razoável que o domínio dessa superfície associada à função $N_{f}=G\left(\sigma_{a}, \tau_{a}\right)$ esteja confinado somente ao primeiro quadrante. A equação da elipse não se aplica à curva de nível, a menos por uma restrição apresentada na equação (143).

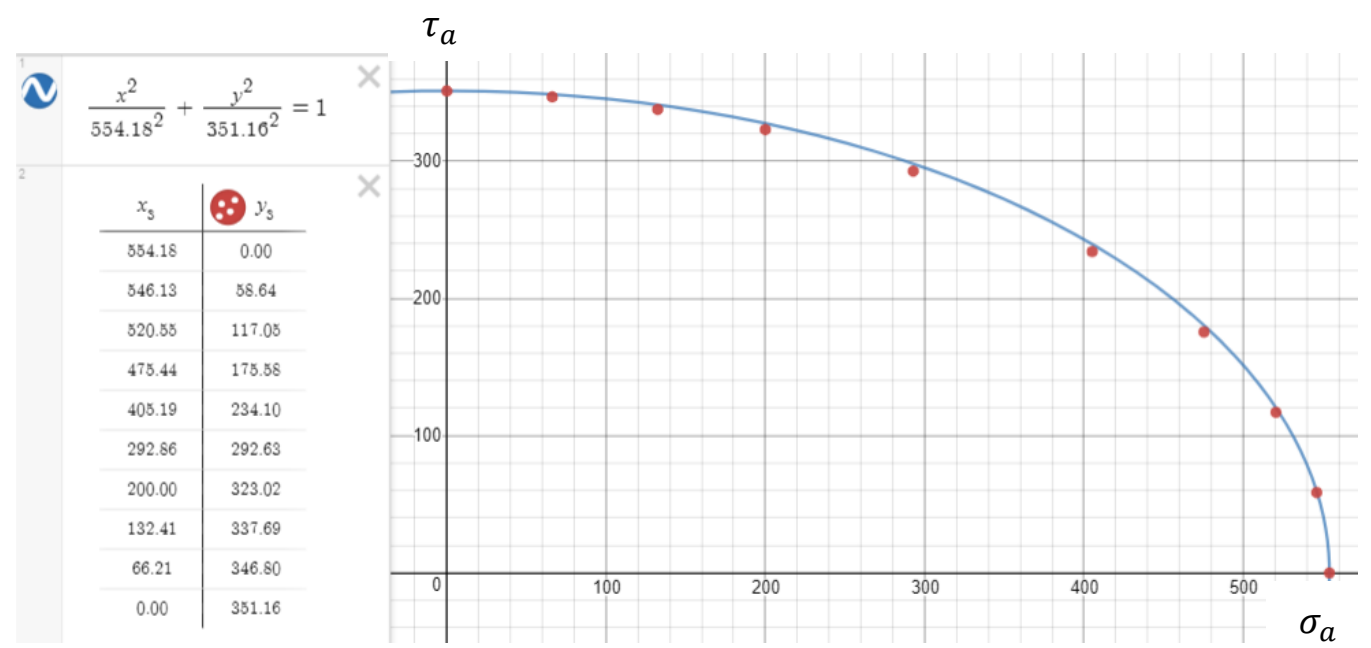

Figura 55 - Correlação entre distribuição de pontos e equação de elipse proposta 
$\frac{\sigma_{a}^{2}}{554,18^{2}}+\frac{\tau_{a}^{2}}{351,16^{2}}=1 \quad, \forall \sigma_{a} \geq 0 \quad, \forall \tau_{a} \geq 0$

É importante ressaltar que a distribuição de pontos indica apenas uma tendência elíptica. Os pontos mais centrais dos arcos de elipse apresentam um pequeno afastamento da elipse, especialmente para valores de carregamentos maiores, associados a valores de vida em fadiga mais baixos. Esse afastamento dos pontos da curva de nível para a elipse pode ser observado na Fig. 56.

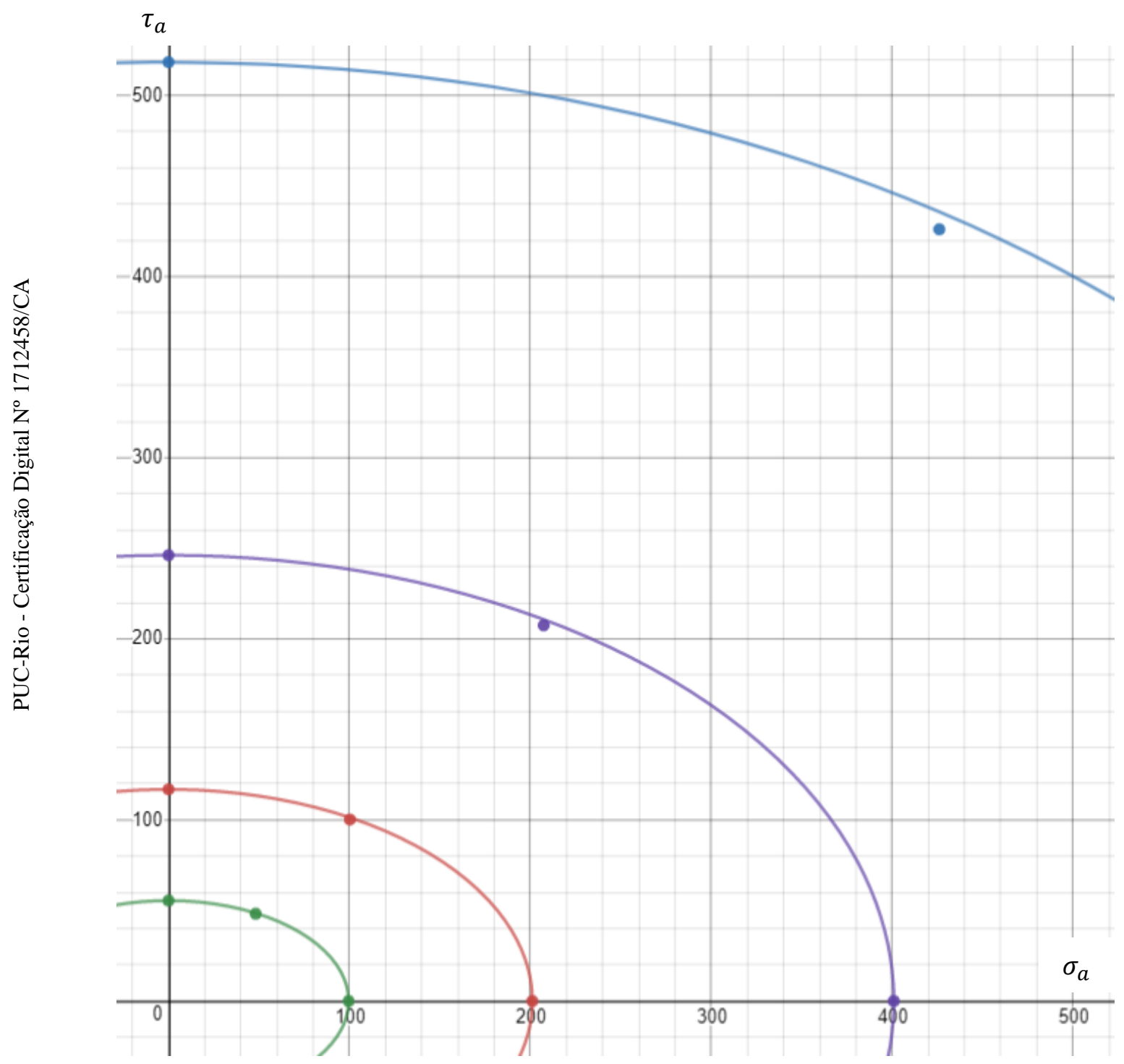

Figura 56 - Afastamento dos pontos centrais dos arcos de elipse para os pontos teóricos das curvas de nível

Naturalmente, esse erro percentual é muito baixo. Tomando como referência reta $y=x$, verifica-se que o afastamento do ponto $(207,42 ; 207,42)$ pertencente 
à curva de nível teórica $N_{f}=10^{6}$ [ciclos] ao ponto $(209,799 ; 209,799)$ pertencente à elipse é um segmento de reta de módulo 3,364 $M P a$, quando a magnitude das tensões envolvidas é superior a $200 \mathrm{MPa}$. A Fig. 57 retrata a condição de afastamento.

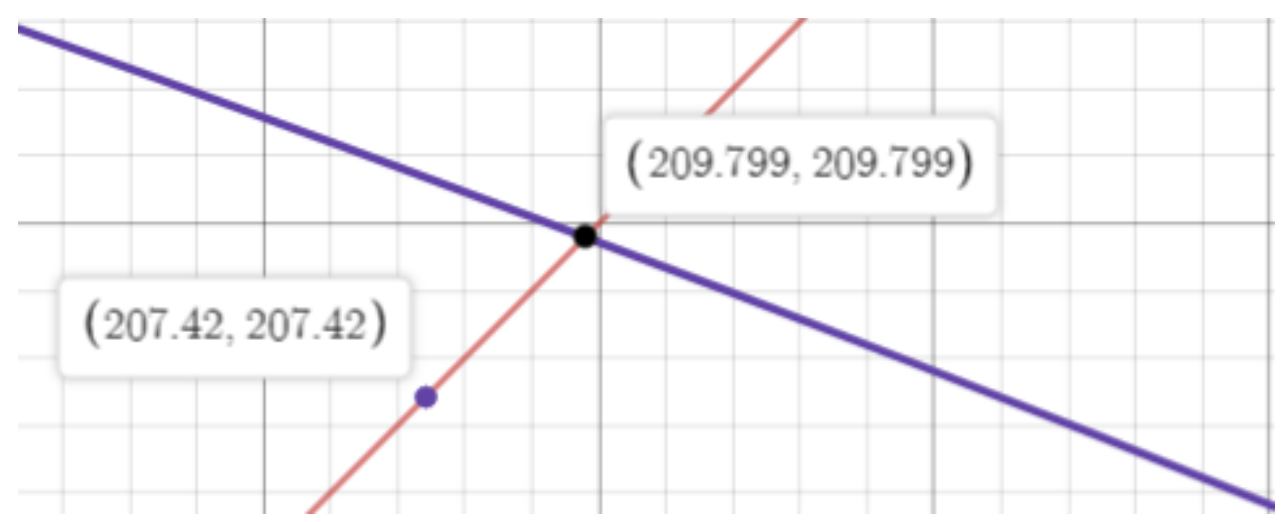

Figura 57 - Afastamento do ponto da curva de nível à elipse proposta $\left(N_{f}=10^{6}\right.$ ciclos $)$

Aplicando o mesmo raciocínio, tomando como referência reta $y=x$, verifica-se que o afastamento do ponto $(426,1 ; 426,1)$ pertencente à curva de nível teórica $N_{f}=10^{3}$ [ciclos] ao ponto $(432,981 ; 432,981)$ pertencente à elipse é um segmento de reta de módulo 9,731 $M P a$, quando a magnitude das tensões envolvidas é superior a $400 \mathrm{MPa}$. A Fig. 58 retrata a condição de afastamento.

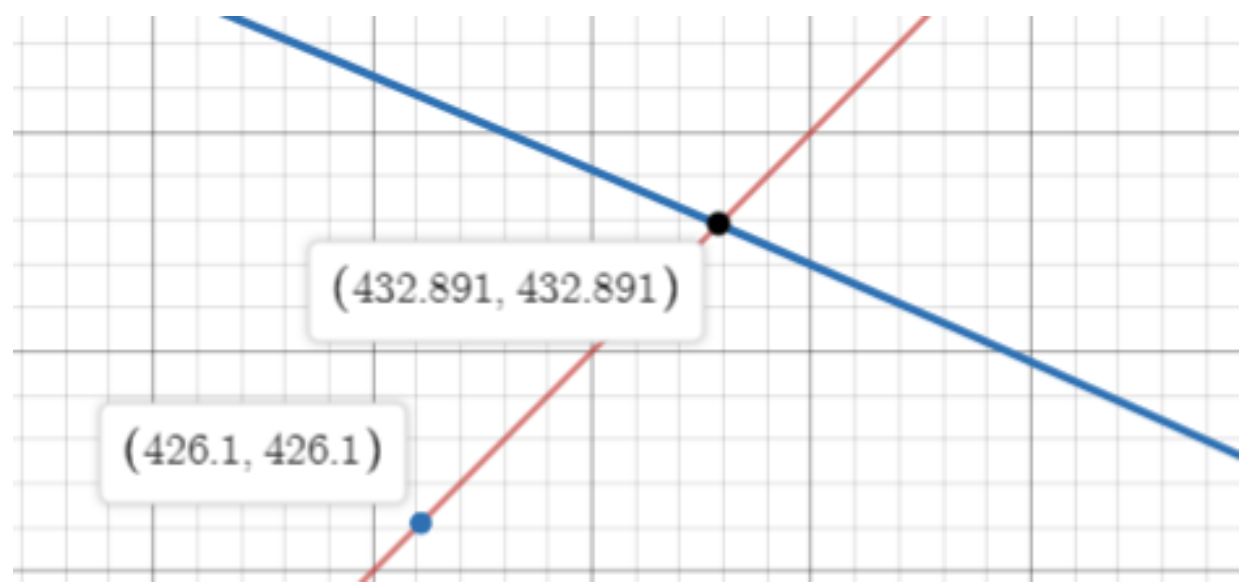

Figura 58 - Afastamento do ponto da curva de nível à elipse proposta $\left(N_{f}=10^{6}\right.$ ciclos $)$ 


\subsection{Generalização da Curva de Wöhler - Estudo das Características de uma Superfície teórica $N_{f}=G\left(\sigma_{a}, \tau_{a}\right)$}

Dando continuidade à ideia de que para cada par ordenado $\left(\sigma_{a_{n}}, \tau_{a_{n}}\right)$ tem associado a si um número de ciclos para falha $N_{f_{n}}$, então é possível generalizar a ideia de curva de Wöhler como uma superfície em um gráfico tridimensional, onde podemos impor um carregamento normal e um carregamento de torção para coletar um determinado número de ciclos para falha.

A rigor, temos duas curvas de Wöhler sendo uma relacionando amplitude de tensão normal e número de ciclos para falha e a outra relacionando amplitude de tensão cisalhante com o número de ciclos para falha. Colocando tensão normal e tensão cisalhante como eixos horizontais e número de ciclos para falha no eixo vertical, essas curvas nada mais são do que as interseções da superfície com o os dois planos verticais do sistema de eixos.

Entretanto, essa extrapolação pode ser bastante complicada, assim como a própria equação da superfície também pode o ser, e por isso requer um estudo mais profundo para determinação da mesma. Entretanto, é possível inferir algumas características pertinentes, que podem vir a contribuir para trabalhos futuros.

A priori, é possível aplicar sobre o material qualquer amplitude de tensão normal totalmente reversível $\sigma_{a}$ combinada a qualquer valor de amplitude de tensão cisalhante totalmente reversível $\tau_{a}$. Apesar de parecer uma premissa simples, dado que são as condições de carregamento e estas estão integralmente controladas pelos experimentadores, é possível extrair dessa informação o fato de que a função $G\left(\sigma_{a}, \tau_{a}\right)$ é contínua em seu domínio. A rigor, a imagem da função é discreta, pois trabalha-se com valores inteiros de números de ciclos. Entretanto, esse rigor pode ser desconsiderado nesse primeiro momento, e a função como um todo pode ser tratada como contínua tanto em seu domínio quanto em sua imagem.

Outra premissa aparentemente simples também fornece uma informação relevante. É natural concluir que condições de carregamentos maiores entregam uma vida em fadiga inferior do que aquela observada quando o componente mecânico está submetido condições de carregamentos menos severas. Sendo assim, é natural concluir que a função é sempre decrescente e monótona em $\sigma_{a}$, bem como sempre decrescente e monótona em $\tau_{a}$. Afinal, para um determinado valor de $\sigma_{a}$, 
incrementos em $\tau_{a}$ sempre fornecerão uma expectativa de vida inferior para o componente mecânico. Analogamente, para um determinado valor de $\tau_{a}$, incrementos em $\sigma_{a}$ sempre fornecerão uma expectativa de vida menor.

Como só faz sentido tratar de amplitudes de tensão positivas, todo o domínio da superfície está restrito ao primeiro quadrante do plano $\sigma_{a} \tau_{a}$. Também é fácil de identificar que todos os pontos que compõem a superfície são positivos, porque também não é aplicável tratar de um número de ciclos negativo. Entretanto, como é de se esperar, conforme escolhemos uma combinação de carregamentos suficientemente pequenos, o número de ciclos para falha cresce bastante, tendendo a infinito confirme escolhemos pontos cada vez mais próximos da origem.

Entretanto, a origem do sistema de eixos, o ponto $(0,0)$, é um ponto em que a função não está definida. Afinal, apesar de o componente estrutural apresentar vida infinita sob justificativa de que nunca atingirá a fratura, sob o ponto de vista matemático ele não estará sujeito a nenhum ciclo de carregamento. Sendo assim, sob o ponto de vista matemático, o correto é fazer a ressalva de que a função não está definida nesse ponto.

Por fim, supondo tensão média nula ou positiva, não é possível aplicar uma amplitude de tensão $\sigma_{a}$ superior ao limite de resistência mecânica $\sigma_{u}$, visto que o material fraturaria no pico positivo do primeiro ciclo, caracterizando não um ensaio de fadiga, mas um ensaio monotônico de tração. Analogamente, existirá também um valor de tensão cisalhante que uma vez aplicado levará o material à fratura em seu primeiro ciclo, também caracterizando um ensaio monotônico de torção. Sendo assim, é razoável estabelecer uma curva de nível última, aquela composta por condições de carregamento tais que levam o material à fratura em seu primeiro ciclo. Segundo o modelo, podemos calcular a equação da curva de nível final, cuja representação gráfica está disponível na Fig. 59, e seu equacionamento apresentado na equação (144). 


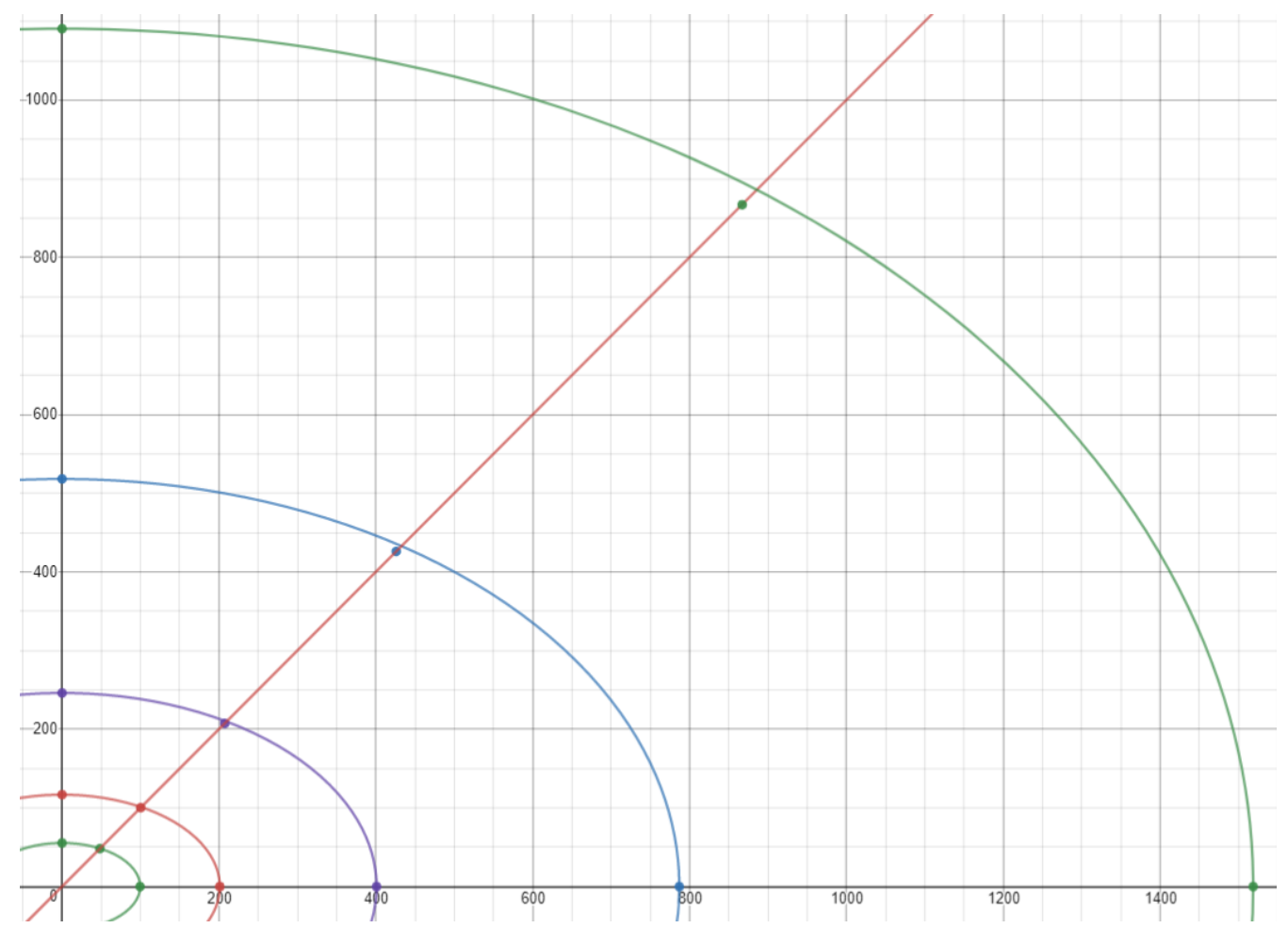

Figura 59 - Em verde, a curva de nível última $\left(N_{f}=1\right.$ ciclo $)$

$$
\frac{\sigma_{a}^{2}}{1518,63^{2}}+\frac{\tau_{a}^{2}}{1090,73^{2}}=1 \quad, \forall \sigma_{a} \geq 0 \quad, \forall \tau_{a} \geq 0
$$

Como se pode perceber, a equação (143) sugere que, para um ensaio de tração simples, o material resistiria até 1518,63 $M P a$, o que é bastante acima do limite de resistência mecânica. Embora a ideia de que a superfície deve ser limitada seja razoável, é fácil perceber que essa abordagem não está correta. Isso se deve ao fato de que o modelo é previsto para um número número de ciclos mais compatível com o regime de fadiga de alto ciclo (high cycle fatigue), tornando-se muito errôneo para valores de tensões muito elevadas, direcionando a vida em fadiga para o regime de fadiga de baixo ciclo (low cycle fatigue).

A Fig. 56 apresenta uma idealização qualitativa da superfície, obtida a partir da extrapolação das curvas de Wöhler obtidas nos ensaios uniaxiais. A rigor, havia uma curva relacionando $N_{f}$ e $\sigma_{a}$ pertencente ao plano $N_{f} \sigma_{a}$ e outra curva relacionando $N_{f}$ e $\tau_{a}$ pertencente ao plano $N_{f} \tau_{a}$. Idealizando que essas curvas são dadas pela interseção da superfície com os planos verticais, podemos unificar os dados presentes nas Tabelas 6 e 7, é possível obter o conjunto de 10 pontos, conforme expresso na Tabela 15. 
Tabela 15 - Pontos da utilizados para a idealização da Superfície G.

\begin{tabular}{|c|c|c|}
\hline$\sigma_{a}[\mathrm{MPa}]$ & $\tau_{a}[\mathrm{MPa}]$ & $N_{f}[$ ciclos $]$ \\
\hline $1.183,60$ & 0 & 1 \\
\hline 0 & $1.089,40$ & 1 \\
\hline 676,40 & 0 & $10^{3}$ \\
\hline 0 & 516,64 & $10^{3}$ \\
\hline 386,55 & 0 & $10^{6}$ \\
\hline 0 & 245,01 & $10^{6}$ \\
\hline 220,90 & 0 & $10^{9}$ \\
\hline 0 & 116,19 & $10^{9}$ \\
\hline 126,24 & 0 & $10^{12}$ \\
\hline 0 & 55,10 & $10^{12}$ \\
\hline
\end{tabular}

Usando o apoio de software computacional, foi possível unir os referidos pontos, dando uma ideia de superfície. Essa curva está limitada a $\sigma_{a_{\max }}=$ 1183,6 MPa , sendo esse valor cerca de 30\% superior ao limite de resistência mecânica do material. Apesar de ainda não ser o valor ideal, já representa uma melhoria em relação à proposta anterior. O eixo associado a cisalhamento, por sua vez, mostra-se limitado a 1089,4 MPa, o que ainda é um valor bastante alto e pode ser melhorado conforme novos estudos forem conduzidos.

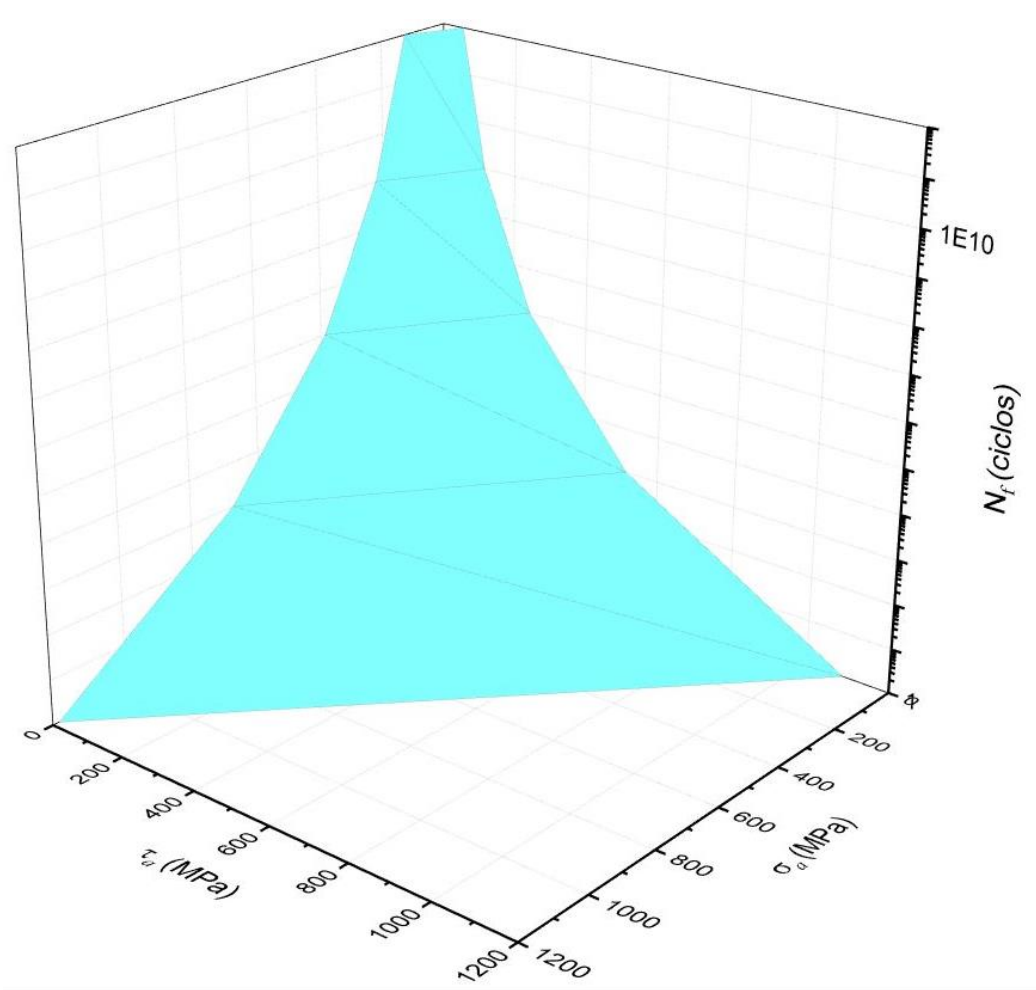

Figura 60 - Superfície idealizada para a função $G$ 


\section{5 \\ Conclusões}

Após realizar experimentos e aplicar os modelos, pode-se concluir que:

- Ensaios de tração-compressão e torção simples totalmente reversíveis permitiram o levantamento experimental de duas curvas de Wöhler para o material. Os resultados foram consistentes.

- A partir das curvas de Wöhler, foi possível determinar os parâmetros $m$ e $m *$, permitindo a utilização do critério de Carpinteri \& Spagnoli modificado, com o intuito de prever o número de ciclos para falha.

- O modelo de Carpinteri \& Spagnoli modificado apresentou parcial consistência para carregamentos biaxiais, embora sejam necessários mais pontos experimentais para dar suporte a essa conclusão.

- Margens de erro de até 35\% para mais ou para menos são consideradas razoáveis.

- O critério deve abranger também ensaios uniaxiais. O modelo apresentou resultados consistentes para torção pura e discrepantes para traçãocompressão.

- O modelo não tem solução analítica, então o presente estudo desenvolveu um método de solução numérica que se mostrou eficaz.

- A aplicação do critério de Carpinteri \& Spagnoli modificado é pouco prático por ser função de $N_{\max }$ e $C_{a}$, variáveis que dependem da determinação de plano crítico.

- O presente trabalho propõe a busca por uma relação direta entre $\sigma_{a}, \tau_{a} \mathrm{e}$ $N_{f}$ e discute suas características qualitativamente. 
- A superfície apresentada é uma superfície idealizada qualitativamente, extrapolando as curvas de Wöhler obtidas. Essa superfície precisa ser testada experimentalmente.

- Uma superfície experimental relacionando $N_{f}=G\left(\sigma_{a}, \tau_{a}\right)$ pode ser levantada e seu equacionamento obtido por meio de softwares como MATLAB, sendo esta uma sugestão para trabalhos futuros.

- Devido ao seu equacionamento complicado, o presente trabalho estudou a função $N_{f}=G\left(\sigma_{a}, \tau_{a}\right)$ por meio de curvas de níveis teóricas, e identificou uma tendência na distribuição dos pontos das curvas de nível em formato de elipse.

- São características dessa função foram propostas:

○ contínua em seu domínio;

○ sempre decrescente e monótona em todas as direções;

○ não definida na origem;

○ domínio está definido apenas para valores positivos de $\sigma_{a}$ e $\tau_{a}$;

o o modelo precisa de limites superiores. 


\section{6}

\section{Sugestões para Trabalhos Futuros}

Procurar fazer a adaptação para vida em fadiga finita para todos os demais modelos citados no presente estudo.

Comparar experimentalmente a previsão teórica para vida finita em fadiga referente a todos os modelos com os resultados colhidos em experimentos.

Buscar uma coleção de pontos teóricos de todos os modelos que projete a mesma vida em fadiga, isto é, obter uma coleção de pontos que componham curvas de níveis para cada modelo.

Buscar modelar a o equacionamento da teórica $N_{f}=G\left(\sigma_{a}, \tau_{a}\right)$ a partir da extrapolação das curvas de Wöhler obtidas nesse trabalho, e verificar sua consistência experimentalmente. 


\section{Referências Bibliográficas}

Bathias, C. (2003). An understanding of very high cycle fatigue of metals. International Journal of Fatigue, Volume 25, pp. 1101-1107.

Carpinteri\&Spagnoli. (2001). Multiaxial high-cycle fatigue criterion for hard metals. International Journal of Fatigue, Volume 23, pp. 135-145.

Carpinteri\&Spagnoli. (2013). Structural integrity assessment of metallic components under multiaxial fatigue: the C-S criterion and its evolution. Fatigue Fract Engng Mater Struct, Volume 36, 870-883.

Castro\&Meggiolaro. (2009). Técnicas e Práticas de Dimensionamento Estrutural sob Cargas Reais de Serviço. Createspace Independent Publishing Platform.

Dieter, G. (1986). Metalurgia Mecânica. McGraw-Hill Education; 3 edition.

Dowling, N. E. (2012). Mechanical Behavior of Materials: Enginnering Methods for Deformation, Fracture, and Fatigue ( $4^{\circ}$ ed.). Prentice Hall.

Feiferis, A. d. (2018). Avaliação Estrutural de Eixo Virabrequim Sob Fadiga Multiaxial. Dissertação de Mestrado.

Findley. (1959). A theory for the effect of mean stress on fatigue of metals under, Citado no livro Multiaxial Fatigue (Socie \& Marquis).

Giovani, A. (s.d.). Relatório Técnico de Propriedades Mecânicas dos aços DIN 34CrMo6 e DIN 42 CrMo4.

Gonçalves, R. A. (2017). Contribuição na Avaliação da Vida Útil de Eixo Virabrequim Sob Fadiga Multiaxial. Tese de Doutorado.

Griffith. (1920). The Phenomena of Rupture and Flow in Solids, Citado no livro Metalurgia Mecânica (Dieter).

K.S. Ravi Chandran, P. C. (2009). Competing failure modes and complex S-N curves in fatigue of structural materials. International Journal of Fatigue, Volume 32, pp. 482-491.

Kumar, R. N. (2010). Standing Contact Fatigue Analysis of Steels with Different Microstructures. Tese de Mestrado.

Liu\&Mahadevan. (2005). Multiaxial high-cycle fatigue criterion and life prediction for metals. International Journal of Fatigue, Volume 27, 790-800.

Matake. (1977). An explanation on fatigue limit under combined stress, Citado no livro Multiaxial Fatigue (Socie \& Marquis).

McDiarmid. (1990). A general criterion for high cycle multiaxial fatigue failure, Citado no livro Multiaxial Fatigue (Socie \& Marquis). 
Medeiros, R. J. (s.d.). Sobre a Análise de Problemas Bidimensionais de Engenharia de Estruturas em Regime de Não-Linearidade Material e Geométrica pelo Método dos Elementos Finitos. Dissertação de Mestrado.

Meyers. (2009). Mechanical Behavior of Materials. Cambridge.

Mughrabi, H. (2006). Specific features and mechanisms of fatigue in the ultrahigh-cycle regime. International Journal of Fatigue, Volume 28, pp. 1501-1508.

Neubauer, P. d. (2018). Determinação Experimental de Curvas de Resistência do aço DIN 42CrMo4. Dissertação de Mestrado.

Nishihara\&Kawamoto. (1945). The Strength of metals under combined alternating bending and torsion with phase difference, Citado em Multiaxial high-cycle fatigue criterion for hard metals (Carpinteri \& Spagnoli).

Nogueira, L. B. (2017). Estudo da Influência de Defeitos Microestruturais no Limiar de Fadiga de aços estruturais. Dissertação de Mestrado.

Papadopoulos, I. V. (1997). A comparative study of multiaxial high-cycle. International Journal of Fatigue, Volume 19, pp. 219-235.

Peixoto, T. A. (2018). Interação entre Aspectos Microestruturais e Iniciação de Trincas de Fadiga em Aços Estruturais. Dissertação de Mestrado.

Schijve, J. (2008). Fatigue of Structures and Materials. Springer.

Socie\&Marquis. (1999). Multiaxial Fatigue. Society of Automotive Engineers Inc.

Suresh. (2001). Fatigue of Materials. Cambridge University Press.

Takahashi, B. X. (2014). Metodologia Moderna para Análise de Fadiga Baseada em Elementos Finitos de Componentes Sujeitos a Fadiga Uni e Multiaxial. Dissertação de Mestrado.

Teixeira, M. C. (2018). Comportamento do Aço DIN 34CrNiMo6 em Fadiga de Altíssimo Ciclo. Dissertação de Mestrado. 